University of South Florida

DIGITAL COMMONS

@ UNIVERSITY OF SOUTH FLORIDA
Digital Commons @ University of

South Florida

$5-1-2013$

\title{
Analysis of Movable Bus Stop Boarding and Alighting Area
}

CUTR

Follow this and additional works at: https://digitalcommons.usf.edu/cutr_nctr

\section{Recommended Citation}

"Analysis of Movable Bus Stop Boarding and Alighting Area," National Center for Transit Research (NCTR) Report No. CUTR-NCTR-RR-2013-10, Center for Urban Transportation Research, University of South Florida, 2013.

DOI: https://doi.org/10.5038/CUTR-NCTR-RR-2013-10

Available at: https://scholarcommons.usf.edu/cutr_nctr/62

This Technical Report is brought to you for free and open access by the National Center for Transit Research (NCTR) Archive (2000-2020) at Digital Commons @ University of South Florida. It has been accepted for inclusion in Research Reports by an authorized administrator of Digital Commons @ University of South Florida. For more information, please contact digitalcommons@usf.edu. 


\section{Analysis of Movable Bus Stop Boarding and Alighting Areas}
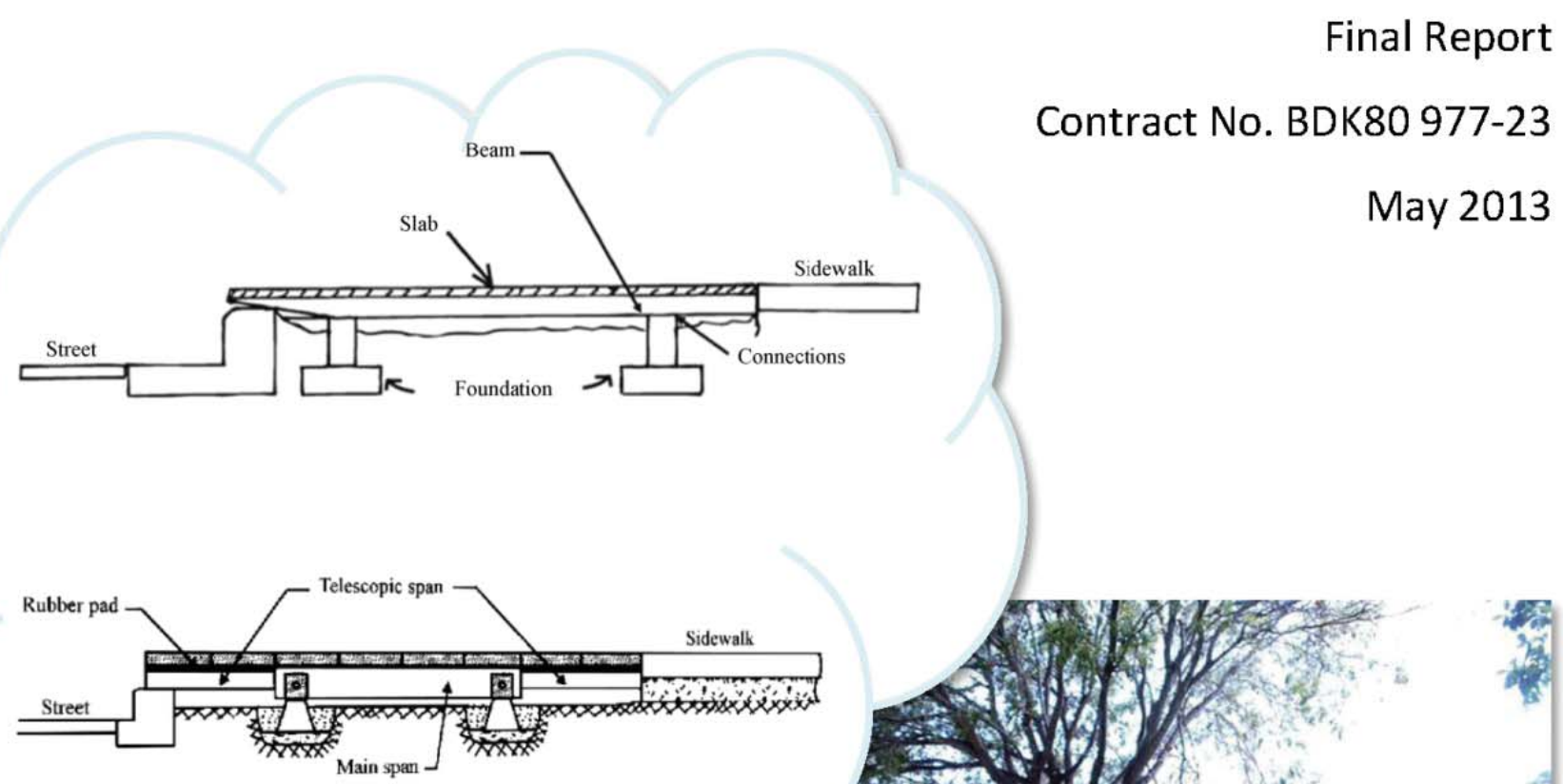

Prepared by: Lehman Center for Transportation Research Florida International University

Prepared for:

Research Center Florida Department of Transportation
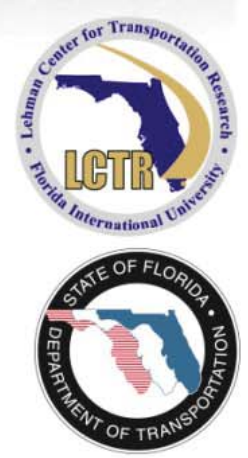


\section{Final Report}

Contract No. BDK80 977-23

\section{Analysis of Movable Bus Stop Boarding and Alighting Areas}

Prepared for:

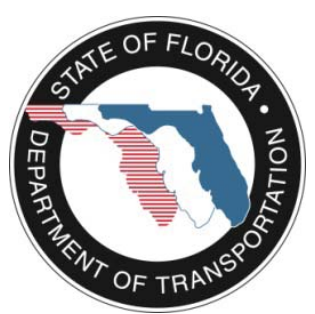

Research Center

Florida Department of Transportation

605 Suwannee Street, M.S. 30

Tallahassee, FL 32399-0450

Prepared by:

Nakin Suksawang, Ph.D., P.E., Assistant Professor

Albert Gan, Ph.D., Professor

Priyanka Alluri, Ph.D., Research Associate Kirolos Haleem, Ph.D., Research Associate

Katrina Meneses, Graduate Research Assistant

Fabian Cevallos, Ph.D., Transit Program Director

Dibakar Saha, Graduate Research Assistant

Lehman Center for Transportation Research

Florida International University

10555 West Flagler Street, EC 3680

Miami, FL 33174

Phone: (305) 348-3116

Fax: (305) 348-2802

E-mail: gana@fiu.edu

May 2013 


\section{DISCLAIMER}

The opinions, findings, and conclusions expressed in this publication are those of the authors and not necessarily those of the State of Florida Department of Transportation. 
METRIC CONVERSION CHART

\begin{tabular}{|c|c|c|c|c|}
\hline SYMBOL & WHEN YOU KNOW & MULTIPLY BY & TO FIND & SYMBOL \\
\hline \multicolumn{5}{|c|}{ LENGTH } \\
\hline in & inches & 25.4 & millimeters & $\mathrm{mm}$ \\
\hline $\mathrm{ft}$ & feet & 0.305 & meters & $\mathrm{m}$ \\
\hline yd & yards & 0.914 & meters & $\mathrm{m}$ \\
\hline mi & miles & 1.61 & kilometers & $\mathrm{km}$ \\
\hline mm & millimeters & 0.039 & inches & in \\
\hline $\mathbf{m}$ & meters & 3.28 & feet & $\mathrm{ft}$ \\
\hline m & meters & 1.09 & yards & yd \\
\hline km & kilometers & 0.621 & miles & $\mathrm{mi}$ \\
\hline SYMBOL & WHEN YOU KNOW & MULTIPLY BY & TO FIND & SYMBOL \\
\hline \multicolumn{5}{|c|}{ AREA } \\
\hline in $^{2}$ & square inches & 645.2 & square millimeters & $\mathrm{mm}^{2}$ \\
\hline $\mathrm{ft}^{2}$ & square feet & 0.093 & square meters & $\mathrm{m}^{2}$ \\
\hline $\mathrm{yd}^{2}$ & square yard & 0.836 & square meters & $\mathrm{m}^{2}$ \\
\hline ac & acres & 0.405 & hectares & ha \\
\hline $\mathrm{mi}^{2}$ & square miles & 2.59 & square kilometers & $\mathrm{km}^{2}$ \\
\hline $\mathrm{mm}^{2}$ & square millimeters & 0.0016 & square inches & in $^{2}$ \\
\hline $\mathbf{m}^{2}$ & square meters & 10.764 & square feet & $\mathrm{ft}^{2}$ \\
\hline $\mathrm{m}^{2}$ & square meters & 1.195 & square yards & $\mathrm{yd}^{2}$ \\
\hline ha & hectares & 2.47 & acres & $\mathrm{ac}$ \\
\hline $\mathrm{km}^{2}$ & square kilometers & 0.386 & square miles & $\mathrm{mi}^{2}$ \\
\hline SYMBOL & WHEN YOU KNOW & MULTIPLY BY & TO FIND & SYMBOL \\
\hline \multicolumn{5}{|c|}{ VOLUME } \\
\hline fl oz & fluid ounces & 29.57 & milliliters & $\mathrm{mL}$ \\
\hline gal & gallons & 3.785 & liters & $\mathrm{L}$ \\
\hline $\mathrm{ft}^{3}$ & cubic feet & 0.028 & cubic meters & $\mathrm{m}^{3}$ \\
\hline $\mathrm{yd}^{3}$ & cubic yards & 0.765 & cubic meters & $\mathrm{m}^{3}$ \\
\hline $\mathrm{mL}$ & milliliters & 0.034 & fluid ounces & $\mathrm{fl} \mathrm{oz}$ \\
\hline $\mathbf{L}$ & liters & 0.264 & gallons & gal \\
\hline $\mathrm{m}^{3}$ & cubic meters & 35.314 & cubic feet & $\mathrm{ft}^{3}$ \\
\hline $\mathrm{m}^{3}$ & cubic meters & 1.307 & cubic yards & $\mathrm{yd}^{3}$ \\
\hline
\end{tabular}


Technical Report Documentation Page

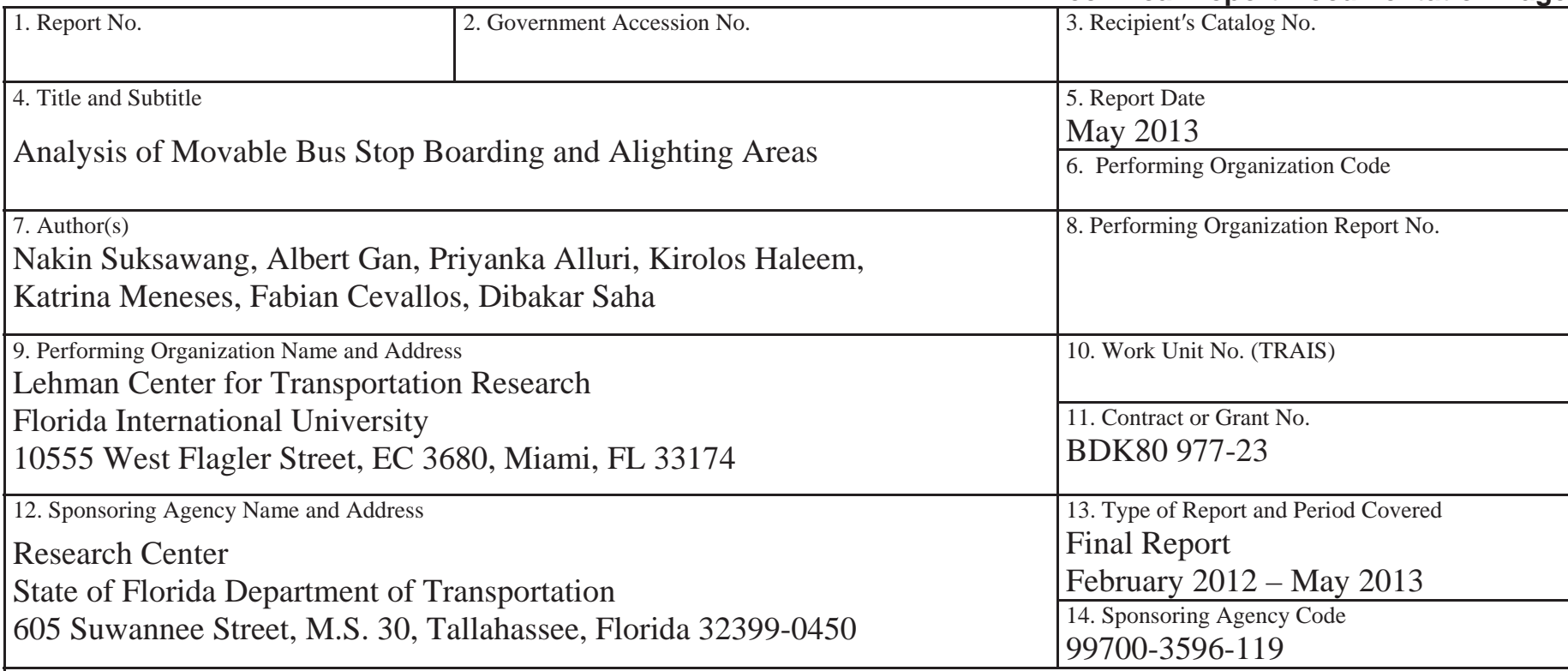

15. Supplementary Notes

Ms. Diane Quigley of the Public Transit Office at the Florida Department of Transportation served as the Project Manager for this project.

16. Abstract

This study explored the feasibility of using movable and reusable boarding and alighting (B\&A) pads at bus stops. Potential design alternatives in terms of materials and structural support for these pads were evaluated. The review focused on the existing and alternative design materials, especially in applications other than for transit purposes, which could potentially replace the existing conventional cast-in-place concrete slab.

An online national survey of bus transit agencies was conducted to determine how transit agencies are meeting the Americans with Disabilities Act (ADA) bus stop accessibility requirements and to get feedback and related information on the potential use of movable B\&A pads at bus stops. A total of 84 transit agencies from 31 states and Puerto Rico responded to the survey. From the responses, none of the transit agencies were found to be using movable B\&A pads. The potential benefits for using movable B\&A pads were identified to be lower installation and maintenance cost, ease of installation and use, quicker installation, flexibility, portability, and passenger accessibility. Some potential concerns included lower durability, strength, and stability; greater risk of theft; space limitations; safety; and aesthetics.

Six materials (i.e., concrete/asphalt, metal, rubber, thermoplastic, composite, and wood), along with their commercially available products, were evaluated based on their structural performance, long-term durability, adaptability, life cycle cost, aesthetics, and safety and accessibility of transit riders with mobility devices. Out of the six materials, plastic lumber and metal were found to have the highest potential to replace the conventional design. The plastic lumber presents the most viable option but the metallic materials, even though more expensive, have more potential for quicker installation, which can benefit transit agencies with anticipated frequent route changes. Additionally, the designs of each material option were proposed and recommended for further investigation.

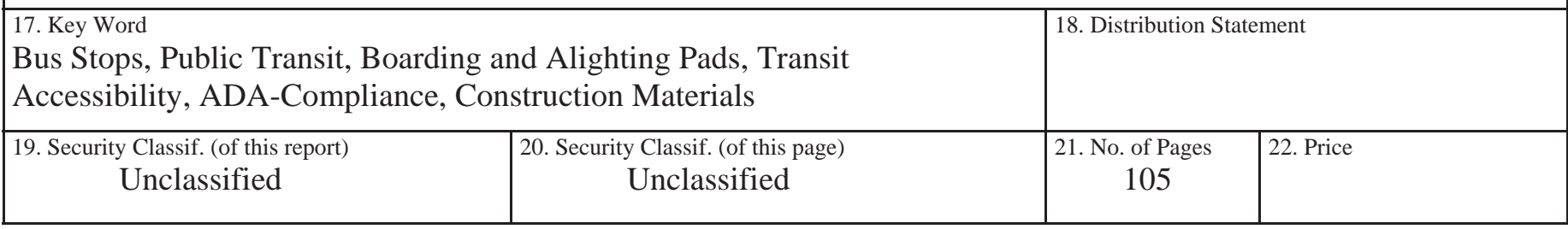

\footnotetext{
Form DOT F 1700.7 (8-72) Reproduction of completed page authorized
} 


\section{ACKNOWLEDGEMENTS}

This research was funded by the Research Center of the Florida Department of Transportation (FDOT) under the direction of Mr. Darryll Dockstader. We are particularly grateful to our Project Manager, Ms. Diane Quigley, of the FDOT Public Transit Office, for her guidance and support throughout the project. We would also like to thank Ms. Gabrielle Matthews, also of the FDOT Public Transit Office, for her review and thoughtful comments. Many transit planners and professionals from around the country participated in our online survey for this project and their contribution is gratefully acknowledged. A special thanks is due to Ms. Vicki Morrison of the FDOT Research Center for her editing of this report. 


\section{EXECUTIVE SUMMARY}

Bus stops are key links in the journeys of transit riders, particularly for those individuals with disabilities. Because of physical, sensory, or mental challenges, people with disabilities often rely on public transportation as their primary source of transportation. However, inaccessible bus stops could discourage or prevent them from using fixed-route bus services, and thus, forcing them to use the more expensive paratransit services. The Americans with Disabilities Act (ADA) requires that a firm, stable, slip-resistant surface be provided at all bus stops for boarding and alighting (B\&A) purposes. For those bus stops with additional facilities such as benches and shelters, a minimum $5^{\prime} \times 8^{\prime}(1.5 \mathrm{~m} \times 2.4 \mathrm{~m})$ B\&A pad with connected sidewalk of $3^{\prime}(0.9 \mathrm{~m})$ clear passage width, $2 \%$ maximum slope, and 1:12 (8.33\%) curb cut slope must be provided.

In Florida and across the country, the practice has been to install concrete pads at bus stops along a bus route. When bus routes are relocated to address changing ridership demand and service needs, the bus stops are abandoned, leaving the concrete pads in place. When considering current economic conditions and long term sustainability of infrastructure, reusable products could be a wise investment. Therefore, the main purpose of this project is to explore the feasibility of using movable and reusable bus stop B\&A pads for transit agencies as an inexpensive means to meeting ADA requirements. Accordingly, this project has four objectives:

1. Conduct a national survey of transit agencies about the use of movable B\&A pads.

2. Research and evaluate the existing materials for potential use in constructing B\&A pads.

3. Develop and evaluate design alternatives for movable B\&A pads.

4. Recommend specific materials and design alternatives for potential testing and implementation.

\section{National Survey of Transit Agencies}

An online national survey of bus transit agencies was conducted to determine how transit agencies are meeting the ADA bus stop accessibility requirements and to get feedback and related information on the potential use of movable B\&A pads at bus stops. A total of 84 transit agencies responded to the survey. From the survey analysis, it was found that one-fifth of the responding agencies have over $90 \%$ of their bus stops fully ADA-compliant. The responding agencies also indicated that the potential benefits for using movable pads included lower installation and maintenance cost, ease of installation and use, quicker installation, flexibility, portability, and passenger accessibility. Some potential concerns for installing movable pads were identified as lower durability, strength and stability; greater risk of theft; space limitations; safety; and aesthetics. In general, a majority of responding transit agencies showed interest in potential alternatives for ADA-compliant movable B\&A pads.

\section{Potential Design Materials}

A review of the existing materials for potential use in constructing movable B\&A pads at bus stops was conducted. This review included materials that are typically used in other transportation applications, outside of the transit environment, that are flexible such that they can be removed and reinstalled. The following materials and products were reviewed in detail: 
1. Concrete/Asphalt Materials
a. Concrete and Asphalt Pads
b. Embedded Concrete Rubber (ECR)
c. TraCast Crossing Product
d. Concrete Pavers
e. Precast Concrete Pedestrian Panels
f. Precast Concrete Boardwalk

2. Metallic Materials
a. Steel Road Plates
b. Heavy Duty Aluminum Roadway
c. PortaPad

3. Rubber Materials
a. Full-Depth Heavy-Duty Rubber
b. Rubber Pedestrian Crosswalk
c. Flexi-Pave

4. Thermoplastic Materials
a. PortaPath
b. ArmorDeck
c. HexaDeck
d. Plastic Lumber Walkway
e. SupaTrac
f. Plastic Grates

5. Composite Materials
a. Mobi-Mat

6. Wooden Materials
a. Roll-out Walkways

The six categories of materials, along with their commercially available products, were evaluated based on their structural performance, long-term durability, adaptability, life cycle cost, aesthetics, and safety and accessibility of transit riders with mobility devices. Out of the six materials, plastic lumber and metals are found to have the highest potential to replace the conventional design. Plastic lumber is rated highest based on design considerations, material properties, and life cycle cost. It has good strength (even though not as high as concrete) and it is also considerably light (even though not as light as composite material). Plastic lumber is also one of the cheapest and most durable systems. However, its performance under hurricane force wind has to be further evaluated for it to be recommended for extensive adoption.

\section{Design Alternatives}

Two design alternatives, the plastic lumber pad and the metallic pad, were proposed for further investigation. The plastic lumber pad is the most cost effective solution; however, it requires 
more time for installation. If transit agencies anticipate frequent bus route changes, the installation time could potentially deter its use. On the other hand, the metallic pad is more expensive but its installation is quicker and is recommended for transit agencies that demand more mobility with their B\&A pads. These new design alternatives are anticipated to minimize maintenance of traffic (MOT) and the need for heavy machinery to excavate, fill, and/or compact the soil. The advantage of the metallic pad lies in its construction speed, while the plastic lumber pad design is cheaper and can span farther. Both the design alternatives rely on the concept of bridge construction and consist of four major components, i.e., foundation, slab, beam, and connections.

Both plastic lumber and metallic pads use small foundations that can be installed easily and without heavy machinery. The foundation is a readily available precast concrete pier block that can be purchased from any home improvement store. The connections comprise custom made metallic (galvanized steel or stainless steel) U-brackets that connect the foundations to the beams. The difference between the two alternatives lies in the slab and beam components. The plastic lumber pad uses separate components to form the slabs and beams, whereas the metallic pad uses a single component. The plastic lumber pad is more adaptable to different site conditions since the beam is designed to be of variable length. As these are new alternatives that can potentially replace the conventional and the readily available systems, further study is needed to understand their applications and associated costs. 


\section{TABLE OF CONTENTS}

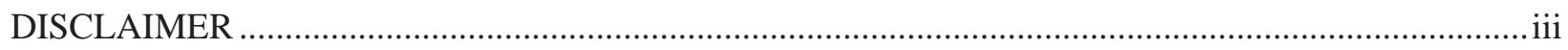

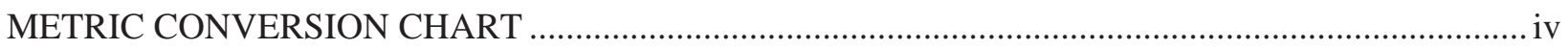

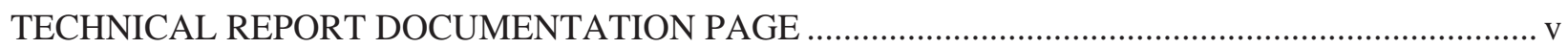

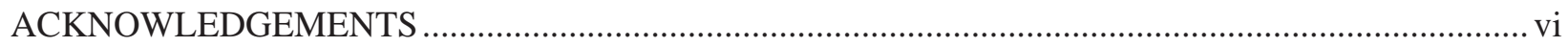

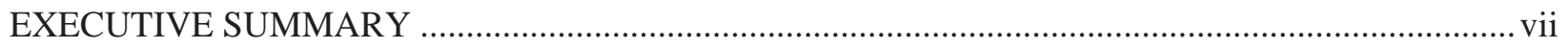

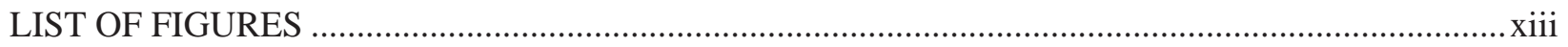

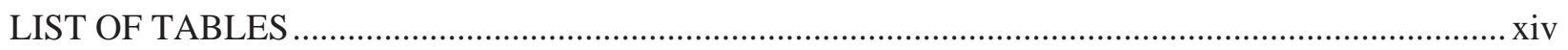

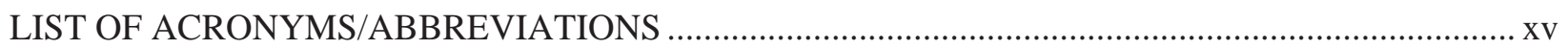

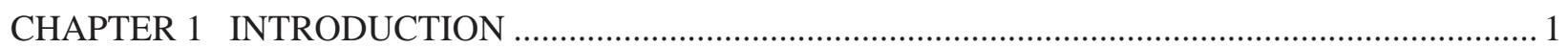

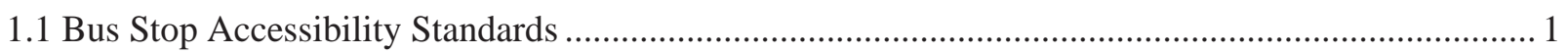

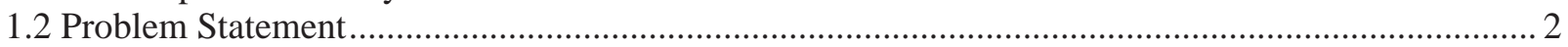

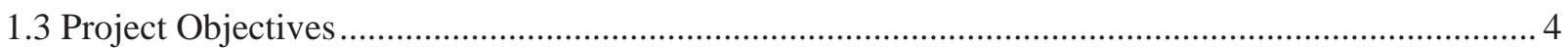

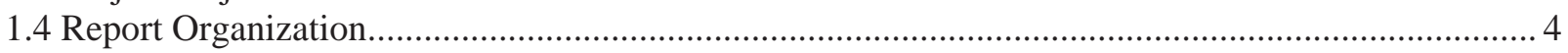

CHAPTER 2 NATIONAL SURVEY OF TRANSIT AGENCIES ….............................................. 5

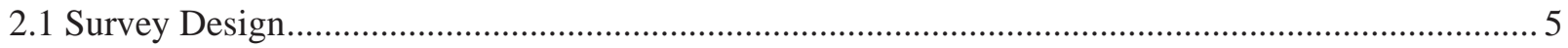

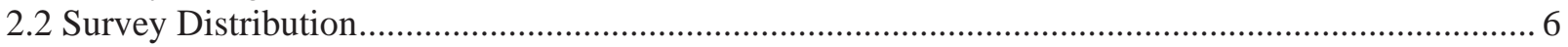

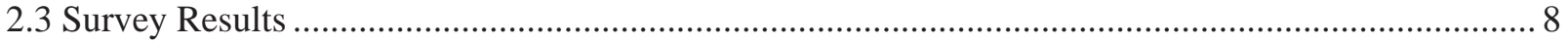

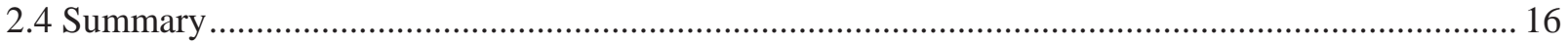

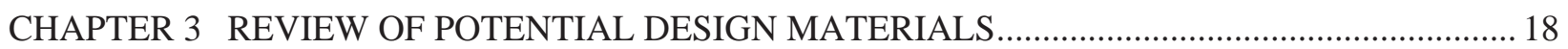

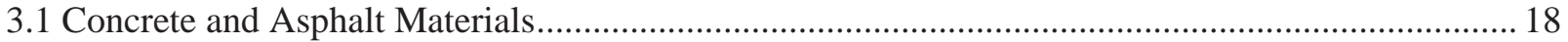

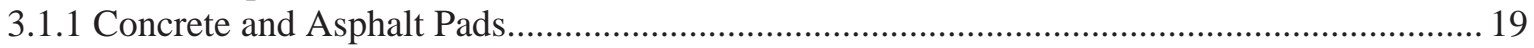

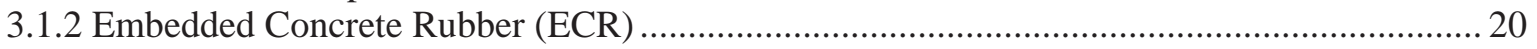

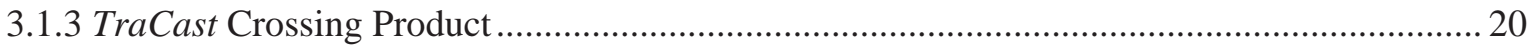

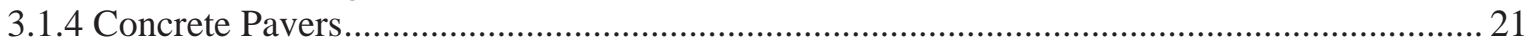

3.1.5 Precast Concrete Pedestrian Panels.................................................................................... 21

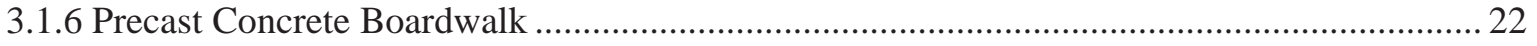

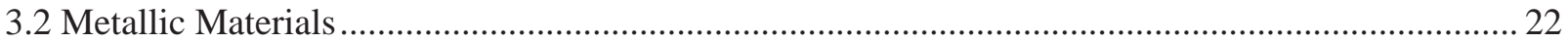

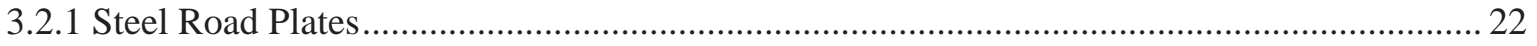

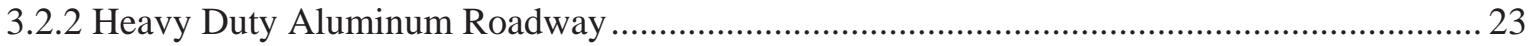

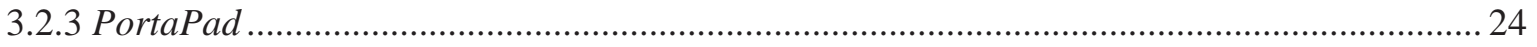

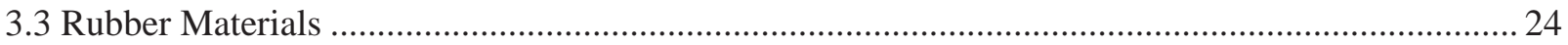

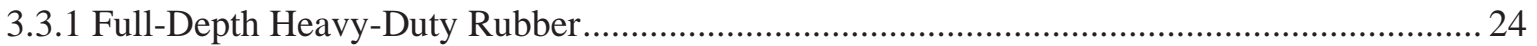

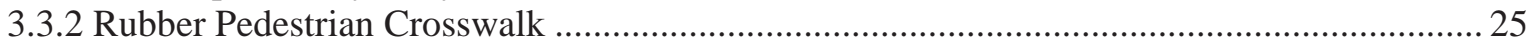

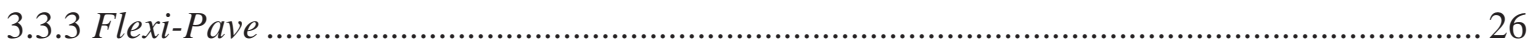

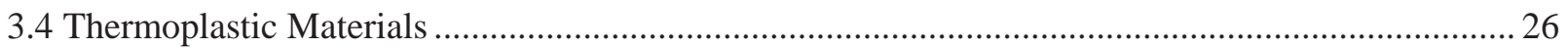

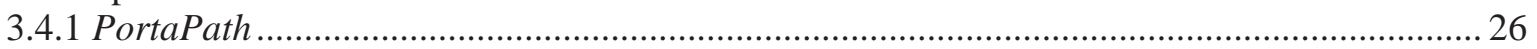

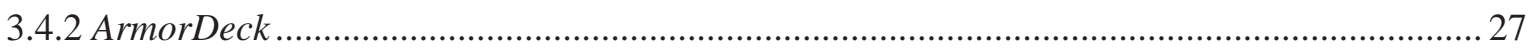

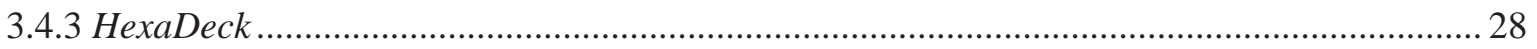

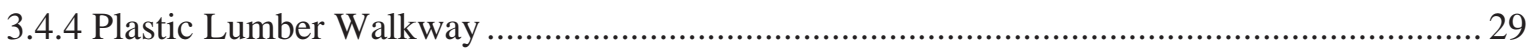




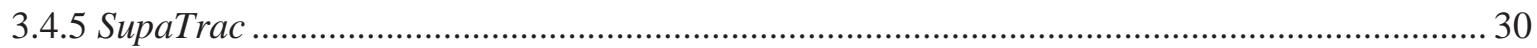

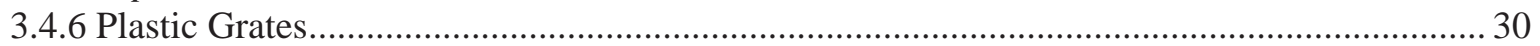

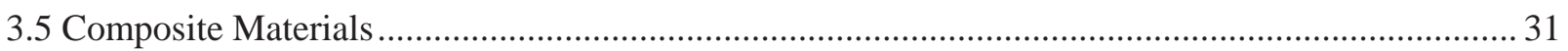

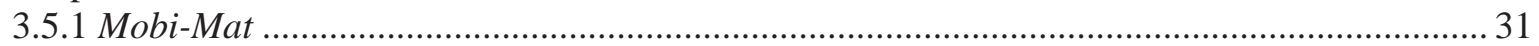

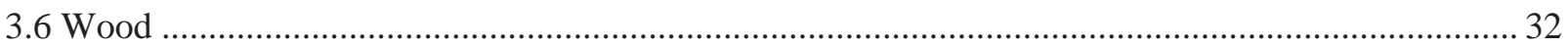

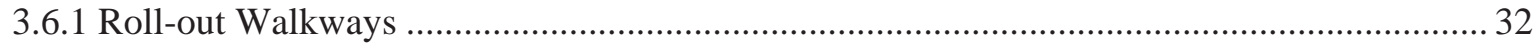

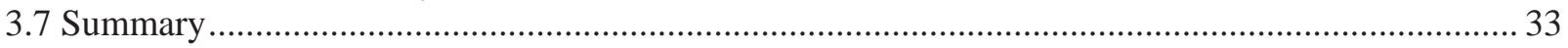

CHAPTER 4 EVALUATION OF POTENTIAL DESIGN MATERIALS ………………………….......... 34

4.1 Concrete/Asphalt ……………………………………………………………………… 35

4.1.1 Structural Performance................................................................................................... 36

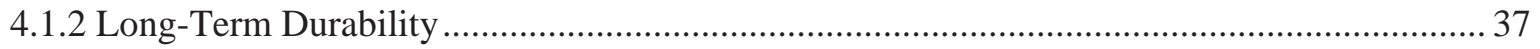

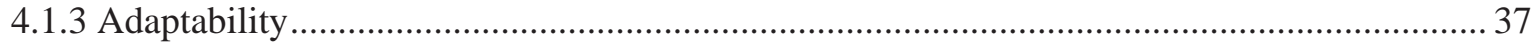

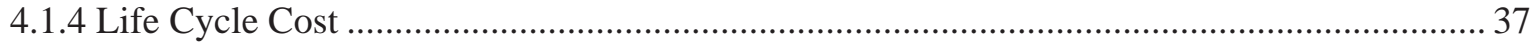

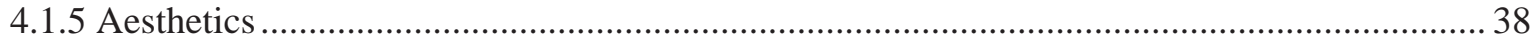

4.1.6 Safety and Accessibility of Transit Riders with Mobility Devices ........................................ 38

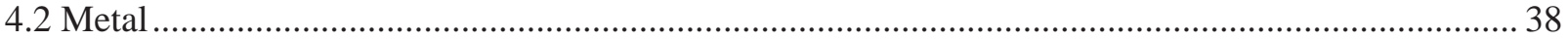

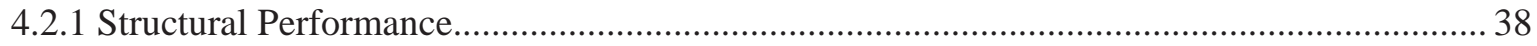

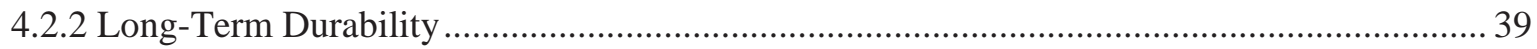

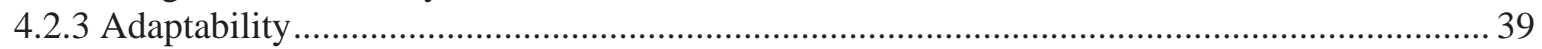

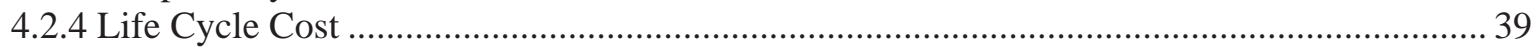

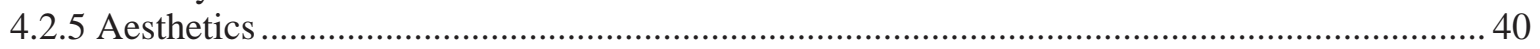

4.2.6 Safety and Accessibility of Transit Riders with Mobility Devices .......................................... 40

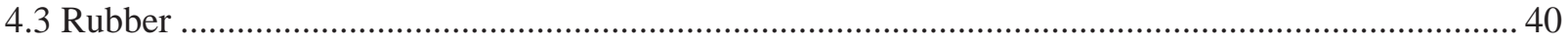

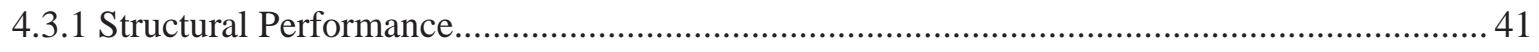

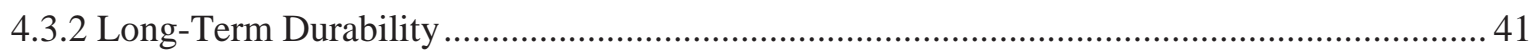

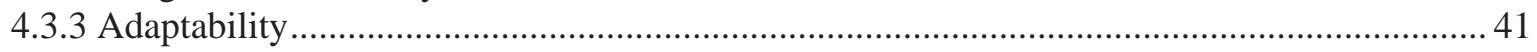

4.3.4 Life Cycle Cost ....................................................................................................... 41

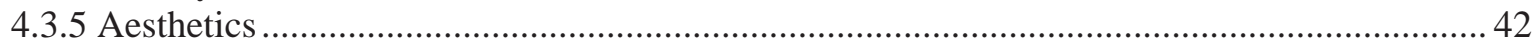

4.3.6 Safety and Accessibility of Transit Riders with Mobility Devices ......................................... 42

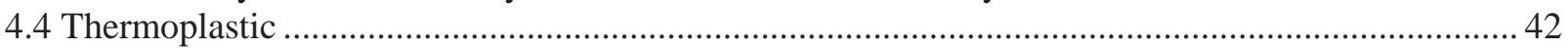

4.4.1 Structural Performance............................................................................................... 42

4.4.2 Long-Term Durability …………………………………………………………… 42

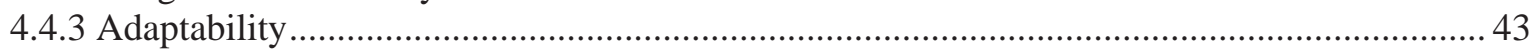

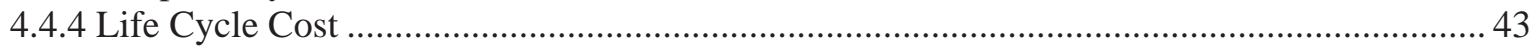

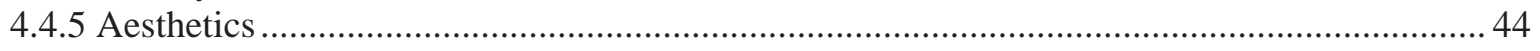

4.4.6 Safety and Accessibility of Transit Riders with Mobility Devices .......................................... 44

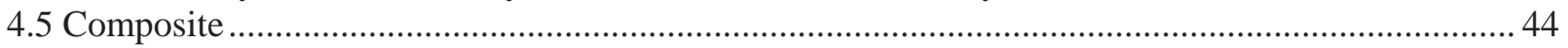

4.5.1 Structural Performance............................................................................................... 44

4.5.2 Long-Term Durability ............................................................................................... 45

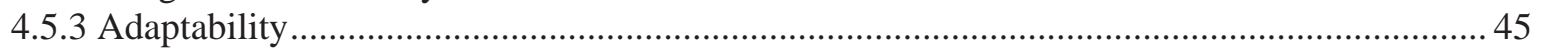

4.5.4 Life Cycle Cost ………………………………………………………………… 45

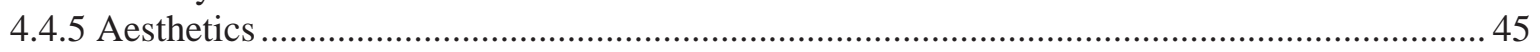

4.5.6 Safety and Accessibility of Transit Riders with Mobility Devices .......................................... 45

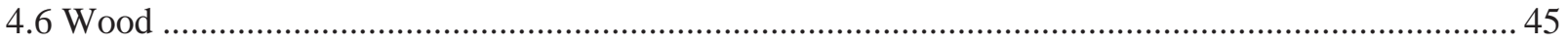

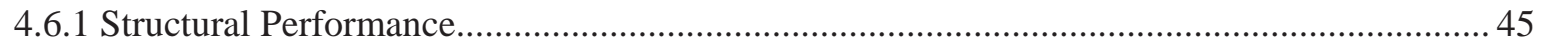

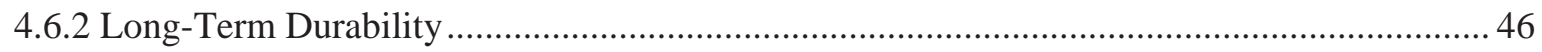

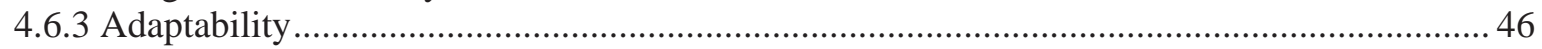

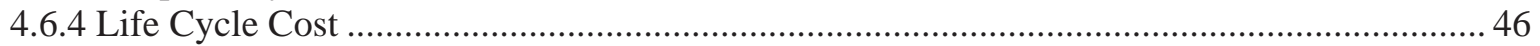

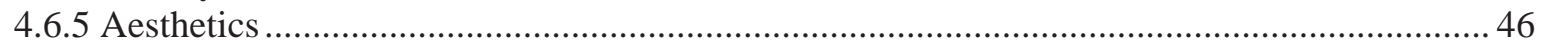

4.6.6 Safety and Accessibility of Transit Riders with Mobility Devices ......................................... 46 


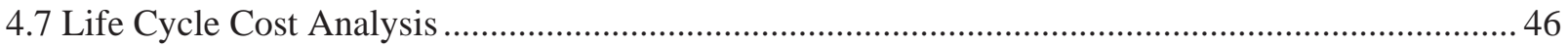

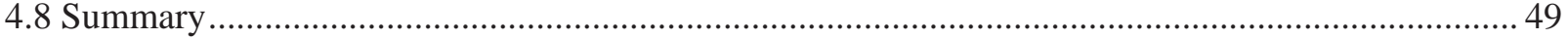

CHAPTER 5 DESIGN OF MOVABLE BOARDING AND ALIGHTING PADS ...............................51

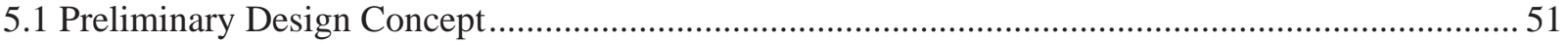

5.2 Foundation

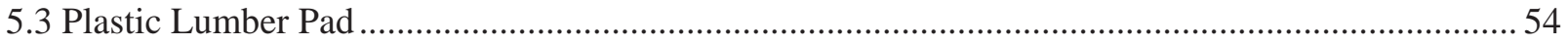

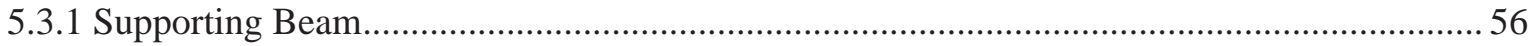

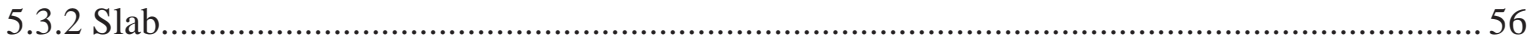

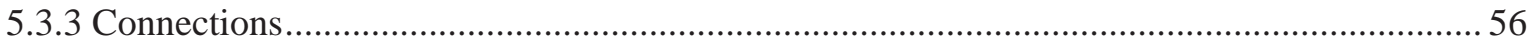

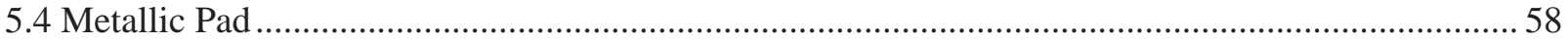

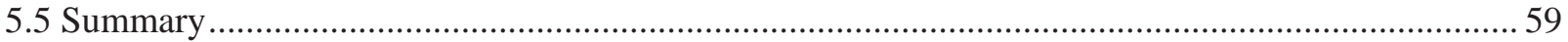

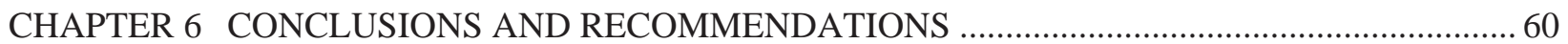

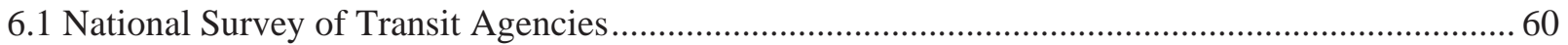

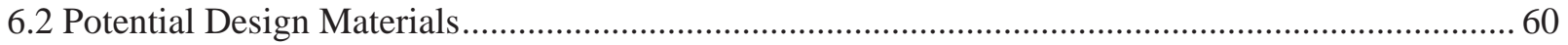

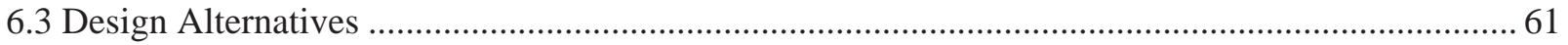

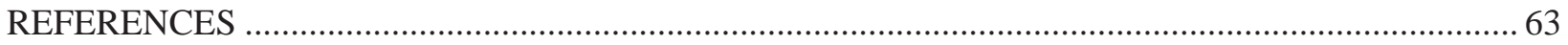

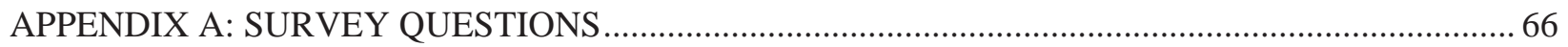

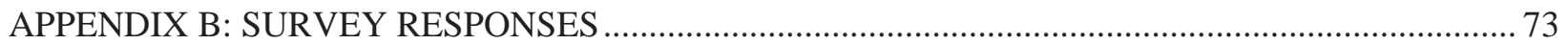




\section{LIST OF FIGURES}

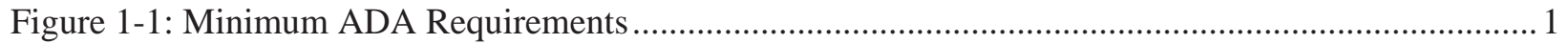

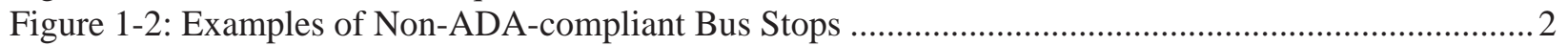

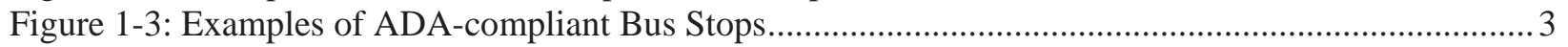

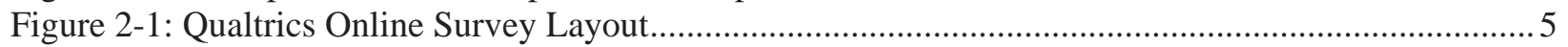

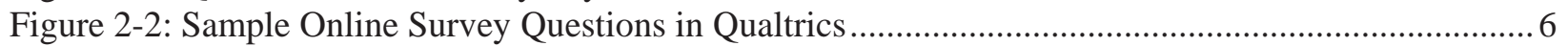

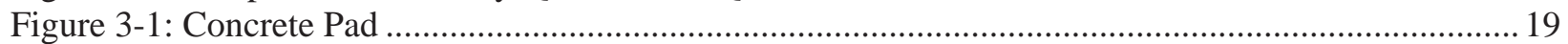

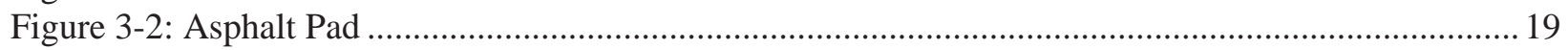

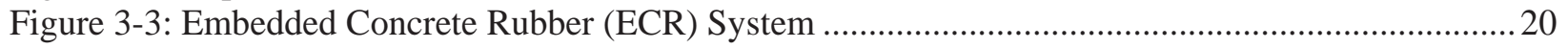

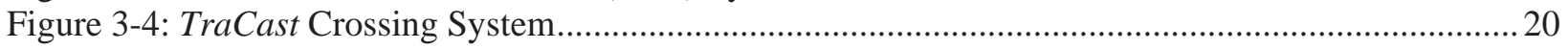

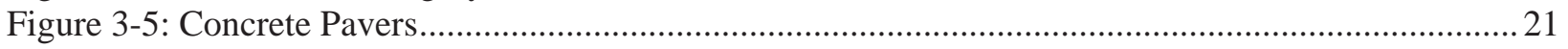

Figure 3-6: Precast Concrete Pedestrian Panels at Light Rail Station .................................................21

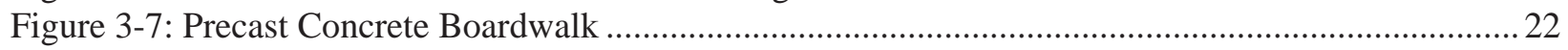

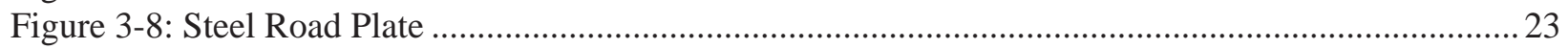

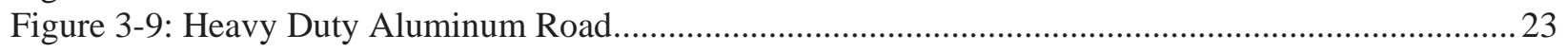

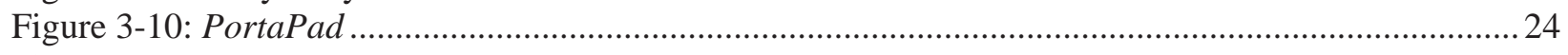

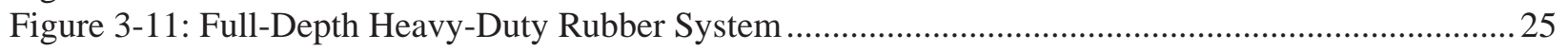

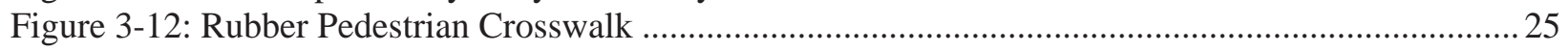

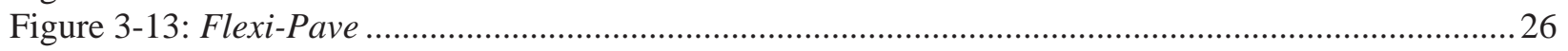

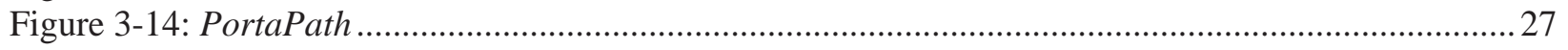

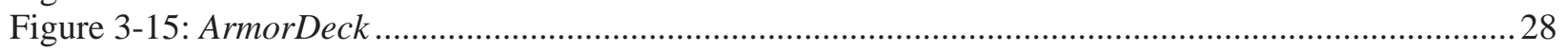

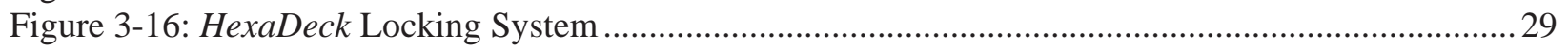

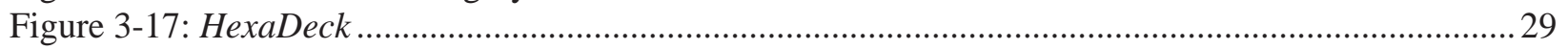

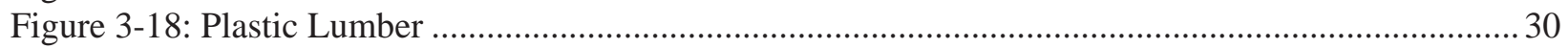

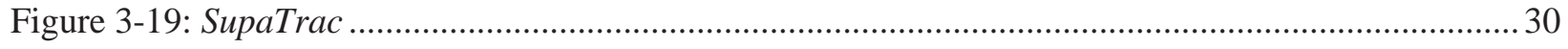

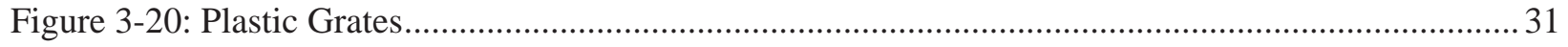

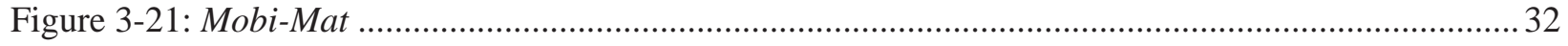

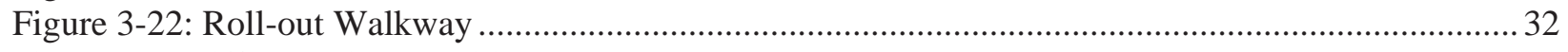

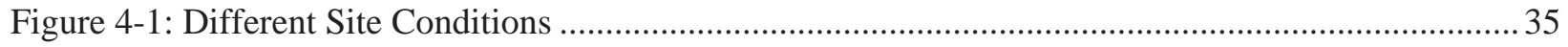

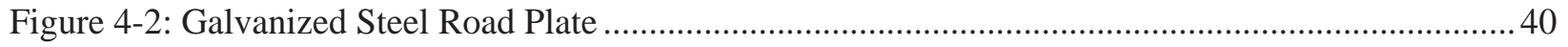

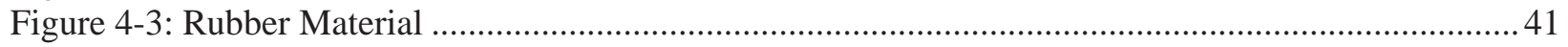

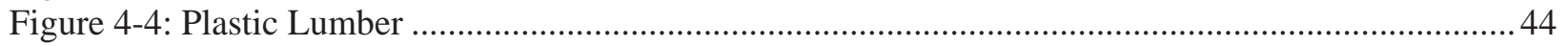

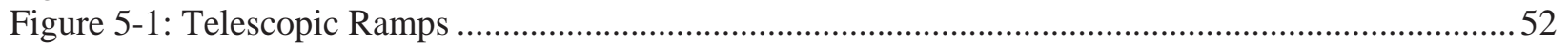

Figure 5-2: Preliminary Design Concept of the Proposed Movable B\&A Pads .........................................5 52

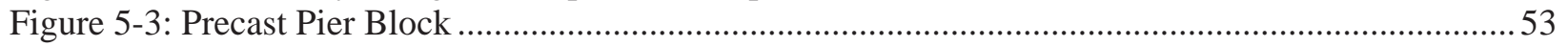

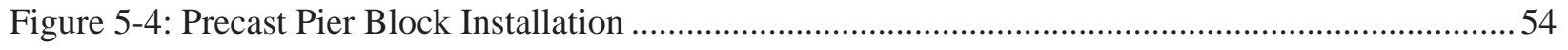

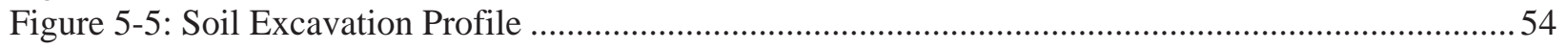

Figure 5-6: Plastic Lumber Pad Using Interlocking Beams Concept ....................................................55

Figure 5-7: Plastic Lumber Pad Using Telescopic Beams Concept.........................................................55

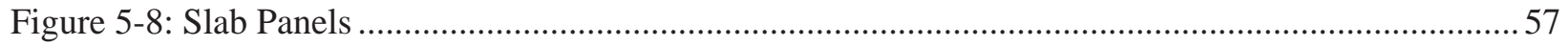

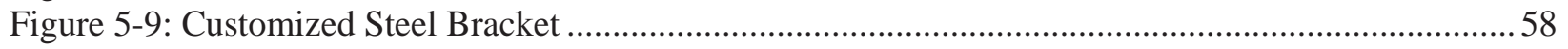

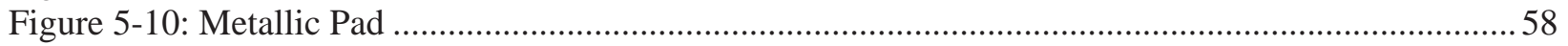




\section{LIST OF TABLES}

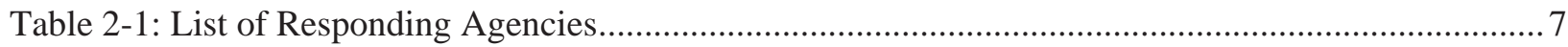

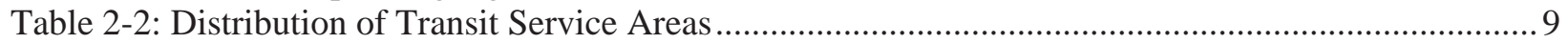

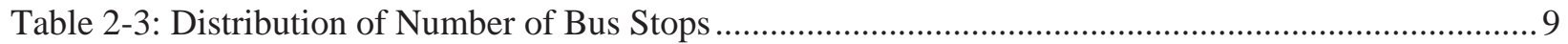

Table 2-4: Distribution of Fully ADA-Compliant Bus Stops ............................................................. 9

Table 2-5: Total Budget for Bus Stop ADA Improvements in Previous and Current Years ...................... 11

Table 2-6: Average Total Cost of Installing Bus Stop Boarding and Alighting Pads .............................. 11

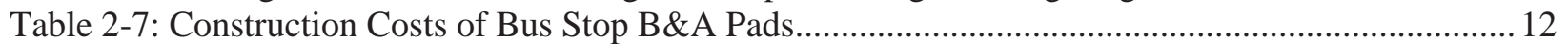

Table 2-8: Frequency of Changing Bus Routes ............................................................................... 13

Table 2-9: Bus Stop Facilities That Are Reused by Transit Agencies................................................... 14

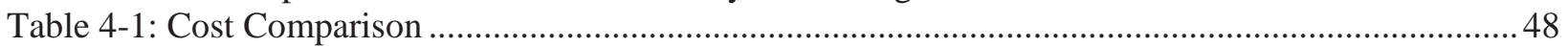

Table 4-2: Evaluation of Design Materials for Their Potential Use as Movable B\&A Pads ..................... 49

Table B-1: Criteria for Selecting and Prioritizing Bus Stops for ADA Improvements ............................ 74

Table B-2: Average Cost for Construction of Bus Stop Boarding and Alighting Pads .............................78

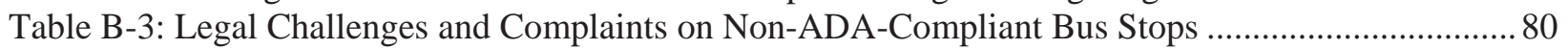

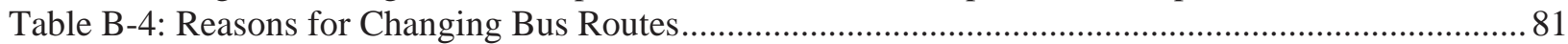

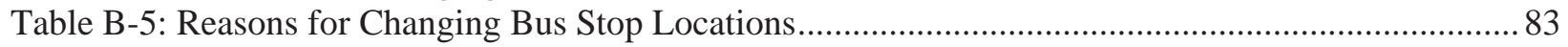

Table B-6: Benefits for Using Movable Bus Stop Boarding and Alighting Pads .....................................85

Table B-7: Limitations with Using Movable Bus Stop Boarding and Alighting Pads ..............................8 87

Table B-8: Opinions on Using Movable Bus Stop Boarding and Alighting Pads ..................................... 89

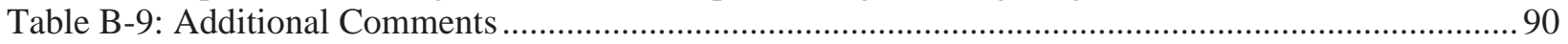




\section{LIST OF ACRONYMS/ABBREVIATIONS}

ABS

ADA

ADAAG

B\&A Pads

$\mathrm{BCT}$

DOD

ECR

FDOT

FHWA

FTA

HDPE

MOT

NTD

PP

PS

PVC

UV
Acrylonitrile Butadiene Styrene

Americans with Disabilities Act

Americans with Disabilities Act Accessibility Guidelines

Boarding and Alighting Pads

Broward County Transit

Department of Defense

Embedded Concrete Rubber

Florida Department of Transportation

Federal Highway Administration

Federal Transit Administration

High Density Polyethylene

Maintenance of Traffic

National Transit Database

Polypropylene

Polystyrene

Polyvinyl Chloride

Ultraviolet 


\section{CHAPTER 1 INTRODUCTION}

Bus stops are key links in the journeys of transit riders, particularly for those individuals with disabilities. Because of physical, sensory, or mental challenges, people with disabilities often rely on public transportation as their primary source of transportation. However, inaccessible bus stops could discourage or prevent them from using fixed-route bus services, forcing them to use the more expensive paratransit services. A bus stop can be inaccessible because of the lack of a firm, stable, slip-resistant boarding and alighting (B\&A) area and/or connected sidewalks with curb ramps.

\subsection{Bus Stop Accessibility Standards}

The Americans with Disabilities Act (ADA) of 1990 prescribes the minimum requirements for bus stop accessibility for riders with disabilities. Title II of the ADA covers sidewalk and street construction and transit accessibility, referencing the ADA Accessibility Guidelines (ADAAG) for all new construction and alterations undertaken by or on behalf of a state or local government. In addition, the Department of Justice Title II Regulation specifically mandates ADA-compliant curb ramps when sidewalks or streets are newly constructed or altered (U.S. Access Board, 2006a). Figure 1-1 illustrates the ADA minimum standards for bus stop B\&A areas. As shown in the figure, the standards require firm, stable, slip-resistant B\&A area with connected sidewalks of $3^{\prime}(0.9 \mathrm{~m})$ clear passage width, 1:50 (2\%) maximum cross slope, and $1: 12(8.33 \%)$ curb cut slope. While it is not mandated by ADA, a 5' $(1.5 \mathrm{~m})$ construction width (with a $3^{\prime}(0.9 \mathrm{~m})$ clear passage width) is preferred for sidewalks to accommodate patrons with physical disabilities. Figures 1-2 and 1-3 give examples of non-ADA-compliant and ADAcompliant bus stops, respectively.

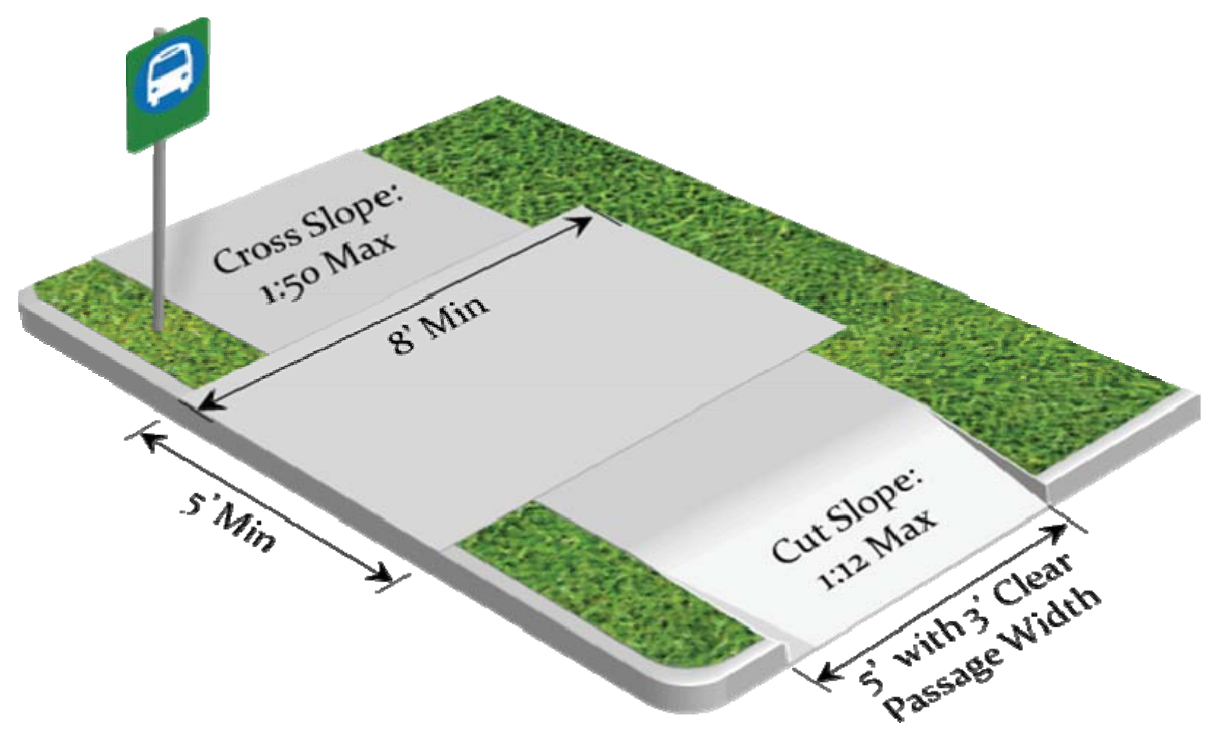

Figure 1-1: Minimum ADA Requirements 


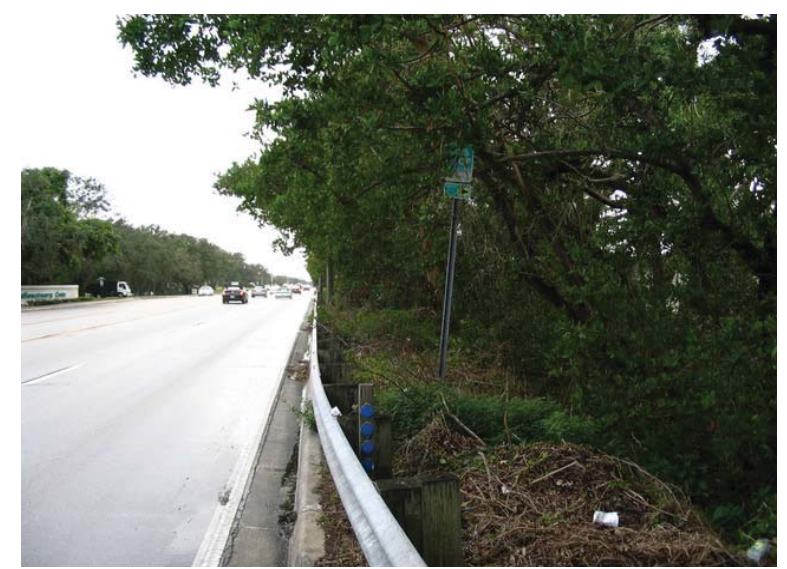

(a) No loading area, no sidewalk, and with physical barriers.

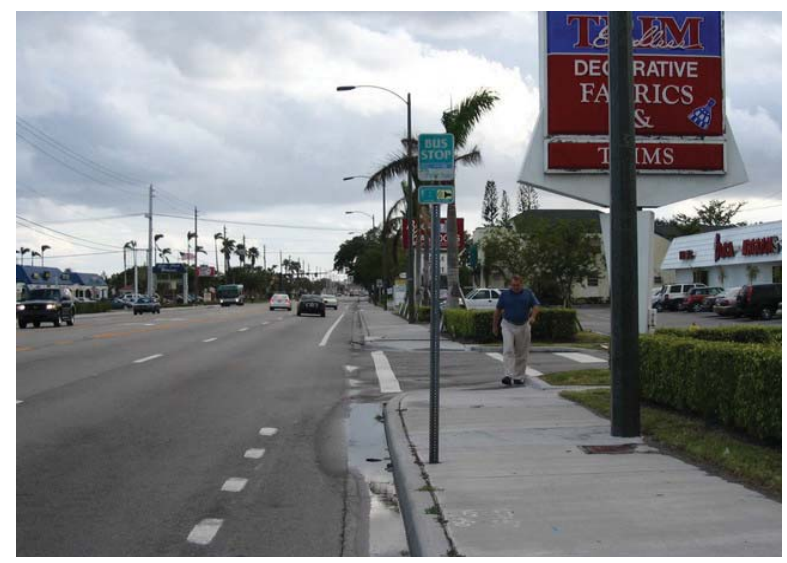

(c) Sidewalk does not meet the minimum depth requirement of $8^{\prime}$ and it is also obscured by a pole.

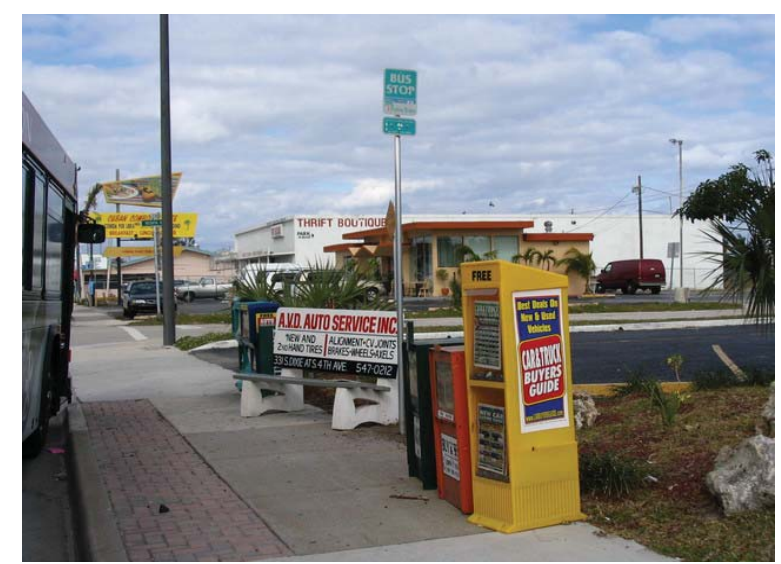

(b) Depth of the B\&A area barely meets the minimum $8^{\prime}$ requirement; however, it is obscured by a bench and paper kiosks.

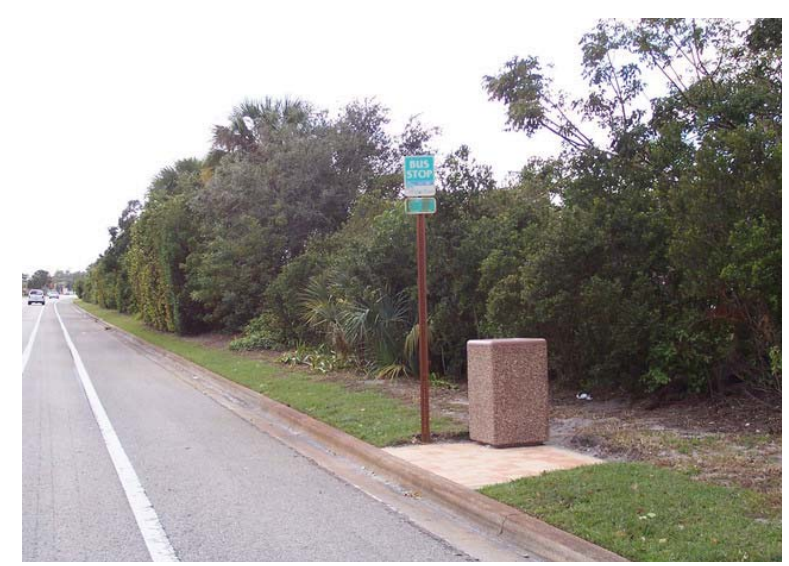

(d) Although there is not a sidewalk, the shoulder may serve as the accessible path; however, the B\&A pad does not meet the size requirement and is also obscured by a trash can.

\section{Figure 1-2: Examples of Non-ADA-compliant Bus Stops}

\subsection{Problem Statement}

While the ADA requirements are well-intentioned, compliance with such requirements inevitably present a major burden on the transit agencies. Transit agencies have to either build ADA-compliant bus stops or provide complimentary paratransit service at non-ADA-compliant bus stops. These paratransit services can cost up to three times the average cost of a fixed route trip, so transit agencies may choose to make their stops more accessible by providing paved surfaces and clear paths to these stops. 


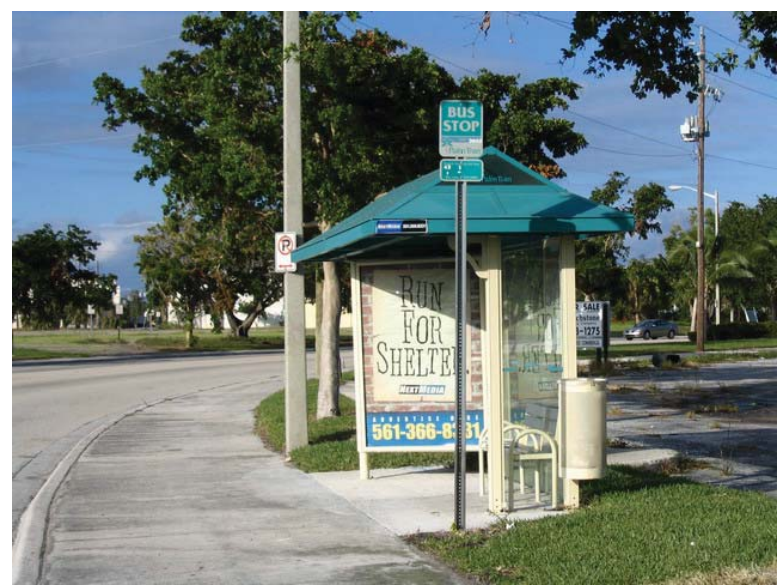

(a) Sidewalk with usable extended area for bus shelter that also serves as a B\&A pad.

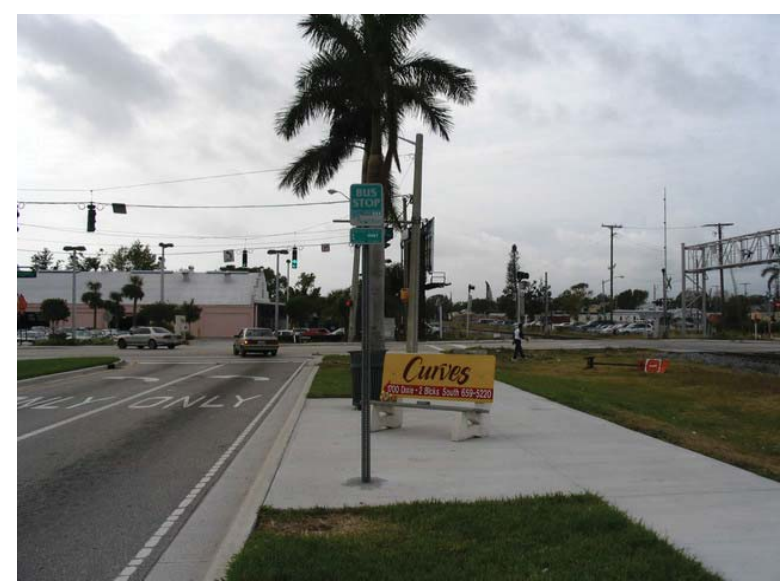

(c) B\&A pad suitable for both front- and reardoor boarding and alighting (but with partial obstructions).

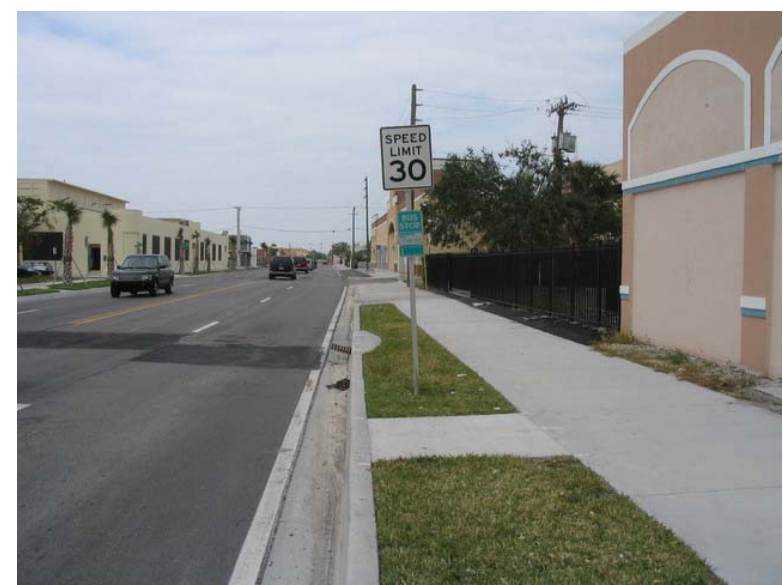

(b) B\&A pad together with sidewalk meets the $5^{\prime} \times 8^{\prime}$ minimum requirement.

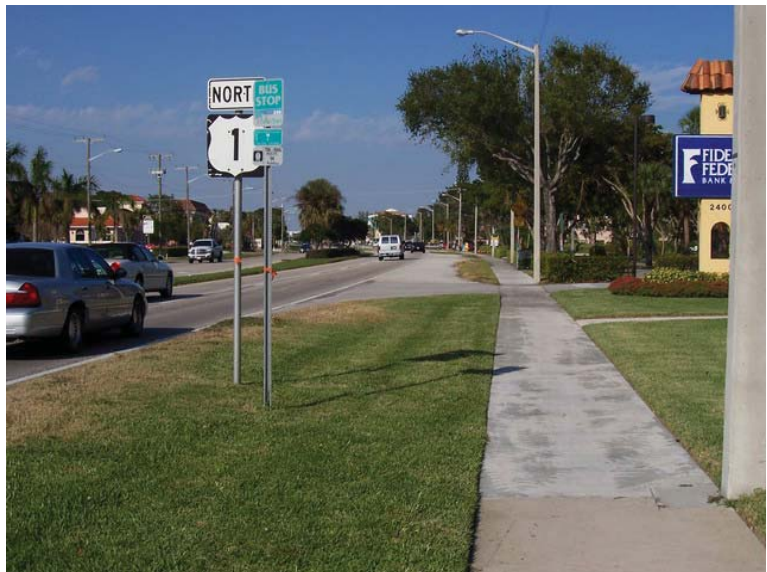

(d) Although there is not a concrete pad, the grass area meets the requirement of a firm, stable, and slip-resistant surface.

\section{Figure 1-3: Examples of ADA-compliant Bus Stops}

Florida transit agencies have been installing permanent features such as concrete slabs and other amenities at bus stops to meet ADA requirements; however, economic conditions have caused many transit agencies to discontinue or reconfigure routes to reduce costs and maximize system efficiencies. Services along particular routes are often terminated or relocated, leaving in place the permanent bus stop features such as the concrete pad along a roadway right of way. Additionally, because these concrete pads cannot be relocated as is, new concrete pads may be required at new bus stops along the newly relocated transit routes. This constant removal and installation of these permanent features can be costly to transit agencies and/or local governments. Considering that several of Florida's larger urbanized transit agencies have service areas containing thousands of bus stops which may be relocated every few years due to changes in ridership and/or transit services, the costs involved are significant. 
To maximize limited capital revenues, the Florida Department of Transportation (FDOT) is interested in exploring the feasibility of using B\&A pads that are movable and reusable. The use of movable pads not only could result in potential savings in construction materials and installation, but could also reduce or even totally eliminate the cost for maintenance of traffic (MOT), which is one of the more expensive line items. Movable pads could also reduce the construction duration, and thus saving on labor cost and reducing construction impacts to traffic and abutting businesses and residents.

The most critical design element in the construction of B\&A pads is the materials used. Section 810.2.1 of the latest version of ADAAG, as amended in 2006, states that "bus stop B\&A areas shall have a firm, stable surface." As part of the requirements for Accessible Route under Section 403.2 of ADAAG, it further requires that the surface be "slip-resistant". While the conditions that qualify a surface as a firm, stable, and slip-resistant have not been defined, a supplemental document called A Guide to ADAAG Provisions, published by United States Access Board, states that "accessible routes do not necessarily have to be paved, but must be firm, stable, and slipresistant so that they are safe and usable by people who use wheelchairs or who walk with difficulty" (U.S. Access Board, 2006b). This guidance is especially important as it clearly provides a basis for using materials other than a paved surface for bus stop B\&A areas. The installation of concrete or asphalt B\&A pads is required when a transit agency improves or enhances the transit stop through the addition of benches, shelters, trash receptacles or other street furniture.

\subsection{Project Objectives}

The main purpose of this project is to explore the feasibility of using movable bus stop B\&A pads. Accordingly, this project has four objectives:

1. Conduct a national survey of transit agencies about the use of movable B\&A pads.

2. Research and evaluate the existing materials for potential use in constructing B\&A pads at bus stops.

3. Develop and evaluate design alternatives for movable B\&A pads.

4. Recommend specific materials and design alternatives for further testing and implementation.

\subsection{Report Organization}

The rest of the report is organized as follows. Chapter 2 discusses the design and administration of the national survey of transit agencies, analyzes the responses, and summarizes the results. Chapter 3 covers the review of the existing materials, including concrete/asphalt, metal, rubber, thermoplastic, composite, and wood, for potential use in constructing B\&A pads. Chapter 4 evaluates the potential materials based on several criteria, including structural performance, long-term durability, adaptability, life cycle cost, aesthetics, and safety and accessibility of transit riders with mobility devices. Chapter 5 develops design alternatives and recommends alternatives for further testing and implementation. Finally, Chapter 6 provides the relevant conclusions and recommendations for further investigation. 


\section{CHAPTER 2 NATIONAL SURVEY OF TRANSIT AGENCIES}

Understanding the status and practice of transit agencies across the country in meeting the ADA bus stop accessibility requirements and getting their insights on movable bus stop pads is vital in developing design alternatives for ADA compliant movable B\&A pads. The review of the use, design, and performance of B\&A pads also helps to understand the outlooks of the transit agencies. This information was obtained through the national survey of transit agencies. The survey mainly focused on the agencies' service areas, ADA compliancy of their bus stops, and agencies' opinions on the feasibility of using movable B\&A pads. In addition, the survey aimed to gather the experience from agencies that have been installing movable pads or were aware of other agencies that use movable pads. This chapter first describes the preparation, design, and distribution processes of the survey. The results and key findings of the survey are then summarized.

\subsection{Survey Design}

While designing the survey questions, the intention was to make it short, concise, and less time consuming (about 15 minutes to complete). A total of 18 questions were included in the survey, and are given in Appendix A. The survey questions were posted online via the Qualtrics website (http://www.qualtrics.com). Qualtrics is a website designed for conducting online surveys and it includes user-friendly icons and menus including built-in functions for displaying questions. Figure 2-1 shows a screenshot of the website. The website incorporates functions to edit the designed survey, distribute the survey, and view the survey results. Figure 2-2 shows a screenshot from the online survey showing a set of questions.

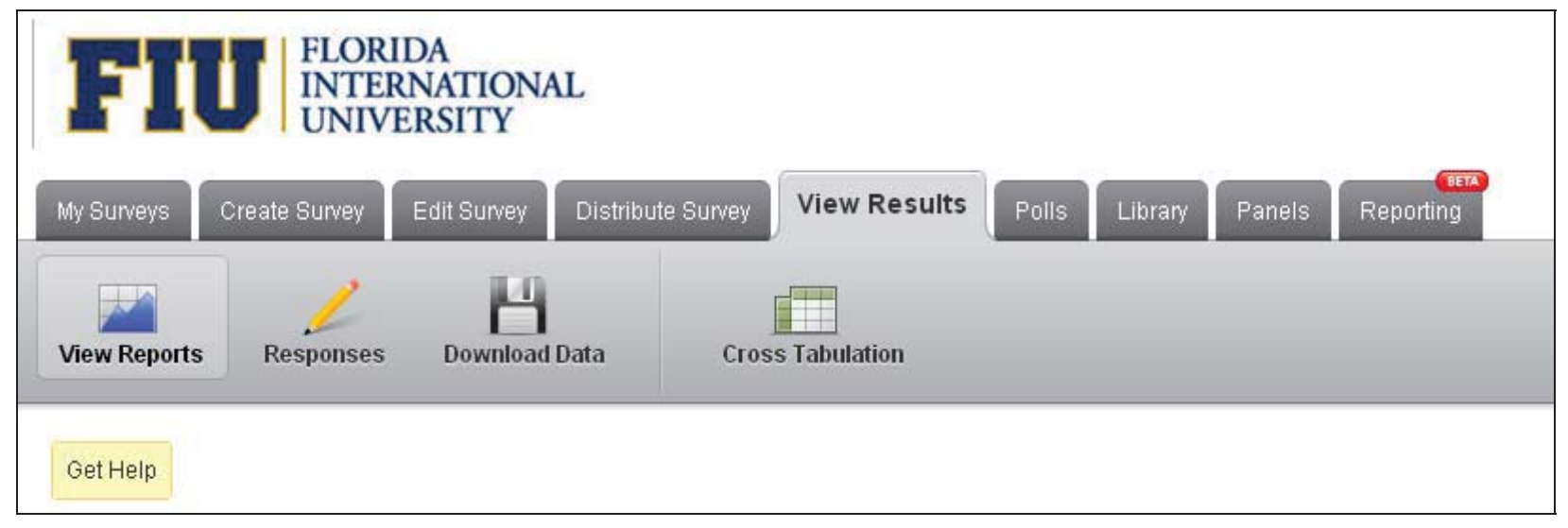

Figure 2-1: Qualtrics Online Survey Layout 
Q5. What is the total budget allocated to bus stop ADA improvements last and this year?

Lastyear:

This year:

Q6. What is the approximate average total cost associated with the installation of a bus stop boarding and alighting pad at your agency?

Q7. Please list and provide the average cost of three major line items (e.g., Maintenance of Traffic) associated with the construction of bus stop boarding and alighting pads at your agency.

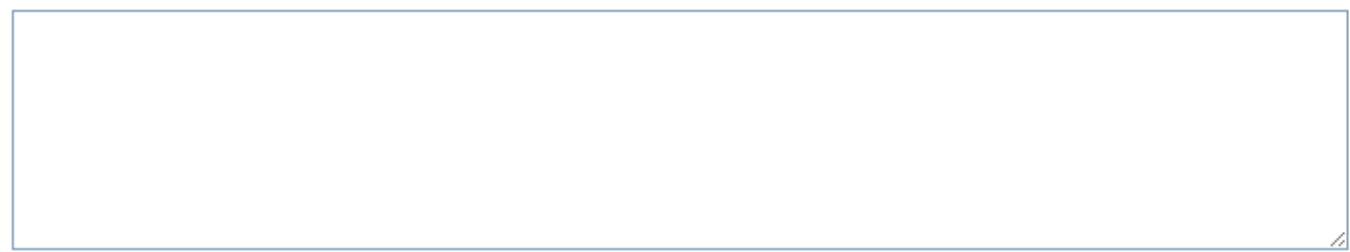

Q8. Have there been any legal challenges and/or complaints to non-ADA compliant bus stops?

Yes

No

Prev Next

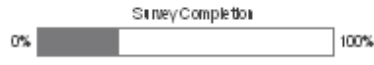

Figure 2-2: Sample Online Survey Questions in Qualtrics

\subsection{Survey Distribution}

Prior to distributing the survey, the complete list of transit agencies that operate bus transit systems and report to the National Transit Database (NTD) program of the Federal Transit Administration (FTA) was compiled. An online link to the survey was then generated and sent out via an invitation email to the entire list of transit agencies. Multiple reminder emails were also sent out to agencies that did not respond. In total, 84 transit agencies from 31 states and Puerto Rico responded to the survey. Table 2-1 lists the responding agencies by city and state. 
Table 2-1: List of Responding Agencies

\begin{tabular}{|c|c|c|}
\hline Agency Name & City & State \\
\hline - Metropolitan Area Commuter System & Fairbanks & Alaska \\
\hline - Birmingham Jefferson County Transit & Birmingham & Alabama \\
\hline - Gadsden Transportation Services & Gadsden & Alabama \\
\hline - Fort Smith Transit & Fort Smith & Arkansas \\
\hline - Intercity Transit & Hot Springs & Arkansas \\
\hline - Pine Bluff Transit & Pine Bluff & Arkansas \\
\hline - City of Tucson Department of Transportation & Tucson & Arizona \\
\hline - Northern Arizona Intergovernmental Public Transportation Authority & Flagstaff & Arizona \\
\hline - Yuma County Intergovernmental Public Transportation Authority & Yuma & Arizona \\
\hline - City of Santa Rosa City Bus & Santa Rosa & California \\
\hline - Eastern Contra Costa Transit Authority & Antioch & California \\
\hline - Los Angeles County Metropolitan Transportation Authority & Los Angeles & California \\
\hline - Sacramento Regional Transit District & Sacramento & California \\
\hline - SunLine Transit Agency & Thousand Palms & California \\
\hline - Gold Coast Transit & Oxnard & California \\
\hline - Paso Express Transit & Paso Robles & California \\
\hline - Santa Cruz Metropolitan Transit District & Santa Cruz & California \\
\hline - Unitrans & Davis & California \\
\hline - Visalia Transit & Visalia & California \\
\hline - San Mateo Transit District & San Carlos & California \\
\hline - Transfort - City of Fort Collins & Fort Collins & Colorado \\
\hline - Connecticut Transit & Hartford & Connecticut \\
\hline - Middletown Area Transit & Middletown & Connecticut \\
\hline - Broward County Transit & Pompano Beach & Florida \\
\hline - Collier Area Transit & Naples & Florida \\
\hline - Pasco County Public Transportation & Port Richey & Florida \\
\hline - Pinellas Suncoast Transit Authority & St. Petersburg & Florida \\
\hline - South Florida Regional Transportation Authority & Pompano Beach & Florida \\
\hline - Palm Tran & West Palm Beach & Florida \\
\hline - Gainesville Regional Transit System & Gainesville & Florida \\
\hline - Bettendorf Transit & Bettendorf & Iowa \\
\hline - Sioux Area Metro & Sioux City & Iowa \\
\hline - The Jule & Dubuque & Iowa \\
\hline - Citylink Transit & Worley & Idaho \\
\hline - IndyGo & Indianapolis & Indiana \\
\hline - South Bend Public Transportation Company & South Bend & Indiana \\
\hline - LexTran - Transit Authority of LFUCG and Lexington & Lexington & Kentucky \\
\hline - Transit Authority of River City & Louisville & Kentucky \\
\hline - GO BG Transit & Bowling Green & Kentucky \\
\hline - Cape Cod Regional Transit Authority & Hyannis & Massachusetts \\
\hline - Interurban Transit Partnership - The Rapid & Grand Rapids & Michigan \\
\hline - Suburban Mobility Authority for Regional Transportation & Detroit & Michigan \\
\hline - Blue Water Area Transit & Port Huron & Michigan \\
\hline - Mass Transportation Authority & Flint & Michigan \\
\hline - Muskegon Area Transit System & Muskegon Heights & Michigan \\
\hline - Metro Transit & Minneapolis & Minnesota \\
\hline - Rochester Public Transit & Rochester & Minnesota \\
\hline - City of Joplin & Joplin & Missouri \\
\hline
\end{tabular}




\begin{tabular}{|lll|}
\hline Agency Name & City & State \\
- City of Asheville & Asheville & North Carolina \\
- Concord Kannapolis Area Transit & Concord & North Carolina \\
- Jacksonville Transit & Jacksonville & North Carolina \\
\hline - Grand Forks Cities Area Transit & Grand Forks & North Dakota \\
\hline - City of Lincoln-StarTran & Lincoln & Nebraska \\
\hline - Manchester Transit Authority & Manchester & New Hampshire \\
\hline - Santa Fe Trails City of Santa Fe & Santa Fe & New Mexico \\
\hline - Regional Transportation Commission of Washoe County & Reno & Nevada \\
\hline - Westchester County Dept. of Public Works and Transportation & Mount Vernon & New York \\
- Greater Glens Falls Transit & Queensbury & New York \\
\hline - Central Ohio Transit Authority & Columbus & Ohio \\
- Stark Area Regional Transit Authority & Canton & Ohio \\
- Richland County Transit Board & Mansfield & Ohio \\
- Sandusky Transit System & Sandusky & Ohio \\
\hline - TriMet & Portland & Oregon \\
- South Metro Area Regional Transit & Wilsonville & Oregon \\
\hline - Centre Area Transportation Authority & State College & Pennsylvania \\
- Port Authority of Allegheny County & Pittsburgh & Pennsylvania \\
\hline - Municipality of Camuy & Camuy & Puerto Rico \\
- Municipality of Juncos & Juncos & Puerto Rico \\
- Oficina para los Asuntos de las Personas con Impedimentos Municipio & Humacao & Puerto Rico \\
\hline - Putonomo de Humacao & & See Regional Transportation Authority \\
- Spartanburg Area Regional Transit Agency & Florence & South Carolina \\
- Spartanburg County Transportation Services Bureau & Spartanburg & South Carolina \\
\hline - Sun Metro & Spartanburg & South Carolina \\
- City of Mesquite & El Paso & Texas \\
- Tyler Transit & Mesquite & Texas \\
\hline - Arlington Transit & Tyler & Texas \\
\hline - Bristol Virginia Transit & Arlington & Virginia \\
- Everett Transit & Bristol & Virginia \\
\hline & Tacoma & Washington \\
\hline & Everett & Washington \\
\hline & & \\
\hline
\end{tabular}

\subsection{Survey Results}

This section summarizes the results and key findings of the nationwide survey on the use of movable B\&A pads at bus stops. Note that the results are summarized for each question. Appendix B gives the individual agencies' responses to the open ended questions.

\section{Q1. Please describe your agency's service area.}

Table 2-2 shows the distribution of transit service areas for the 84 responding agencies. The table shows that the survey included a good balance of agencies serving large (42.9\%) and small $(48.8 \%)$ urbanized areas. Rural or non-urbanized areas with population under 50,000 and "other" areas with a mix of both rural and small urbanized areas constitute only a small percentage of the surveyed transit service areas, at $3.6 \%$ and $4.8 \%$, respectively. 
Table 2-2: Distribution of Transit Service Areas

\begin{tabular}{|l|c|c|}
\hline Area Type & Frequency & Percentage \\
\hline Large urbanized area & 36 & $42.9 \%$ \\
\hline Small urbanized area & 41 & $48.8 \%$ \\
\hline Rural or non-urbanized area & 3 & $3.6 \%$ \\
\hline Others & 4 & $4.8 \%$ \\
\hline Total & $\mathbf{8 4}$ & $\mathbf{1 0 0 . 0 \%}$ \\
\hline
\end{tabular}

${ }^{+}$Others include regions having a mix of both rural and small urbanized areas.

\section{Q2. How many bus stops does your agency have currently?}

Table 2-3 gives the distribution of the number of bus stops. Five responding agencies indicated that they do not have any bus stops, while two responding agencies were unsure. Over one-third of the responding agencies $(34.5 \%)$ have up to 300 bus stops.

Table 2-3: Distribution of Number of Bus Stops

\begin{tabular}{|l|c|c|}
\hline Number of Bus Stops & Frequency & Percentage \\
\hline 0 & 5 & $6.0 \%$ \\
\hline$\leq 300$ & 29 & $34.5 \%$ \\
\hline 301 to 500 & 9 & $10.7 \%$ \\
\hline 501 to 1,000 & 13 & $15.5 \%$ \\
\hline 1,001 to 3,000 & 11 & $13.1 \%$ \\
\hline$>3,000$ & 15 & $17.9 \%$ \\
\hline Unknown & 2 & $2.4 \%$ \\
\hline Total & $\mathbf{8 4}$ & $\mathbf{1 0 0 . 0 \%}$ \\
\hline
\end{tabular}

\section{Q3. Roughly what percentage of these bus stops is considered fully ADA-compliant?}

Table 2-4 gives the distribution of the percentage of fully ADA-compliant bus stops. About onefifth of the responding agencies $(19.0 \%)$ have over $90 \%$ of their bus stops fully ADA-compliant. On the other hand, $7.1 \%$ of the responding agencies have less than $10 \%$ of fully ADA-compliant bus stops. Further, $19.0 \%$ of the responding agencies either did not have bus stops or were not sure about ADA-compliancy of their bus stops.

Table 2-4: Distribution of Fully ADA-Compliant Bus Stops

\begin{tabular}{|l|c|c|}
\hline Percent of Fully ADA-Compliant Bus Stops & Frequency & Percentage \\
\hline$\leq 10 \%$ & 6 & $7.1 \%$ \\
\hline$>10 \%$ and $\leq 20 \%$ & 7 & $8.3 \%$ \\
\hline$>20 \%$ and $\leq 30 \%$ & 3 & $3.6 \%$ \\
\hline$>30 \%$ and $\leq 40 \%$ & 5 & $6.0 \%$ \\
\hline$>40 \%$ and $\leq 50 \%$ & 8 & $9.5 \%$ \\
\hline$>50 \%$ and $\leq 60 \%$ & 7 & $8.3 \%$ \\
\hline$>60 \%$ and $\leq 70 \%$ & 5 & $6.0 \%$ \\
\hline$>70 \%$ and $\leq 80 \%$ & 7 & $8.3 \%$ \\
\hline$>80 \%$ and $\leq 90 \%$ & 5 & $6.0 \%$ \\
\hline$>90 \%$ and $\leq 100 \%$ & 16 & $19.0 \%$ \\
\hline Unknown and N/A & 15 & $17.9 \%$ \\
\hline Total & $\mathbf{8 4}$ & $\mathbf{1 0 0 . 0 \%}$ \\
\hline
\end{tabular}


Q4. What are the criteria and methods used to select and prioritize bus stops for ADA improvements?

The following are found to be the methods used by agencies to prioritize bus stops for ADA improvements, where the number of agencies identifying each method is indicated in parentheses.

- High ridership stops (15)

- Accessibility (15)

- Customer/rider complaints and requests (14)

- Presence of ADA landing pads, crosswalks, sidewalks, and curb ramps (10)

- $\operatorname{Cost}(9)$

- Location near a facility (e.g., a medical complex) or an area with a higher concentration of disabled passengers $(8)$

- Availability of right-of-way (7)

- Roadway improvements (5)

- Safety (3)

- Site evaluation (3)

- Ability to get permission from officials (2)

- Others, which include:

- Complexity of the bus stop (1)

- Number of transfer points (1)

- Ease of implementation (1)

- Municipal planning consultation (1)

- Bus operators' and service workers' feedback (1)

- Urgency of need (1)

- Level-of-service procedure (1)

- Surveys (1)

- Level of ADA deficiency and wheelchair count logs (1)

Additionally, some agencies mentioned that they do not improve bus stops since it is the responsibility of the municipalities/jurisdictions in charge.

Q5. What is the total budget allocated to bus stop ADA improvements last and this year?

Table 2-5 shows the distribution of total budget allocated for bus stop ADA improvements in the previous and current years. The distribution of budget in the current year is very similar to the distribution in the previous year, indicating consistency in the extent of funding for bus stop ADA improvements. However, there was a reduction in the average budget, dropping from an average of $\$ 253,475$ per agency in the previous year to $\$ 177,316$ per agency in the current year. Of the 61 agencies that provided their budgets, $22 \%$ indicated a budget increase from the previous year, $31 \%$ indicated a reduction in the allocated budget, and $47 \%$ indicated that there has been no change in budget allocation for ADA improvements at bus stops. 
Table 2-5: Total Budget for Bus Stop ADA Improvements in Previous and Current Years

\begin{tabular}{|l|c|c|c|c|}
\multirow{2}{*}{ Total Budget } & \multicolumn{2}{|c|}{ Previous Year } & \multicolumn{2}{c|}{ Current Year } \\
\cline { 2 - 5 } & Frequency & Percentage & Frequency & Percentage \\
\hline$\leq 0$ & 24 & $28.6 \%$ & 23 & $27.4 \%$ \\
\hline$\leq \$ 50 \mathrm{~K}$ & 14 & $16.7 \%$ & 14 & $16.7 \%$ \\
\hline$>\$ 50 \mathrm{~K}$ and $\leq \$ 100 \mathrm{~K}$ & 6 & $7.1 \%$ & 6 & $7.1 \%$ \\
\hline$>\$ 100 \mathrm{~K}$ and $\leq \$ 500 \mathrm{~K}$ & 13 & $15.5 \%$ & 15 & $17.9 \%$ \\
\hline$>\$ 500 \mathrm{~K}$ and $\leq \$ 1$ Million & 3 & $3.6 \%$ & 2 & $2.4 \%$ \\
\hline$>\$ 1$ Million & 2 & $2.4 \%$ & 1 & $1.2 \%$ \\
\hline Unknown and N/A & 22 & $26.2 \%$ & 23 & $27.4 \%$ \\
\hline Total & $\mathbf{8 4}$ & $\mathbf{1 0 0 . 0 \%}$ & $\mathbf{8 4}$ & $\mathbf{1 0 0 . 0 \%}$ \\
\hline
\end{tabular}

Q6. What is the approximate average total cost associated with the installation of a bus stop boarding and alighting pad at your agency?

Table 2-6 gives the distribution of average total cost of installing a bus stop B\&A pad. The table shows that most agencies spent on average less than $\$ 6,000$ toward the installation of B\&A pads. Seven agencies indicated that they spent an average of over $\$ 10,000$.

Table 2-6: Average Total Cost of Installing Bus Stop Boarding and Alighting Pads

\begin{tabular}{|l|c|c|}
\hline Average Total Cost & Frequency & Percentage \\
\hline$>\$ 0$ and $\leq \$ 1,000$ & 9 & $10.7 \%$ \\
\hline$>\$ 1,000$ and $\leq \$ 2,000$ & 10 & $11.9 \%$ \\
\hline$>\$ 2,000$ and $\leq \$ 3,000$ & 3 & $3.6 \%$ \\
\hline$>\$ 3,000$ and $\leq \$ 4,000$ & 3 & $3.6 \%$ \\
\hline$>\$ 4,000$ and $\leq \$ 5,000$ & 5 & $6.0 \%$ \\
\hline$>\$ 5,000$ and $\leq \$ 6,000$ & 9 & $10.7 \%$ \\
\hline$>\$ 6,000$ and $\leq \$ 7,000$ & 1 & $1.2 \%$ \\
\hline$>\$ 7,000$ and $\leq \$ 8,000$ & 1 & $1.2 \%$ \\
\hline$>\$ 8,000$ and $\leq \$ 9,000$ & 1 & $1.2 \%$ \\
\hline$>\$ 9,000$ and $\leq \$ 10,000$ & 2 & $2.4 \%$ \\
\hline$>\$ 10,000$ & 7 & $8.3 \%$ \\
\hline Unknown and N/A & 33 & $39.3 \%$ \\
\hline Total & $\mathbf{8 4}$ & $\mathbf{1 0 0 . 0 \%}$ \\
\hline
\end{tabular}

Q7. Please list and provide the average cost of three major line items (e.g., Maintenance of Traffic) associated with the construction of bus stop boarding and alighting pads at your agency.

Several agencies listed the three major line items, but did not provide costs associated with the line items. A few agencies mentioned that the cost estimates are prepared by the responsible jurisdiction. The following are the major line items associated with the construction of bus stop B\&A pads, where the number of agencies identifying each line item is indicated in parentheses.

- Material installation, e.g., concrete and cement (18) 
- Excavation, maintenance, and state regulation (15)

- Shelter pad installation (11)

- Labor (6)

- Maintenance and control of traffic (5)

- Sidewalk replacement (4)

- Surveying/landscaping (3)

- Property acquisition (3)

- Handicap ramp installation (3)

- Curb and gutter cut (3)

- $\quad$ Equipments (2)

- Drawings (1)

- Planning (1)

- Utility issues (1)

Table 2-7 gives a summary of the cost range and average cost of the line items as indicated by the responding agencies. From this table, it is observed that sidewalk replacement has the highest average cost, followed by handicap ramp installation, labor, and finally, MOT.

Table 2-7: Construction Costs of Bus Stop B\&A Pads

\begin{tabular}{|l|c|c|c|}
\hline Line Item & Minimum Cost & Maximum Cost & Average Cost \\
\hline Sidewalk replacement & $\$ 3,000$ & $\$ 5,055$ & $\$ 3,920$ \\
\hline Handicap ramp installation & $\$ 1,000$ & $\$ 1,500$ & $\$ 1,250$ \\
\hline Labor & $\$ 150$ & $\$ 3,400$ & $\$ 1,225$ \\
\hline MOT & $\$ 300$ & $\$ 1,000$ & $\$ 600$ \\
\hline
\end{tabular}

Q8. Have there been any legal challenges and/or complaints to non-ADA-compliant bus stops?

Of the 84 responding agencies, $65(77.4 \%)$ reported that they had neither encountered any legal challenges nor received any complaints pertaining to non-ADA-compliant bus stops. The remaining $19(22.6 \%)$ responding agencies mentioned that they had encountered legal challenges and/or received complaints about non-ADA-compliant bus stops. Out of these 19 agencies, 17 had received complaints while only two had had a lawsuit brought against their agencies. A majority of complaints were about uneven or non-existence of sidewalks, curb cuts, poor lighting, and inaccessibility.

\section{Q9. How often do you change bus routes?}

Table 2-8 shows the responding agencies' distribution of the frequency of changing bus routes. Nearly one-fifth of the responding agencies (17.9\%) change bus routes once a year; $9.5 \%$ change twice; and $10.7 \%$ change thrice a year. A high percentage of responding agencies $(61.9 \%)$ chose "other" and most of these agencies indicated that they changed bus routes on an "as needed" basis. 
Table 2-8: Frequency of Changing Bus Routes

\begin{tabular}{|l|c|c|}
\hline Frequency of Route Change & Frequency & Percentage \\
\hline Once a year & 15 & $17.9 \%$ \\
\hline Twice a year & 8 & $9.5 \%$ \\
\hline Thrice a year & 9 & $10.7 \%$ \\
\hline Other & 52 & $61.9 \%$ \\
\hline Total & $\mathbf{8 4}$ & $\mathbf{1 0 0 . 0 \%}$ \\
\hline
\end{tabular}

Q10. What are the reason(s) for changing the bus routes?

The following are the main reasons for changing bus routes, where the number of agencies identifying each reason is indicated in parentheses.

- Changes in ridership or passenger demand (27)

- Improving efficiency, connectivity, and quality of service of bus routes (16)

- Funding issues and budget cuts (13)

- Requests made by the municipality and customers (11)

- Construction issues and long-term road closure (9)

- Low productivity (6)

- More accessibility (5)

- Demographic changes (5)

- Changes in schedules (4)

- Providing service to unserved or underserved areas (3)

- Commercial development (3)

- Time saving (3)

- Results from conducted system surveys (2)

- Truncation of routes (2)

- Revenue increase (2)

- Natural disasters (1)

It can be noticed that the most common reasons for changing bus stop routes are changes in passenger demand or ridership, efficiency and connectivity improvement, funding issues and budget cuts, and requests by municipalities and customers.

Q11. Other than for route changes, what are the other reason(s) for changing bus stop locations?

The following are the main reasons for relocating bus stops, where the frequency of selection of each reason is given in parentheses:

- Safety issues (20)

- Requests made by municipality and customers (18)

- Complaints by home owners, businesses, or riders (17)

- Serving new development (11)

- Previous installations that did not consider ADA accessibility (7) 
- Ridership changes (4)

- Spacing adjustment (4)

- Roadway improvements (3)

- Operational performance (2)

- Lack of use (2)

- Vandalism complaints (1)

- Funding issues and budget cuts (1)

It can be noticed that the most common reasons for changing bus stop locations are safety issues, requests by municipalities and customers, complaints by home owners and businesses, new development service, and accessibility consideration.

\section{Q12. When your bus stops are relocated, what bus stop facilities are moved and reused?}

Table 2-9 lists the frequency of selection and the corresponding agency percentage for each type of bus stop facilities moved/reused by the responding agencies. The corresponding percentages are also listed. Note that each agency could select multiple facilities. The table shows that bus stop poles and bus stop signs are most frequently moved and reused by 58 and 55 agencies, respectively. These facilities are followed by shelters and benches by 48 agencies each. Trash receptacles are also moved and reused often. It is also noticed that none of the responding agencies are using movable and reusable B\&A pads.

\section{Table 2-9: Bus Stop Facilities That Are Reused by Transit Agencies}

\begin{tabular}{|l|c|c|}
\hline Bus Stop Facility & Frequency of Selection & Percentage of Agencies $^{\mathbf{1}}$ \\
\hline Bus Stop Pole & 58 & $69 \%$ \\
\hline Bus Stop Sign & 55 & $65 \%$ \\
\hline Shelter & 48 & $57 \%$ \\
\hline Bench & 48 & $57 \%$ \\
\hline Trash Receptacle & 45 & $54 \%$ \\
\hline Other & 4 & $5 \%$ \\
\hline
\end{tabular}

${ }^{1}$ Calculated as the frequency of selection divided by the total number of responding agencies, i.e., 84 .

Q13. Are you aware of any other agencies that have used movable bus stop boarding and alighting pads?

None of the 84 responding agencies were aware of other agencies that use movable bus stop B\&A pads.

Q14. What do you see are the major benefits for using movable bus stop boarding and alighting pads?

Several responding agencies believed that movable bus stop pads could be more useful as a temporary measure until a permanent pad is installed. Summarizing the agencies' responses, the following are the potential benefits for using movable B\&A pads, where the number in parentheses indicates the frequency of selection. 
- Lower installation and maintenance cost (28)

- Ease of installation and use in rural areas with no curbs and sidewalks (8)

- Time saving (6)

- Flexibility (5)

- Portability and reusability (4)

- Passenger accessibility (4)

- Availability (2)

Q15. What do you foresee are the limitations, if any, with using movable bus stop boarding and alighting pads?

On the contrary to the previous question, this question seeks to gather the limitations of using movable pads as seen by the responding agencies. The following are the main limitations of using movable B\&A pads, where the number in parentheses indicates the frequency of selection.

- Lower durability, strength, and stability (20)

- Greater risk of theft (13)

- Effect of weather (8)

- Space limitations/lack of right-of-way (5)

- ADA compliance with connections to sidewalk (4)

- Safety issues (4)

- Ability to conform to different geographical conditions (2)

- Storage of unit when not in use (2)

- Aesthetics (1)

Q16. Please provide any other opinions you may have on using movable bus stop boarding and alighting pads.

The responding agencies identified uneven terrain, liability issues, encroachments onto private properties and buildings, and lack of sidewalks or crosswalks as some of the additional factors to consider in installing movable pads. One agency was curious about how the movable pad, when functional, can have the correct boarding ramp angle. The same agency was also concerned about vandalism and whether the disabled individual can benefit from the pads. Another agency is interested in exploring a larger version of the bus stop pads to support a passenger shelter. One responding agency also indicated that the decision of either using a permanent or temporary pad is essential, while another agency is interested to know about the equipment to move the pads.

Q17. If you are interested in the results of this survey and the outcomes of this research, please answer "Yes" or "No" below and we will send you updates.

Of the 84 responding agencies, 70 agencies indicated that they would be interested to learn about the results of this study. This indicates a good level of interest by the responding agencies in this research. 


\section{Q18. Please use the space below to provide any other comments you may have.}

A majority of the responding agencies agreed that the use of movable pads is a good idea; however, they required more information before implementation. The kind of subsurface, level of soil compaction, warranty, liability, security, texture, budget limits, aesthetics, and evidence of theft protection are some of the areas that need additional information. One important comment is the consideration of the design criteria of the precast bus stop pad to attach sign posts, trash cans, benches, and shelters. Other interesting comments were that some concrete companies would prefer to pour new forms that might impact the use of movable pads. One agency would be also interested to consider a bus stop pad demo once installed.

\subsection{Summary}

In this chapter, a national survey on the use of movable bus stop B\&A pads was designed. The survey included a total of 18 questions and was distributed to transit agencies via an invitation email. A total of 84 transit agencies from across the country responded to the survey. The following are the key findings from the survey responses:

- One-fifth of the responding agencies have over $90 \%$ of their bus stops fully ADAcompliant.

- The main criteria for prioritizing bus stops for ADA improvements include high ridership stops accessibility; rider complaints and requests; presence of ADA-compliant landing pads, accessible pathways, and curb ramps; availability of right-of-way; roadway improvements; high concentration of disability passengers; and safety.

- Most agencies spent an average of less than $\$ 6,000$ per B\&A pad.

- Of the 61 agencies that provided their budgets for bus stop ADA improvements, 22\% indicated a budget increase from the previous year, $31 \%$ indicated a reduction in the allocated budget, and $47 \%$ indicated that there has been no change in budget allocation for ADA improvements at bus stops.

- Material installation, excavation and maintenance, labor, and MOT are the major line items for constructing bus stop B\&A pads. Among the major line items associated with installing movable pads, sidewalk replacement has the highest average cost, followed by handicap ramp installation, labor, and finally, MOT.

- Of all the responding agencies, 22.6\% mentioned that they received customer complaints on ADA compliance and only two agencies had had a lawsuit brought against their agencies.

- A majority of the responding agencies (61.9\%) change bus routes only when needed; the main reasons for changing bus routes are: changes in passenger demand; requests made by jurisdictions and customers; construction issues and roadway closures; commercial development; time saving; and revenue increase.

- The main reasons for changing bus stop locations include safety concerns, municipality requests, complaints by home owners, lack of accessibility, changes in passenger ridership, roadway improvements, vandalism, and funding issues/budget cuts.

- Bus stop poles and signs are more frequently moved and reused when bus stops are relocated. 
- Lower installation and maintenance cost, ease of installation and use, time saving, flexibility, portability, and passenger accessibility are the main reasons for preferring movable bus stop B\&A pads.

- The main limitations with using movable bus stop B\&A pads include lower durability, strength, and stability; greater risk of theft; weather issues; space limitations; safety and aesthetic issues; and ability to conform to different geographic conditions. 


\section{CHAPTER 3 \\ REVIEW OF POTENTIAL DESIGN MATERIALS}

This chapter focuses on the review of alternative design materials that could be used for constructing movable B\&A pads at bus stops. Materials that are being used in other transportation applications that have characteristics suitable for ADA-compliant B\&A pads are reviewed in detail. The following six categories of materials, (1) concrete/asphalt, (2) metal, (3) rubber, (4) thermoplastic, (5) composite, and (6) wood, could potentially be used as B\&A pads. This chapter provides the review of these materials and their commercially available products that can be used for constructing movable B\&A pads. Specifically, the review includes:

1. Concrete/Asphalt Materials
a. Concrete and Asphalt Pads
b. Embedded Concrete Rubber (ECR)
c. TraCast Crossing Product
d. Concrete Pavers
e. Precast Concrete Pedestrian Panels
f. Precast Concrete Boardwalk

2. Metallic Materials
a. Steel Road Plates
b. Heavy Duty Aluminum Roadway
c. PortaPad

3. Rubber Materials
a. Full-Depth Heavy-Duty Rubber
b. Rubber Pedestrian Crosswalk
c. Flexi-Pave

4. Thermoplastic Materials
a. PortaPath
b. ArmorDeck
c. HexaDeck
d. Plastic Lumber Walkway
e. SupaTrac
f. Plastic Grates

5. Composite Materials
a. Mobi-Mat

6. Wooden Materials
a. Roll-out Walkways

\subsection{Concrete and Asphalt Materials}

Concrete and asphalt materials are two most widely used materials for constructing sidewalks. They provide excellent durability and can be cast-in-place in various shapes and sizes. Therefore, they are the preferred materials for constructing flat slabs such as the B\&A pads as they can 
aesthetically blend in with the existing sidewalk and roadway. Despite their advantages, one problem with these materials is their construction and/or removal time. To construct concrete B\&A pads, a concrete mixer truck is needed, and depending on the size of the B\&A pads, MOT will also be required adding to the overall cost of construction. The same applies to asphalt B\&A pads where an asphalt truck and a compacter are needed at the jobsite. Removing concrete or asphalt pads can also be very expensive since the pads will need to be demolished and hauled away.

There are several commercially available products, including concrete and asphalt pads, embedded concrete rubber, Tracast crossing system, precast pedestrian panels, and concrete pavers, that can be used to construct B\&A pads. These systems are discussed further in the following sections.

\subsubsection{Concrete and Asphalt Pads}

Transit agencies currently provide $5^{\prime} \times 8^{\prime}(1.5 \mathrm{~m} \times 2.4 \mathrm{~m})$ B\&A pads that are made of either concrete or asphalt, as shown in Figures 3-1 and 3-2, respectively. However, when compared to other alternatives, their implementation can be both costly and time consuming due to the need for surface preparations and MOT during installation. Note that the costs associated with the different design materials are discussed in Chapter 4. Additionally, the biggest disadvantage is the fact that concrete and asphalt pads are not reusable and do not provide a flexible option in meeting the changing demands of most urban transit agencies.

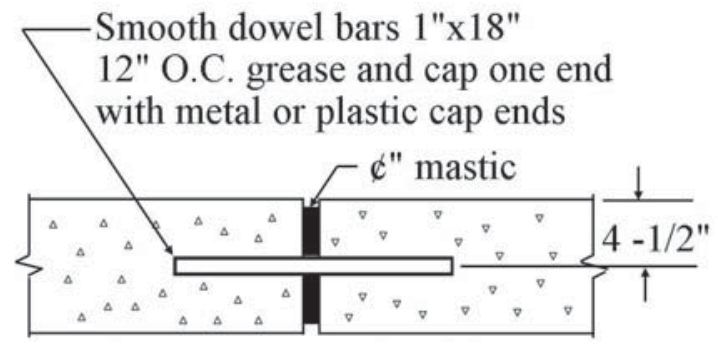

Contraction Joint

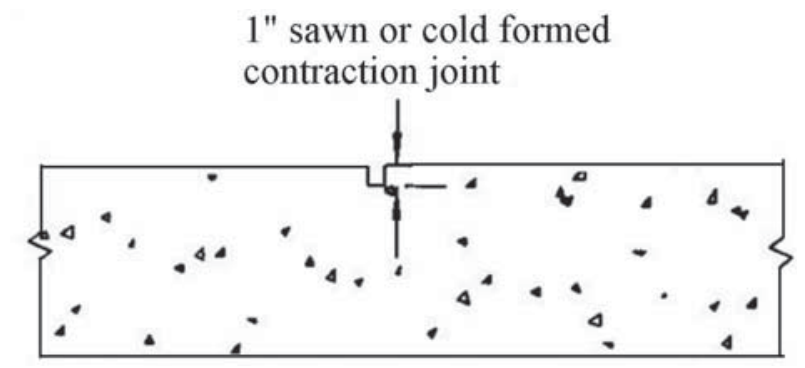

Transverse Expansion Joint

Figure 3-1: Concrete Pad (Source: TriMet, 2010)

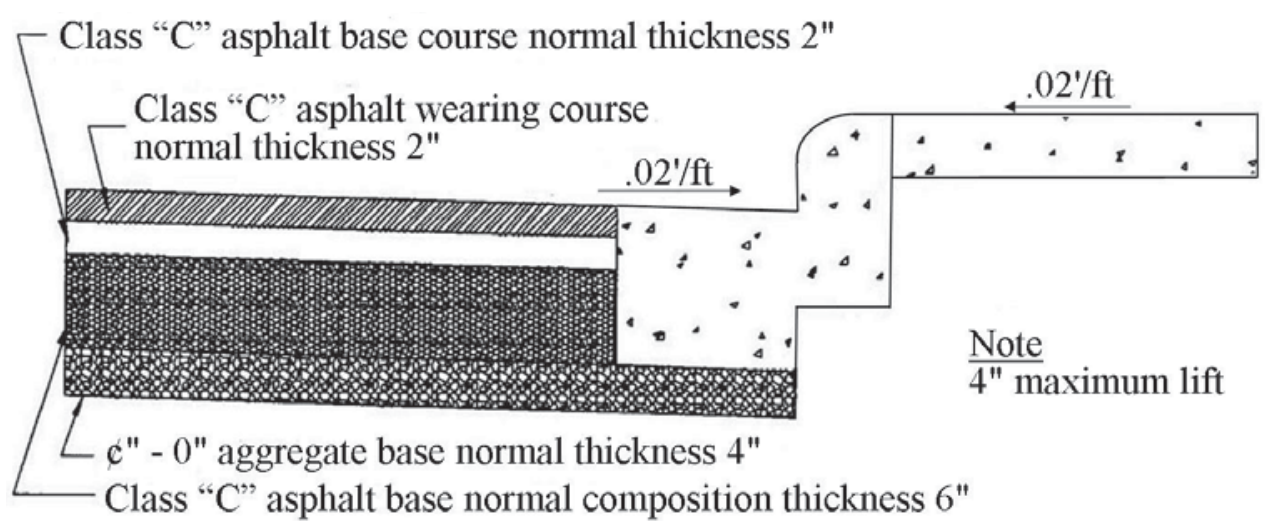

Figure 3-2: Asphalt Pad (Source: TriMet, 2010) 


\subsubsection{Embedded Concrete Rubber (ECR)}

The Embedded Concrete Rubber (ECR) System, designed for vehicles to cross train tracks, has a rubber flange seal formed into the face of the steel reinforced concrete panels. The steel sections on the ECR are coated with rust preventer for maximum protection (OMNI Grade Crossing, 2012a). Figure 3-3 shows the ECR system installed on a highway to cross train tracks.

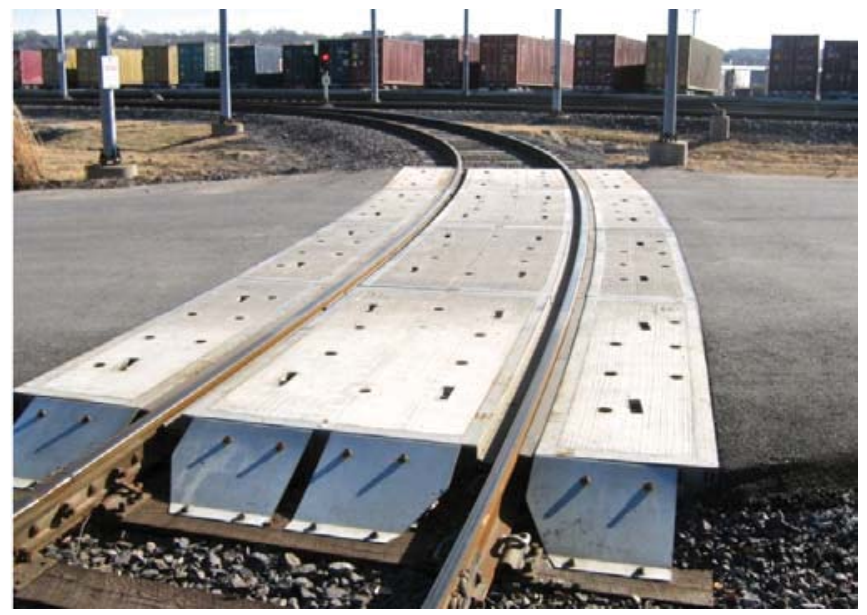

Figure 3-3: Embedded Concrete Rubber (ECR) System (Source: OMNI Grade Crossing, 2012a)

\subsubsection{TraCast Crossing Product}

The TraCast system is a precast concrete pad that is fastened to the railroad tracks. The system could be installed on both stable and unstable ground conditions. The TraCast module requires an excavation of the existing surface that is being replaced. Once the entire material is removed, the area is backfilled and the subsurface drainage is installed on the edge of the crossing. This system is useful for all facilities, including but not limited to highways, industrial areas, ports, and transit facilities (OMNI Grade Crossing, 2012b). Figure 3-4 shows the TraCast system installed on a highway to cross train tracks.

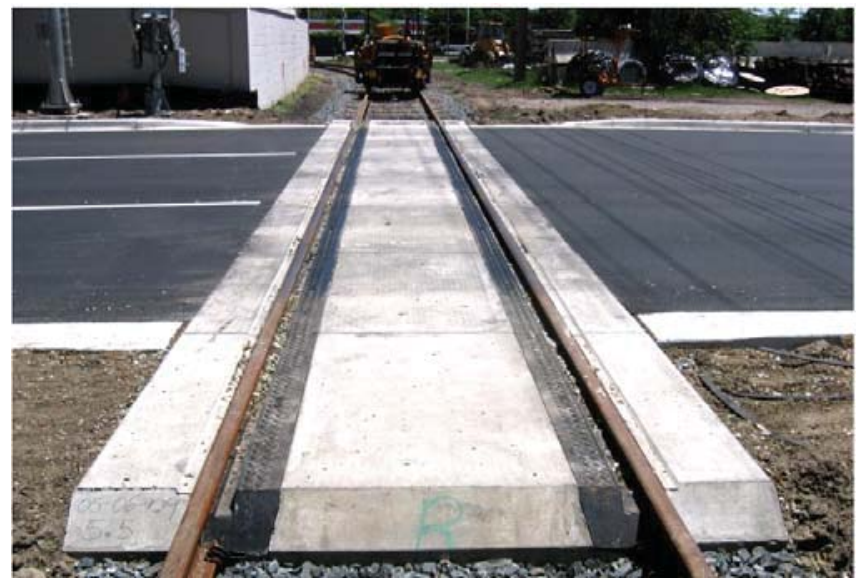

Figure 3-4: TraCast Crossing System (Source: OMNI Grade Crossing, 2012b) 


\subsubsection{Concrete Pavers}

Concrete pavers, also referred to as paving stones, are being increasingly used because of their low installation and maintenance costs. Pavers can also be removed and re-installed easily. For driveways, pedestrian areas, and areas with limited vehicular use, the paver units are typically 23/8" (6 cm) thick; for streets and industrial areas, they are 3-1/8" (approximately $9 \mathrm{~cm}$ ) thick. Figure 3-5 gives examples of concrete pavers in residential areas (ConcreteNetwork.com, 2012).

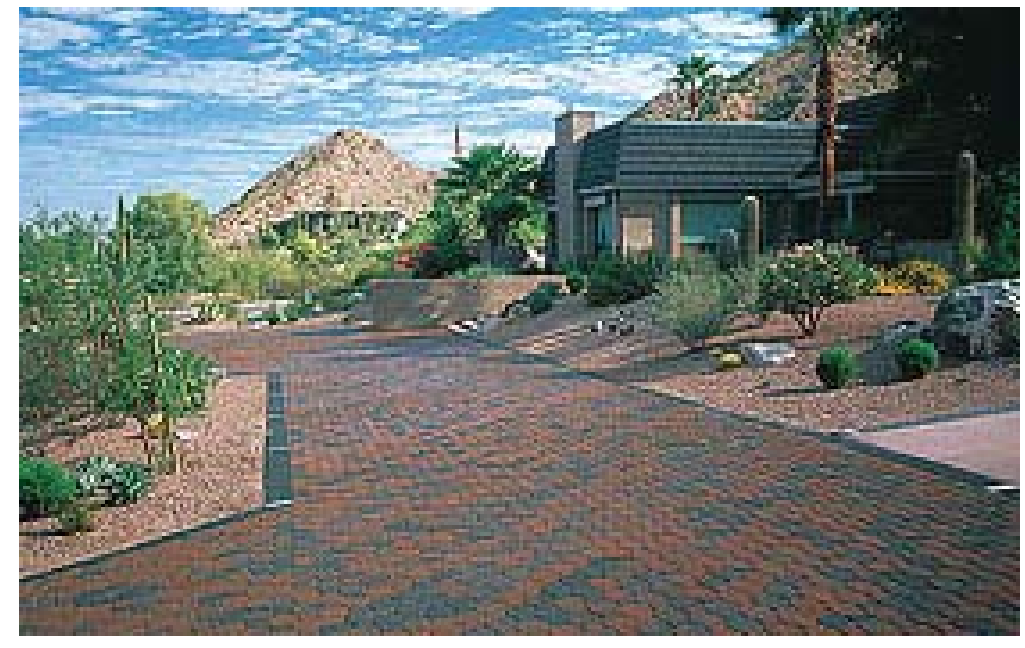

Figure 3-5: Concrete Pavers (Source: Belgard Hardscapes, 2012)

\subsubsection{Precast Concrete Pedestrian Panels}

Precast concrete pedestrian panels are constructed to ensure a smooth walking surface with builtin tapered ends and no bolts or surface deflections. The panels are designed to be slip-resistant and are ADA-compliant. Figure 3-6 shows the precast concrete pedestrian panels connecting two walking paths at a light rail station (Century Group, 2012).

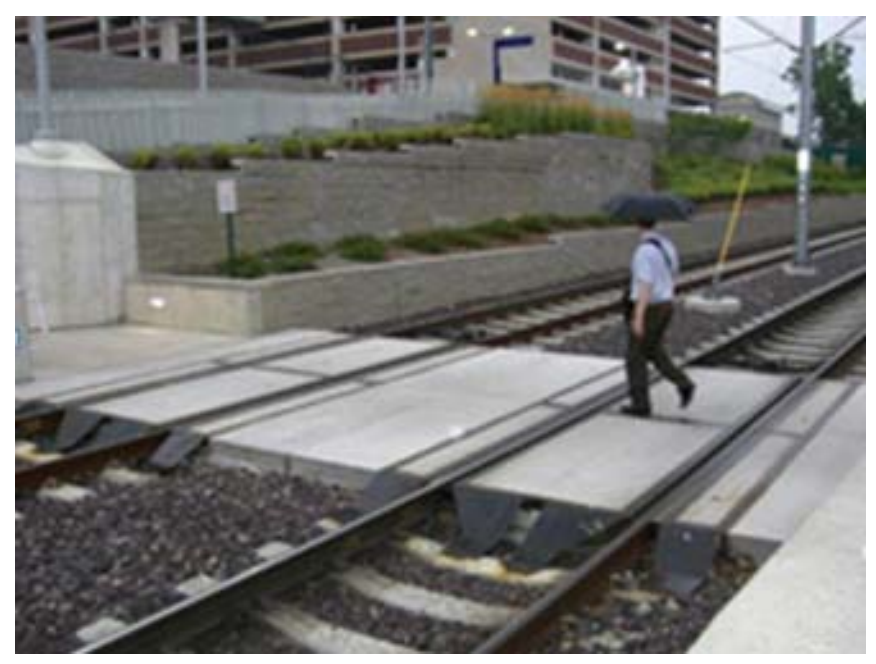

Figure 3-6: Precast Concrete Pedestrian Panels at Light Rail Station (Source: Century Group, 2012) 


\subsubsection{Precast Concrete Boardwalk}

Precast concrete boardwalk system comprises quality precast, modular concrete components that can be easily installed to form pedestrian walkways and boardwalks. With the concrete modules providing durability, strength, and flexible designs, this reinforced concrete component will resist splinters, rotting, warp lift, and other issues that are common with wood panels. The installation requires minimal construction disturbance and can be done by a moderately skilled worker. Figure 3-7 shows an example of the precast boardwalk being used on unstable ground. The boardwalk can be raised above the ground surface and can also be installed on irregular and unstable surfaces (PermaTrak, 2012).

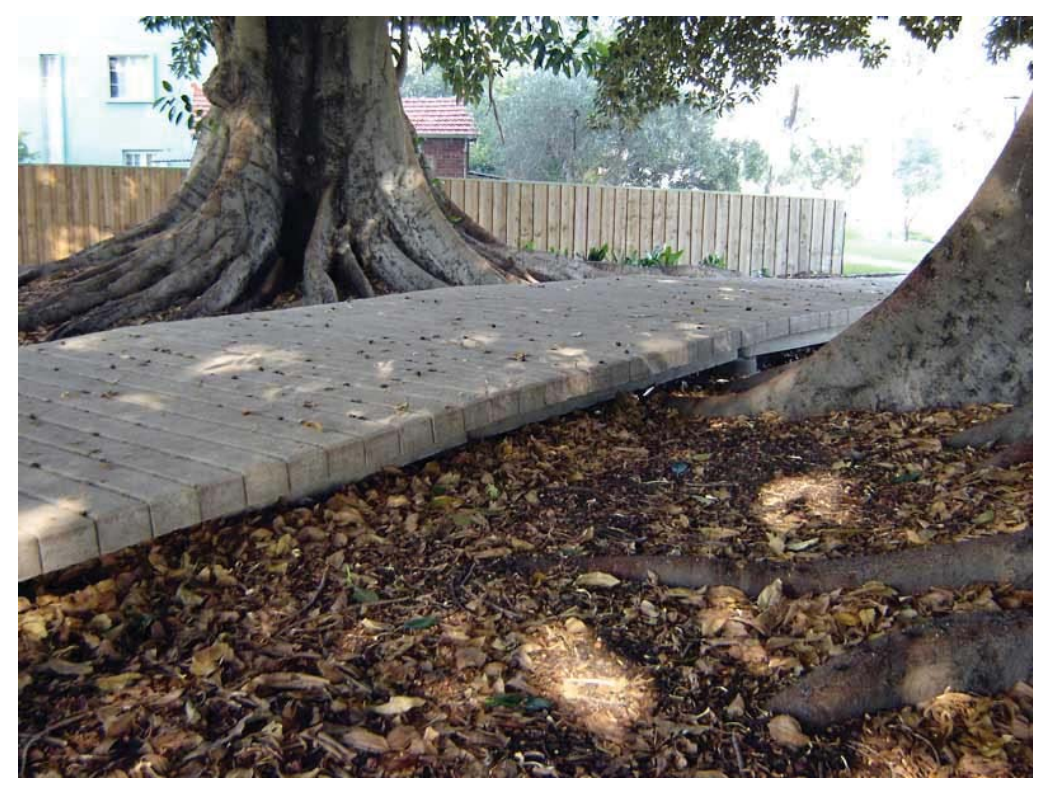

Figure 3-7: Precast Concrete Boardwalk (Source: PermaTrak, 2012)

\subsection{Metallic Materials}

Metallic materials such as steel and aluminum have been used in various products such as railings, poles, and beams. However, they are rarely used in constructing flat slabs because they are expensive and have a smooth surface which is not slip-resistant. Nevertheless, they could be used in flat slabs as a cover plate for manhole, as a temporary cover for trenches, and on special platforms. However, to construct B\&A pads, the metallic materials' surface has to be roughened.

Steel road plates, heavy duty aluminum roadway, and PortaPad are the three commercially available products made from metal that could potentially be used to construct B\&A pads. These products are discussed in the following sections.

\subsubsection{Steel Road Plates}

Steel road plates are manufactured in different sizes and have eye holes for safe lifting and controlled placement. They are designed to cross wider trenches and support heavy weights. Steel road plate thickness is typically $1^{\prime \prime}(2.5 \mathrm{~cm}), 1-1 / 4^{\prime \prime}(3.2 \mathrm{~cm})$, and 1-1/2" $(3.8 \mathrm{~cm})$, with 
varying widths (i.e., $4^{\prime}(1.2 \mathrm{~m}), 5^{\prime}(1.5 \mathrm{~m})$, and $6^{\prime}(1.8 \mathrm{~m})$ in width) and varying lengths (i.e., $8^{\prime}$ $(2.4 \mathrm{~m}), 10^{\prime}(3.0 \mathrm{~m})$, and $12^{\prime}(3.7 \mathrm{~m})$ in length). The plates can also be custom fabricated to the required specifications and the surface finish can be coated with a slip-resistant finish. Figure 3-8 shows the bolting of the steel plate and the texture of the plate shows the ADA-compliant antislip surface (SlipNOT, 2012a).

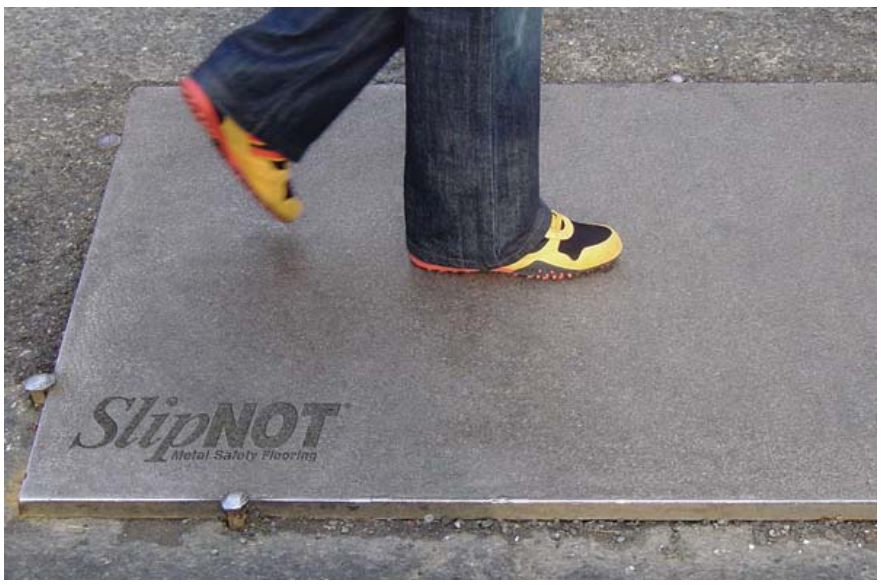

Figure 3-8: Steel Road Plate (Source: SlipNOT, 2012a)

\subsubsection{Heavy Duty Aluminum Roadway}

Perfect for a truck and crane entrance across soft earth, the heavy duty aluminum roadway is installed on pathways to allow fast and safe entrance over wet or damaged ground. The panels are generally $9.8^{\prime}(3 \mathrm{~m})$ in width and $8.2^{\prime}(2.5 \mathrm{~m})$ in length, and have been tested to hold loads of over 100 kilo Newton. The heavy duty aluminum allows the panel to gradually bend and even out the peaks and troughs typical with unstable terrain. These panels are useful for, but not limited to, vehicle access, stage pads, and cranes. Figure 3-9 shows the assembly of the aluminum panels across a dirt path. The panels are hooked on the four corners and mobilized with a small crane (TRAC, 2012b).

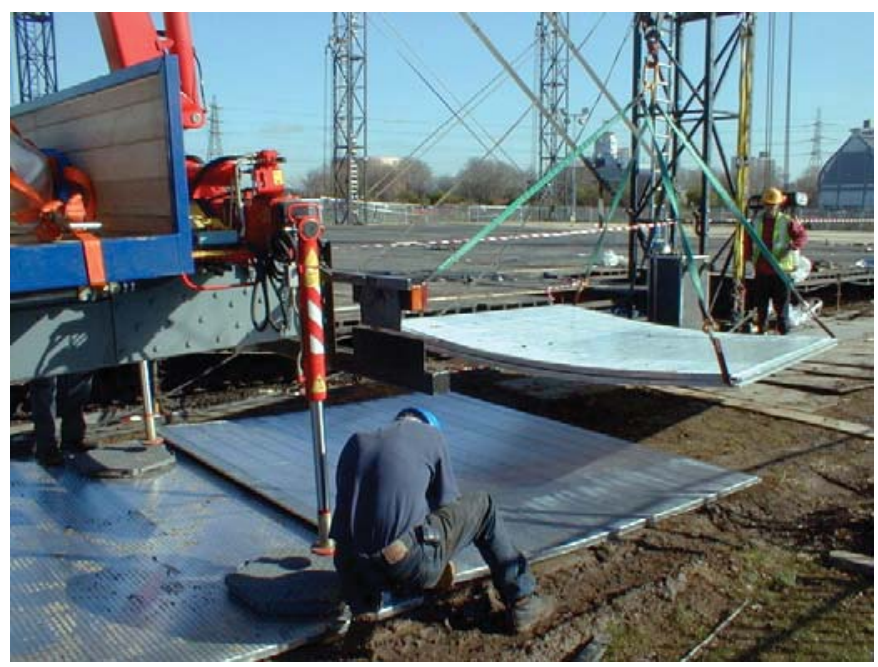

Figure 3-9: Heavy Duty Aluminum Road (Source: TRAC, 2012b) 


\subsubsection{PortaPad}

The PortaPad system is a strong, safe, and reusable helicopter landing platform which has an aluminum deck and an incorporated non-slip surface that is dependable in all weather conditions. Further, the system could be installed on both stable and unstable surfaces; the system uses metal stands and connecters to stabilize and level the pad on unstable areas. Its quick assembly and sturdy frame makes it a feasible option for ADA-compliant movable B\&A pads. The platform is usually $20^{\prime} \times 30^{\prime}(6.1 \mathrm{~m} \times 9.2 \mathrm{~m})$ and will support static loads of 18,000 lb. With an assembly time of about 2 hours, the platform can be relocated and reused when necessary. The materials used for this platform are aluminum on the structural members, beams, channels, legs, and braces, and stainless steel on the fasteners. Further, all its parts are made from either noncorrosive alloy or stainless steel, and it has low maintenance (Heliports Equipment, 2012). Figure 3-10 shows a PortaPad system that is already assembled.

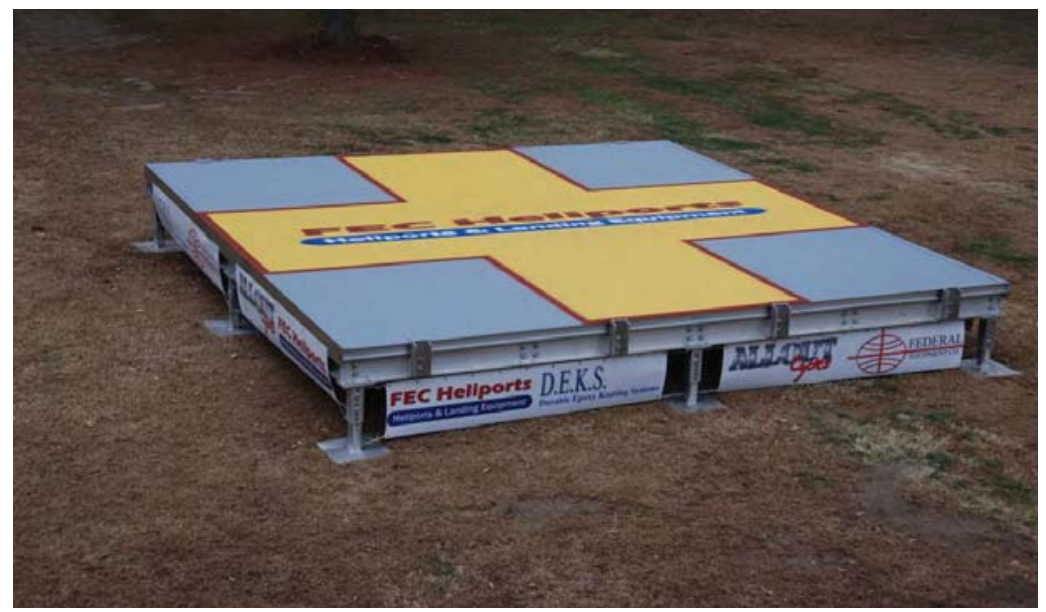

Figure 3-10: PortaPad (Source: Heliports Equipment, 2012)

\subsection{Rubber Materials}

Rubber has been used in the construction industry for many years and it is often used with concrete/asphalt products to lower the cost. It is also used for speed bumps as well as for providing traction on various smooth surfaces. One clear advantage of rubber products is their weight and price. There are many products that have the potential to be used for B\&A pads as shown below.

\subsubsection{Full-Depth Heavy-Duty Rubber}

The full-depth heavy-duty rubber is a low maintenance, low cost, reusable, and durable system. It has the ability to withstand all types of conditions. Additionally, the system panels can be relocated and reused, making it a good alternative design material for B\&A pads at bus stops (OMNI Grade Crossing, 2012c). Figure 3-11 shows the full-depth heavy-duty rubber system installed on a highway to cross train tracks. 


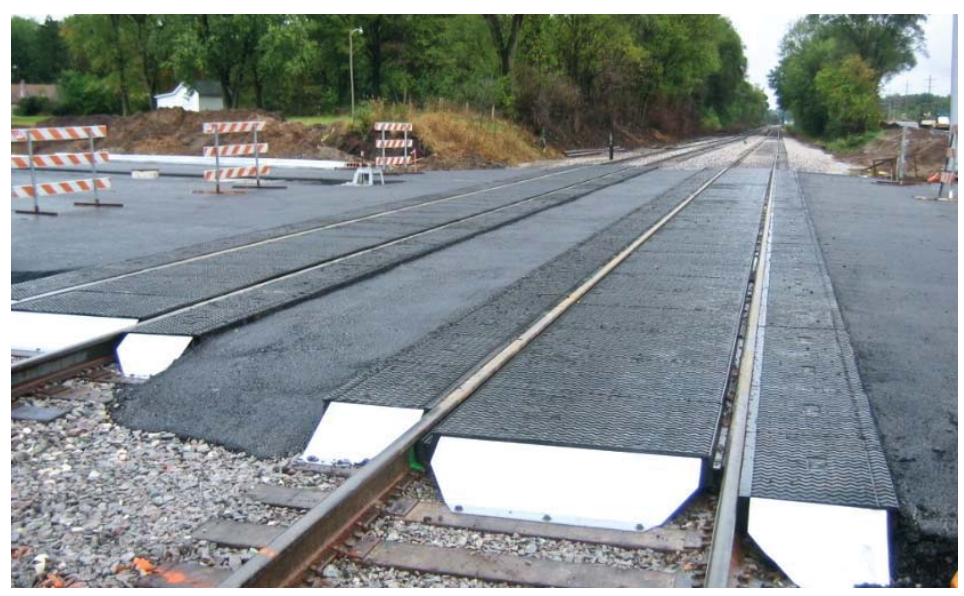

Figure 3-11: Full-Depth Heavy-Duty Rubber System (Source: OMNI Grade Crossing, 2012c)

\subsubsection{Rubber Pedestrian Crosswalk}

Rubber crosswalks are made of vacuumized rubber parts that connect with "I" connector screw caps. Figure 3-12 shows different modules of the rubber pedestrian crosswalk. It has a nonslippery upper surface due to the raised studs, and the different modules can be connected to fit streets of any size (Eastsea Rubber, 2012).
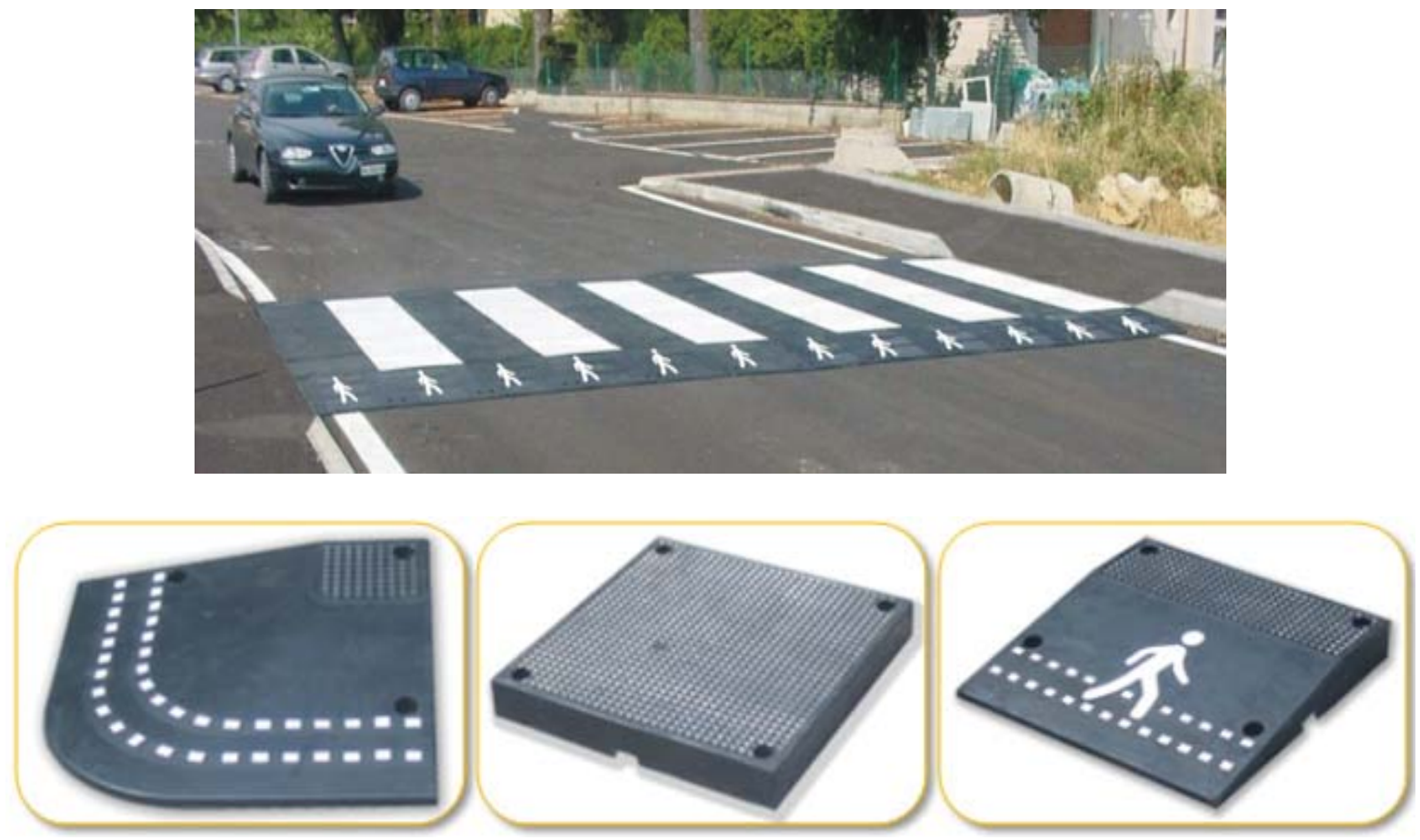

Figure 3-12: Rubber Pedestrian Crosswalk (Source: Eastsea Rubber, 2012) 


\subsubsection{Flexi-Pave}

Flexi-Pave is a rubber granule material that is bounded with a urethane agent to make a flexible, porous, non-cracking, and slip-resistant surface. This material can be installed on wood, steel, aluminum, concrete, asphalt, roofing felt, and compacted aggregate. Flexi-Pave's rubber base makes the surface slip-resistant and the elasticity of the rubber makes it crack resistant. Further, the porous material dissipates water quickly and efficiently. It is also capable of handling freezing conditions because of the specific capabilities of the urethane (elasticity) and rubber (compression) components. Flexi-Pave is resistant to chlorine, ozone, bromine, muriatic acid, salt water, oil, transmission fluid, and hydraulic fluid. As Flexi-Pave absorbs impact well and does not damage quickly, it reduces the maintenance cost. Flexi-Pave has been extensively used in several facilities including bicycle paths, driveways, golf cart paths, handicap ramps, parking lots, sidewalks, and sound barriers (KBI, 2012). Figure 3-13 shows the installation of Flexi-Pave.

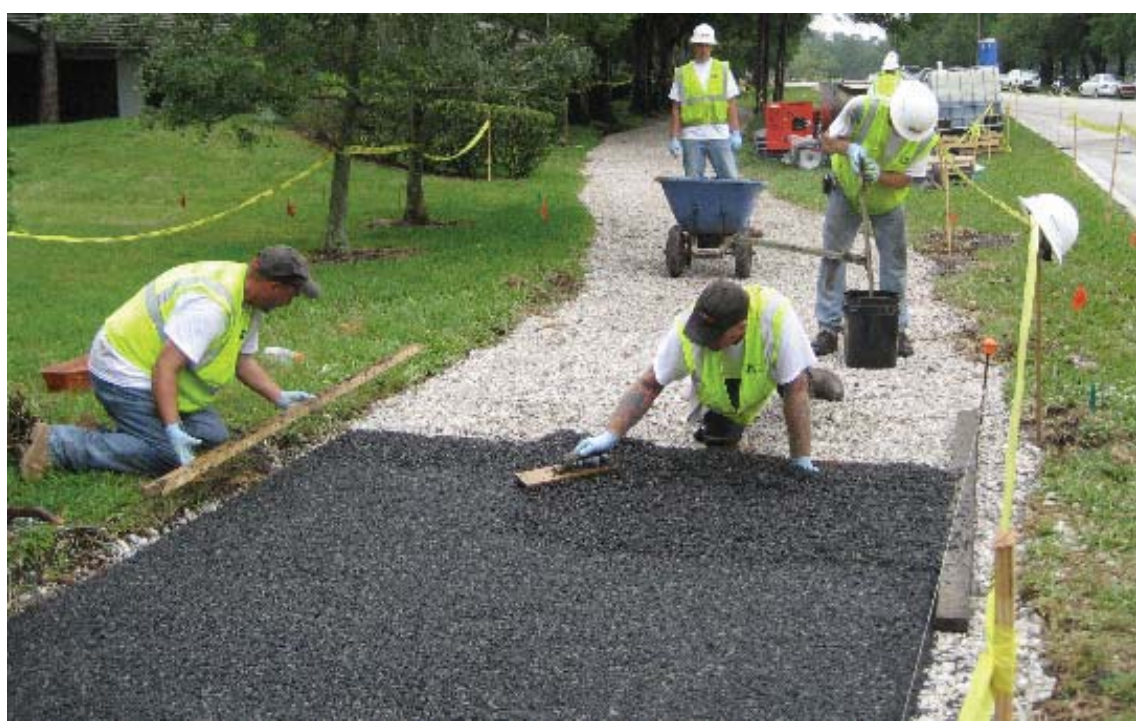

Figure 3-13: Flexi-Pave (Source: Landscape Pavers, 2012)

\subsection{Thermoplastic Materials}

Thermoplastic materials are typically used as cladding and non-structural components in construction. However, it has made ground in the railroad industry particularly with rail road tiles; the existing timber tiles have been replaced with plastic lumber. Plastic lumber is also used to replace timber boardwalk and sea wall. Some commercially available products of thermoplastic materials are discussed below.

\subsubsection{PortaPath}

PortaPath is a flat, light weight, plastic flooring system with an anti-slip surface and automatic water drainage system. Mostly used in the United Kingdom for sporting events, this system can be used for pedestrian walkways, pitch covering, and marquee flooring. The material is a high impact polypropylene that is non-permeable, $100 \%$ recyclable, and ultraviolet (UV) protected. The $12.2^{\prime \prime} \times 3.4^{\prime \prime} \times 0.6^{\prime \prime}(31 \mathrm{~cm} \times 8.6 \mathrm{~cm} \times 1.5 \mathrm{~cm})$ tiles weigh 11 ounces per square foot. The 
plastic material can withstand a vehicle of up to 4,410 lb on a firm surface (TRAC, 2012a). Figure 3-14 shows the detailed configuration of the PortaPath system and its locking mechanism. The module is locked together by locking tabs and secured with a flat head screw driver for complete installation.
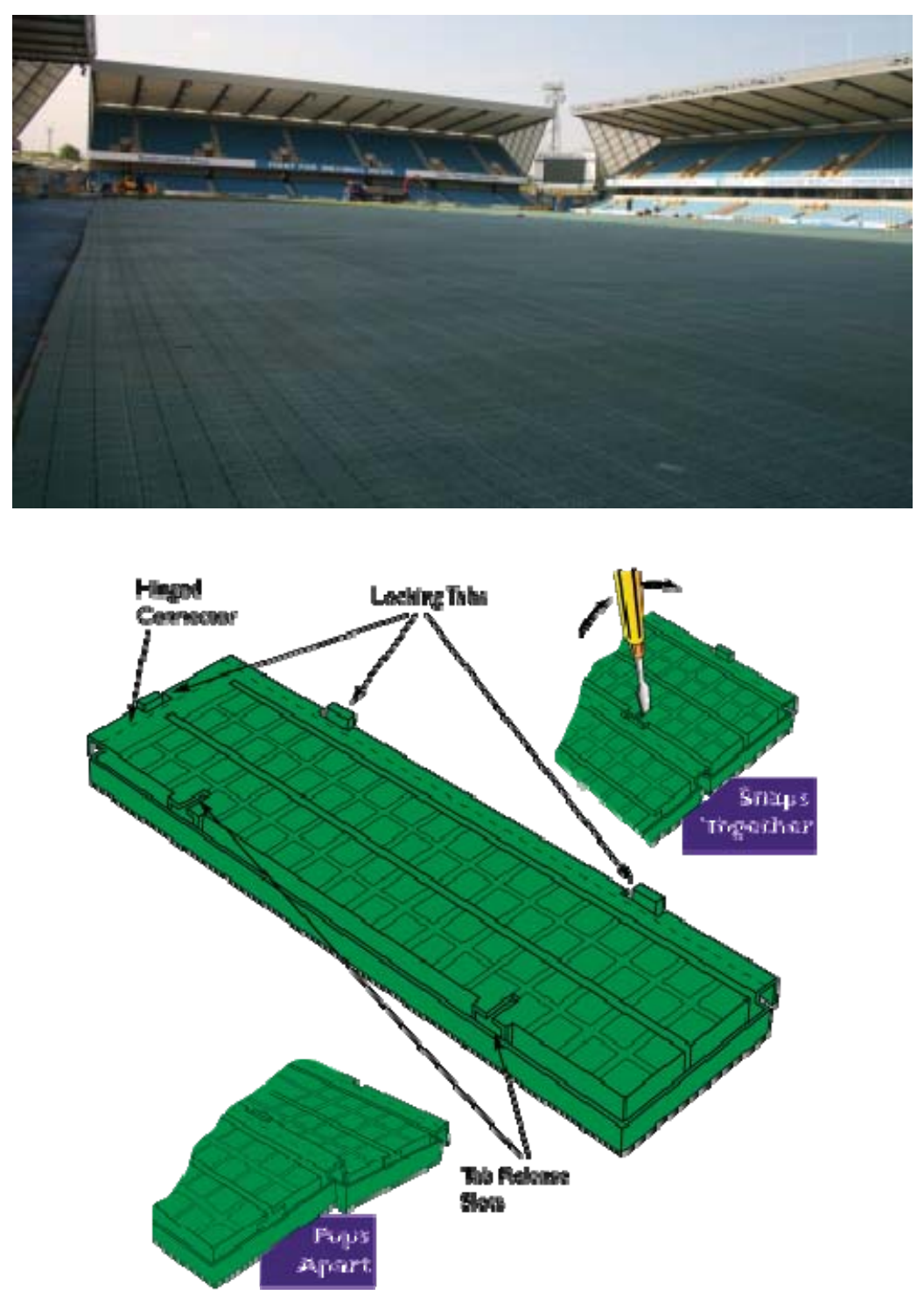

Figure 3-14: PortaPath (Source: TRAC, 2012a)

\subsubsection{ArmorDeck}

ArmorDeck is a high density polyethylene panel that covers a surface area of $45^{\prime \prime} \times 45^{\prime \prime} \times 2^{\prime \prime}(1.1$ $\mathrm{m} \times 1.1 \mathrm{~m} \times 5 \mathrm{~cm}$ ) and weighs $12 \mathrm{lb}$. The edging has sloped transitional pieces with traction and each piece locks together with a cam lock. The understructure of the ArmorDeck consists of a ribbing system that gives the module plenty of strength while still maintaining a minimum surface area contact. Figure 3-15 shows the panels that overlap one another when connected. The module incorporates a containment waterway under the connection area which will detain water 
that seeps from the top surface. ArmorDeck is ideal for unpaved and rough turf. It can be used in dirt, sand, gravel, asphalt, and other types of turf (EventDeck, 2012a).
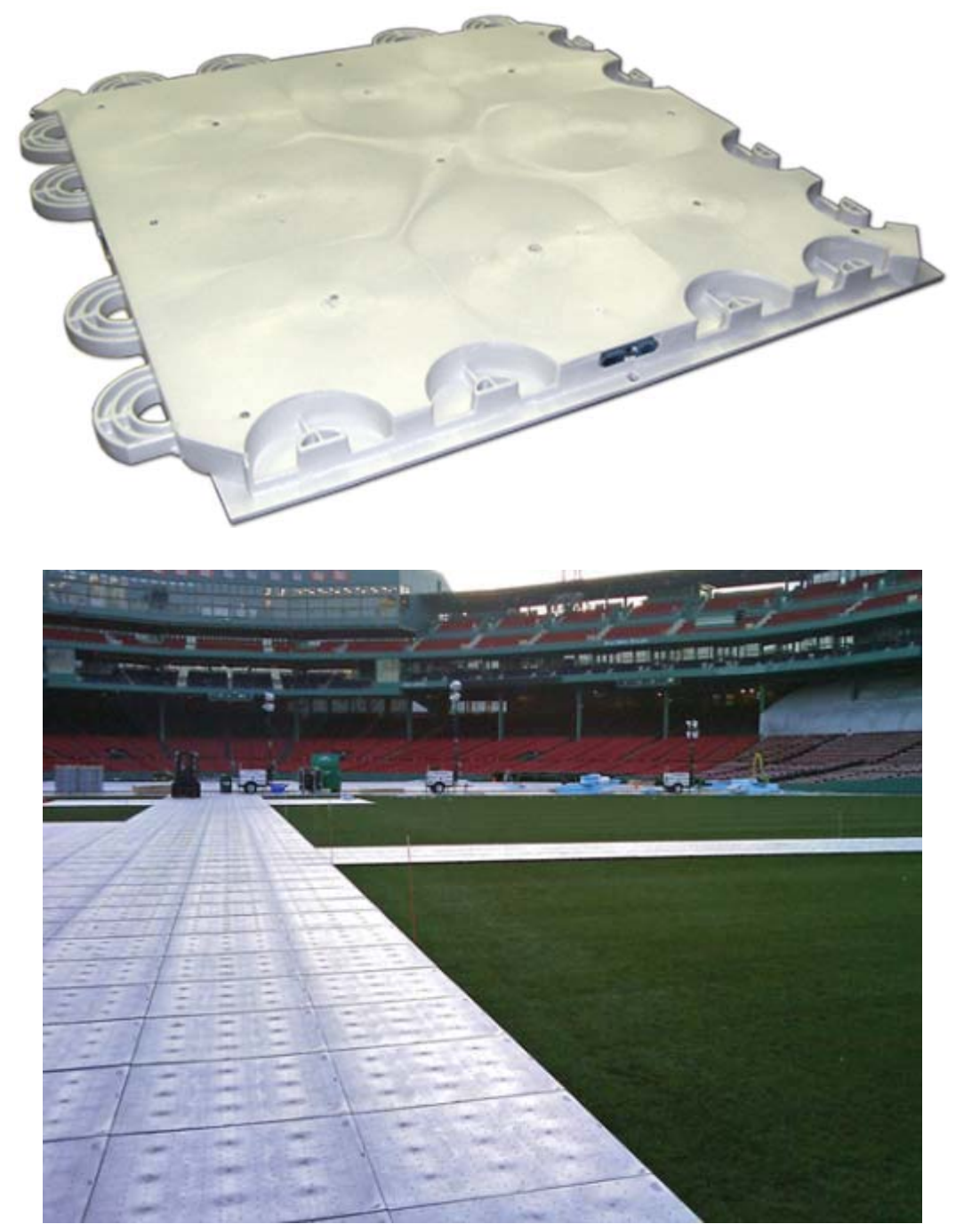

Figure 3-15: ArmorDeck (Source: EventDeck, 2012a)

\subsubsection{HexaDeck}

HexaDeck portable flooring tile is a high density polyethylene with added UV inhibitors. Its unique interlocking system, which requires no tools or machines, makes it easy to install. The tiles simply slide in next to one another using a channel overlay/underlay system, as shown in Figure 3-16. These tiles can handle heavy loads such as forklifts, trucks, cranes, and other utility vehicles. The design allows for the load to be distributed evenly by incorporating multidirectional, concentric, and structural ribbing of over $1 / 8^{\prime \prime}(0.3 \mathrm{~cm})$, as shown in Figure 3 16. The tiles are 3 square feet in hexagonal configuration and 1.9" $(4.8 \mathrm{~cm})$ high, weighing $6 \mathrm{lb}$. Figure 3-17 shows that the module can be used on multiple surfaces such as grass and dirt paths (EventDeck, 2012b). 


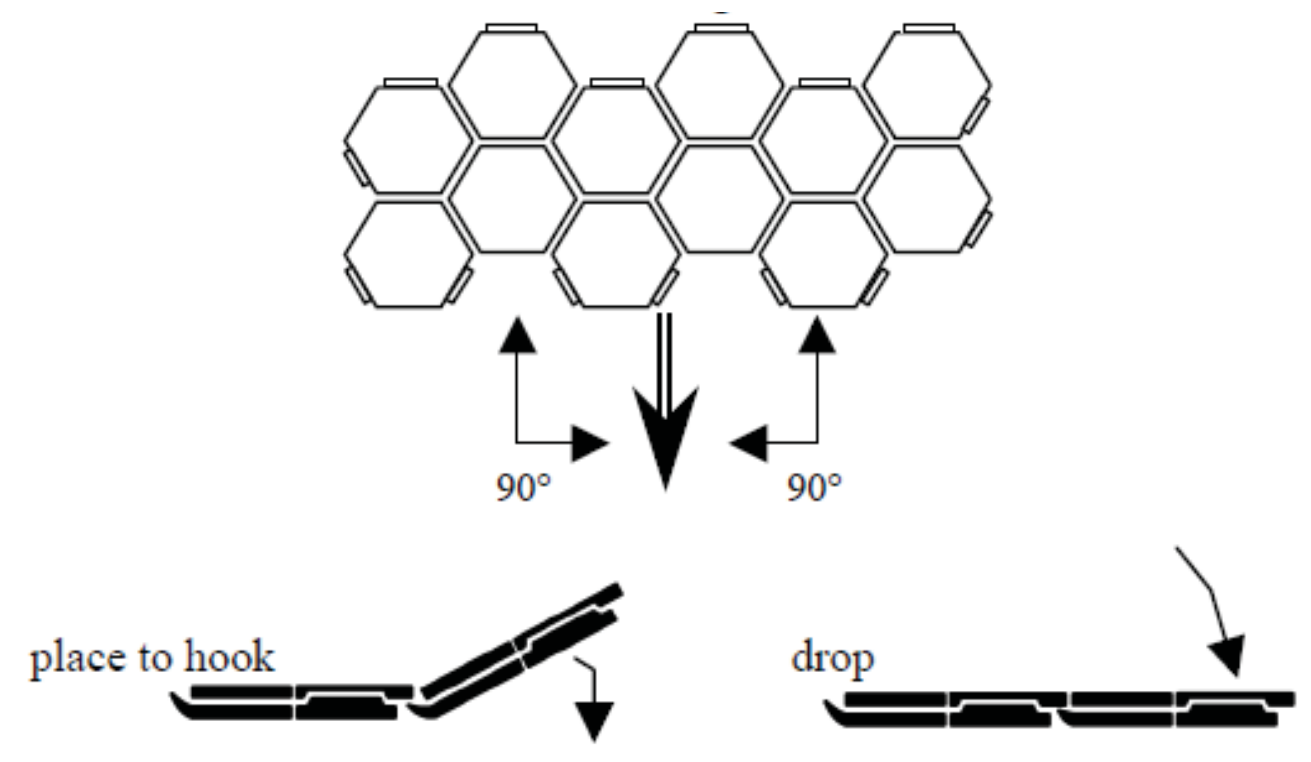

Figure 3-16: HexaDeck Locking System (Source: EventDeck, 2012b)

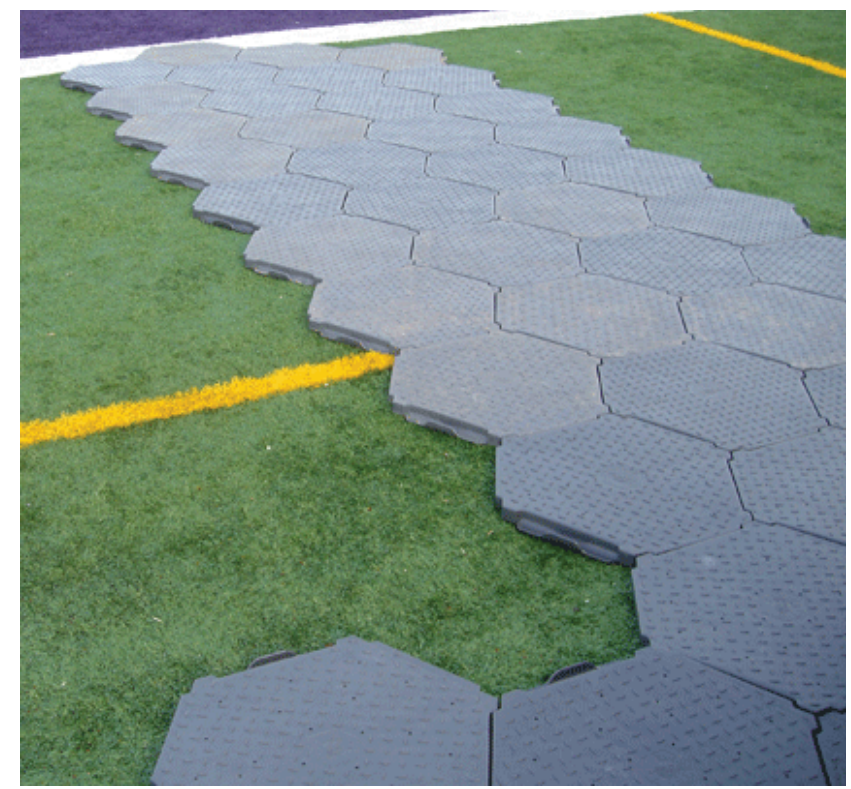

Figure 3-17: HexaDeck (Source: EventDeck, 2012b)

\subsubsection{Plastic Lumber Walkway}

Plastic lumber walkways give a natural look to the area and are relatively maintenance free. The planks that are used as the support beams are made up of plastic lumber, and therefore, do not rot, crack, or splinter like wood. The screws and bolts are stainless steel which makes the structure durable and strong. The planks have a rough texture which makes the walkway slipand algae-resistant. The planks are $5.5^{\prime \prime} \times 1.5^{\prime \prime}(14 \mathrm{~cm} \times 3.8 \mathrm{~cm})$, and can be developed in a variety of lengths. These decks can be used for walkways, boardwalks, bridges, etc. (Murray's 
Recycled Plastic, 2012). Figure 3-18 shows plastic lumber being used as a bridge over water and unstable ground.

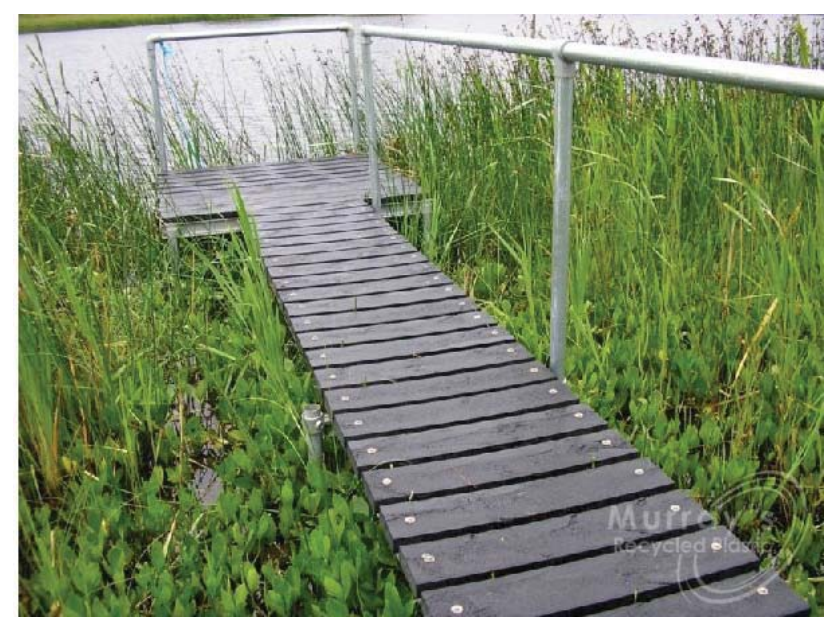

Figure 3-18: Plastic Lumber (Source: Murray's Recycled Plastic, 2012)

\subsubsection{SupaTrac}

SupaTrac is a plastic product for all types of access passageways such as light vehicle entry and pedestrian pathways. Every panel is 3 tiles wide by 4 tiles long. The panel has 1,000 aeration openings per square meter and is installed 1.6" $(4 \mathrm{~cm})$ above the ground, which give the ground underneath the ability to get light, air, and water. As shown in Figure 3-19, the plastic product is mostly used for car parking pads and as walkways for pedestrians. SupaTrac is installed without specialist equipment and has built-in access ramps to allow safe and easy entry for wheelchairs (TRAC, 2012c).

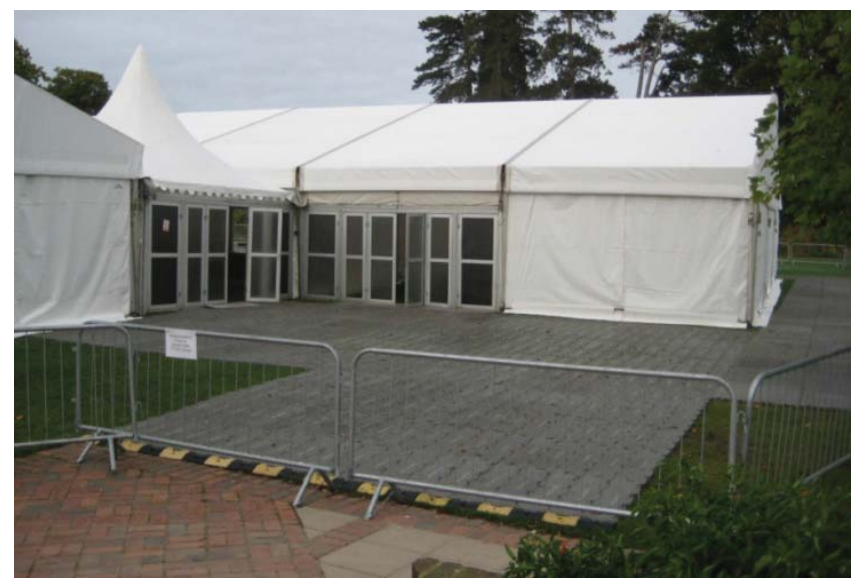

Figure 3-19: SupaTrac (Source: TRAC, 2012c)

\subsubsection{Plastic Grates}

Plastic grates are made up of polymer panels that are porous and allow water, debris, and sunlight through the grates. The ventilated panels do not disrupt the vegetation on the ground. 
These grates are made up of virgin plastic and are reinforced with fiberglass. The panels are offered in multiple sizes ranging from 36" $(0.9 \mathrm{~m})$ to $60^{\prime \prime}(1.5 \mathrm{~m})$ in length, $12^{\prime \prime}(30.5 \mathrm{~cm})$ in standard width, and 1.25" $(3.2 \mathrm{~cm})$ in thickness. The grates are screwed together by pan head stainless steel screws (PlasTEAK, 2012). Figure 3-20 shows an example of plastic grates. From the figure, it can be seen that the surface of the grates has a knurled finish, which is slip-resistant. Figure 3-20 also shows that plastic grates can be installed in different kinds of environments.

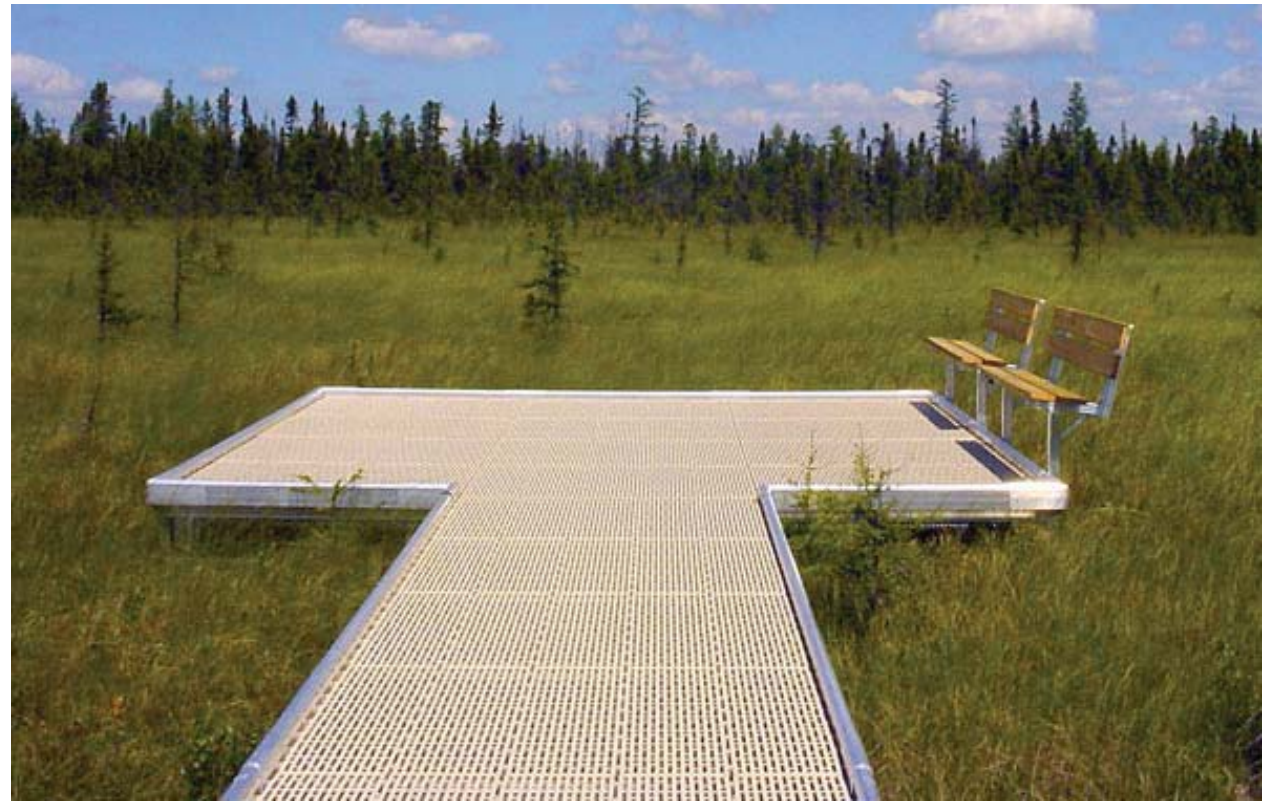

Figure 3-20: Plastic Grates (Source: PlasTEAK, 2012)

\subsection{Composite Materials}

Composite materials such as carbon fiber reinforced polymer have been used for many years by FDOT for repairing bridges. These materials have very good durability but are very expensive. However, there is at least one product, Mobi-Mat, that has the potential to be used for constructing B\&A pads and is discussed below.

\subsubsection{Mobi-Mat}

The Mobi-Mat helipad has the characteristics suitable for a B\&A pad. It is movable, has low level assembly, and is reusable, and therefore, could be a good alternative to the existing B\&A pads. The Mobi-Mat is a light weight, easy to handle, matting system that can sustain helicopter loads. This mat is a fiberglass $6^{\prime} \times 6^{\prime} \times 3 / 8^{\prime \prime}(1.8 \mathrm{~m} \times 1.8 \mathrm{~m} \times 0.95 \mathrm{~cm})$ panel weighing $115 \mathrm{lb}$. The mat can be easily transported by two people and is used to haul large equipment over soft surface. Figure 3-21 shows the Mobi-Mat system being installed in a beach area. As shown in the figure, the mats are stacked for easy assembly and can be used on unstable ground, such as sand (DESCHAMPS, 2012). 

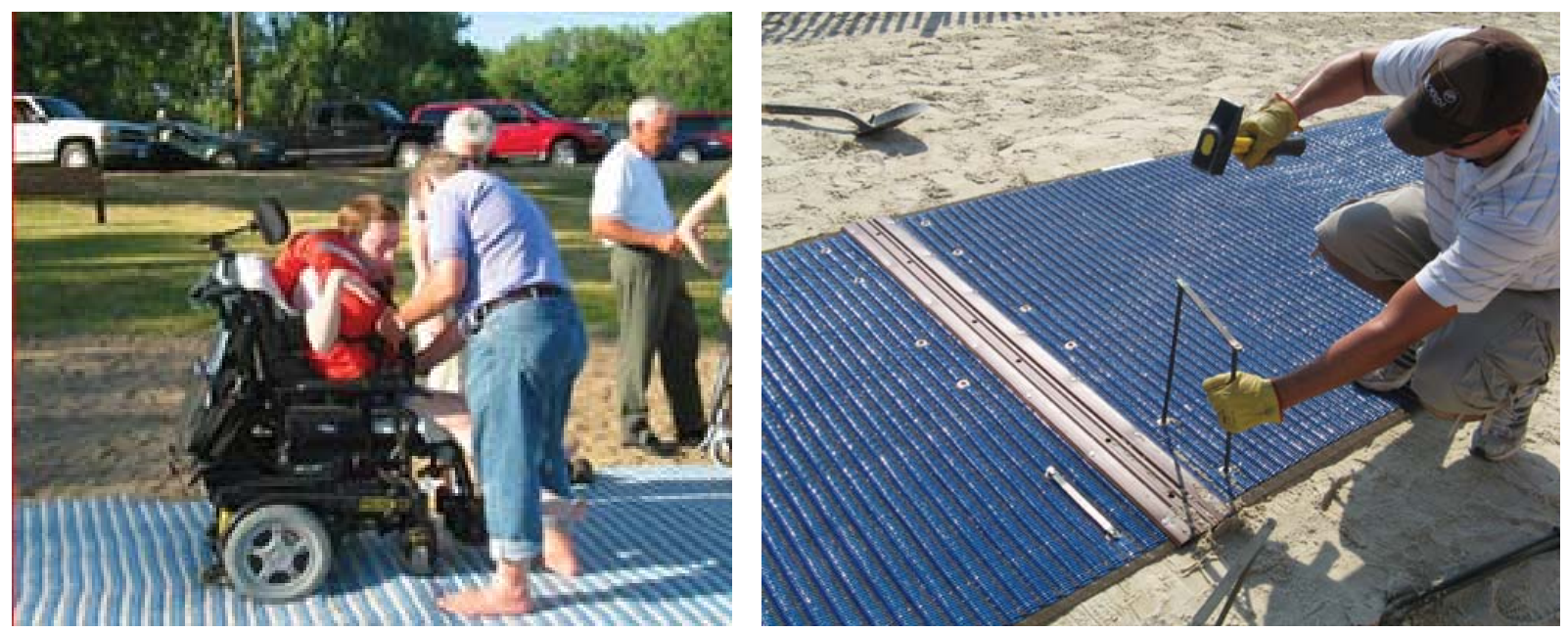

Figure 3-21: Mobi-Mat (Source: UAC Group, 2012 and DNREC, 2012)

\subsection{Wood}

\subsubsection{Roll-out Walkways}

Roll-out walkways are made up of different types of wood such as pressure treated southern pine, cypress, teak, and Trex, a wood and plastic composite. The height of the walkways is dependent on the material used. The panels are connected by a spacer that allows the entire piece of deck to flex. Because these walkways can be custom made, they have the ability to curve at 45 and 90 degrees, as shown in Figure 3-22. Nylon cords or stainless steel rods which pass through the panels make screws and nails unnecessary for assembling this product. As shown in Figure 322 , the walkway has a unique and easy assembly, and can also be used on unstable ground (Mister Boardwalk, 2012).
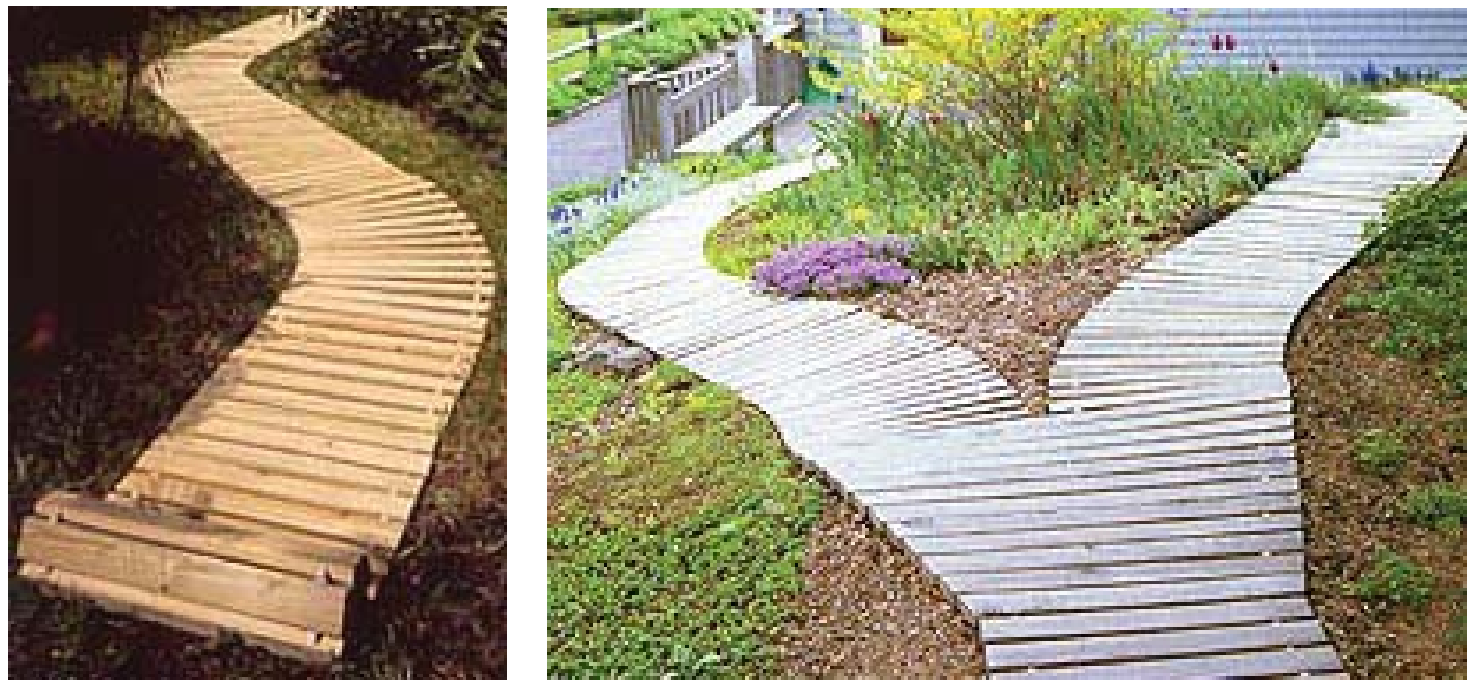

Figure 3-22: Roll-out Walkway (Source: Mister Boardwalk, 2012) 


\subsection{Summary}

This chapter reviewed the existing and alternative design materials for potential use in constructing B\&A pads at bus stops. Currently most transit agencies are using either concrete or asphalt pads as they are readily available. Even though they are commonly used, their implementation can be costly and time consuming and most importantly, they cannot be relocated and reused. Therefore, alternative design materials that have characteristics suitable for ADA-compliant B\&A pads were reviewed. These alternative materials were found to have several advantages, such as low installation and maintenance costs, high durability, and reusability. Further, several of these materials could be installed on unstable surfaces. 


\section{CHAPTER 4 \\ EVALUATION OF POTENTIAL DESIGN MATERIALS}

This chapter focuses on evaluating the six categories of materials (i.e., concrete/asphalt, metal, rubber, thermoplastic, composite, and wood), and their commercially available products discussed in Chapter 3 for their potential use as movable B\&A pads. The evaluation was based on authors' subjectivity. The following sections evaluate the six categories of materials based on the following six criteria:

1. Structural performance

2. Long-term durability

3. Adaptability

4. Life cycle cost

5. Aesthetics

6. Safety and accessibility of transit riders with mobility devices

Structural performance is based on the mechanical properties of the material used to construct the B\&A pads. It dictates whether a small cross-sectional area of the material can be used and/or if the compaction of subgrade is needed, which will ultimately impact the cost and the ease of installation. Long-term durability is based on the material's resistance to physical and chemical degradation. Since the ADA-compliant B\&A pads considered in this research have to be movable, reusable, and relocatable, the materials used for manufacturing these B\&A pads have to last for many years.

Adaptability is one of the most important criteria because, as shown in Figure 4-1, the site profiles vary greatly from bus stop to bus stop. The pads should provide the flexibility to adapt to the variations in site characteristics, such as thickness of subgrade and subgrade conditions. Cost determines the product's feasibility compared to both the existing concrete or asphalt slabs and the other available alternative products. Aesthetics also play an important role; if the proposed B\&A pads do not blend well with the surrounding environment, their acceptance by the local jurisdictions would be difficult. Finally, safety and accessibility of transit riders with mobility devices while using these B\&A pads is clearly an important factor to consider. 


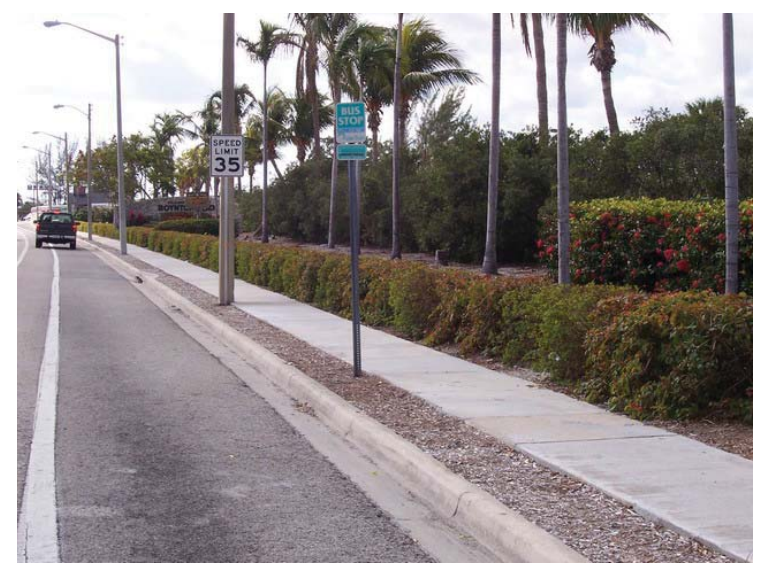

(a) Narrow, hard/steady base

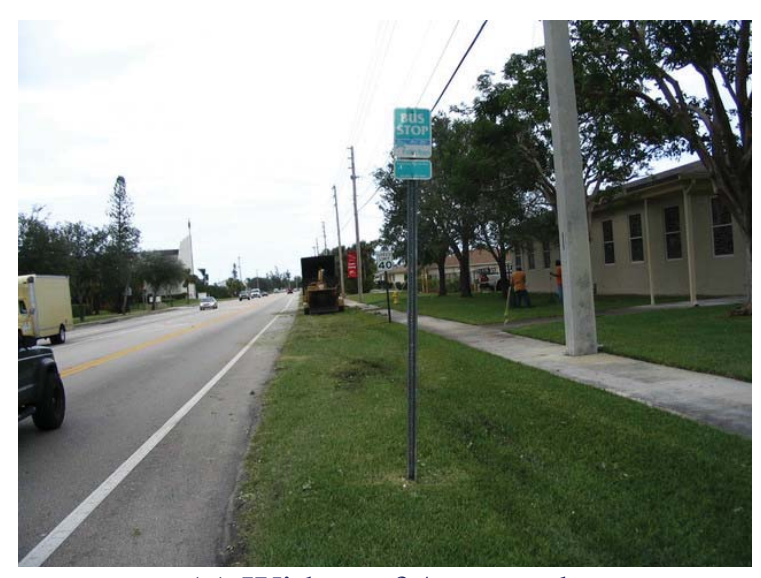

(c) Wide, soft/uneven base

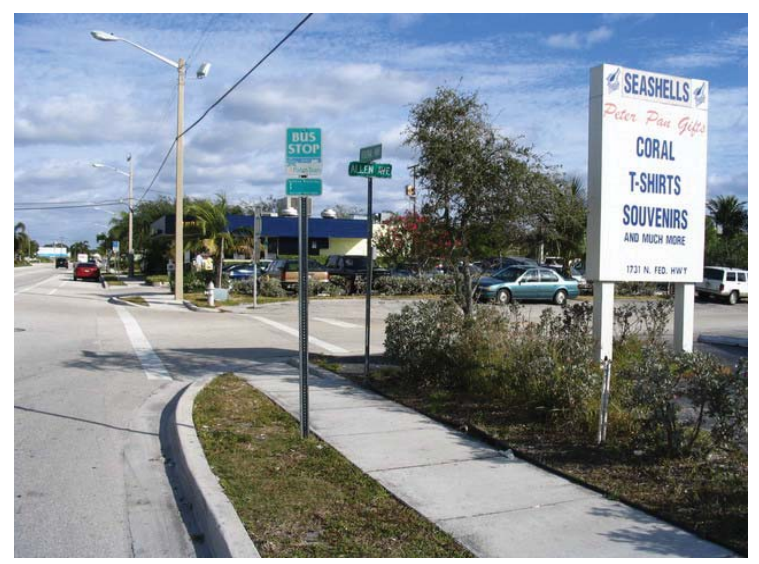

(e) Varying width

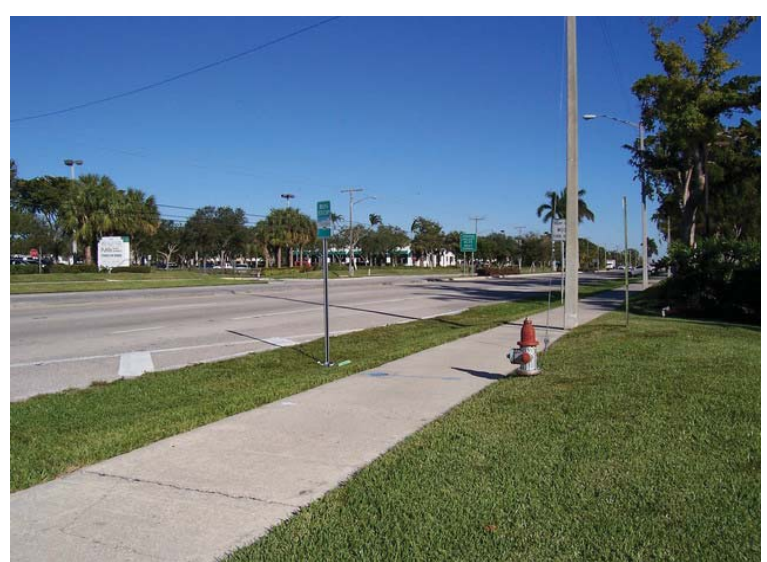

(b) Wide, soft base

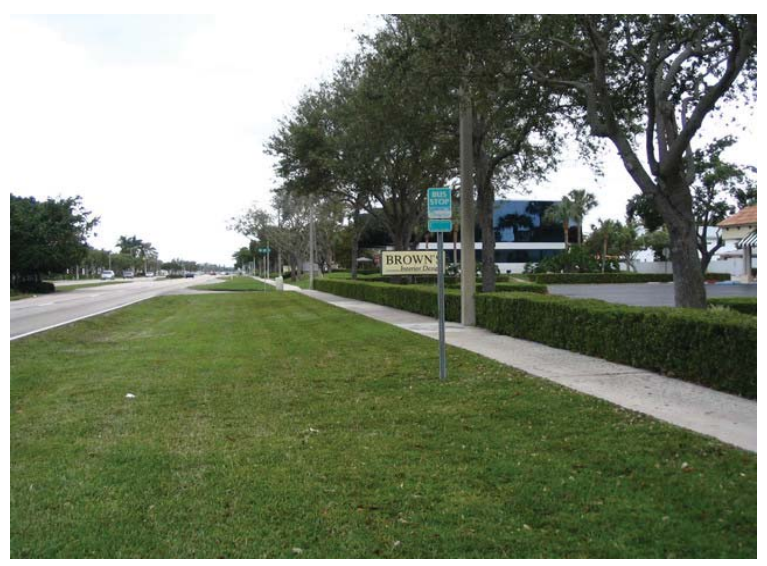

(d) Very wide, soft/uneven base

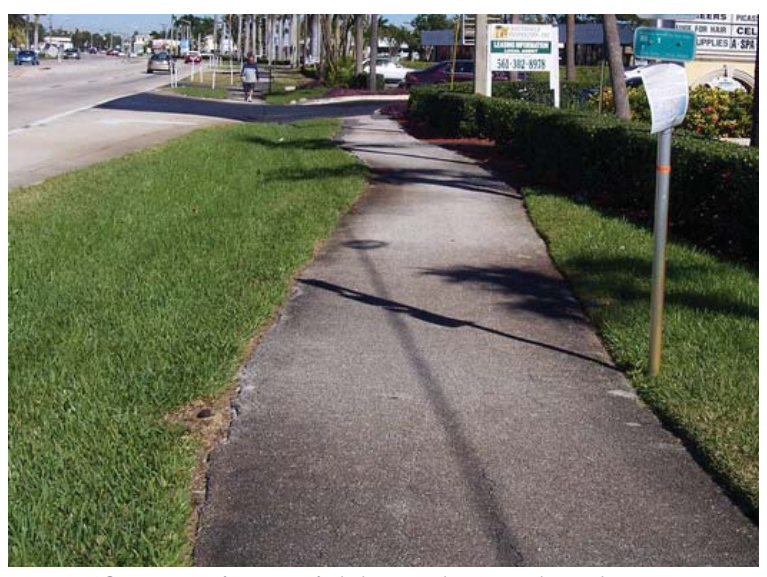

(f) Varying width and rough edges

Figure 4-1: Different Site Conditions

\subsection{Concrete/Asphalt}

As discussed in Chapter 3, six commercially available products that were manufactured using concrete/asphalt materials have the potential to be used in constructing B\&A pads. These 
products consist of traditional cast-in-place concrete/asphalt construction, prefabricated/precast concrete (i.e., ECR, TraCast, precast panels and boardwalk), and concrete pavers, and are evaluated in the following sections.

\subsubsection{Structural Performance}

Overall, both concrete and asphalt materials provide a stable, durable, and skid-resistant pavement at a nominal cost. In fact, they are the preferred materials for the existing B\&A pads. However, it should be noted that there are clear distinctions between concrete and asphalt. One major difference between the two is that asphalt is significantly more flexible (i.e., has greater ability to deform without cracking) than concrete. Further, the stability of asphalt pavement is often controlled by the strength of the base and subbase courses which consist of gravel/stone and compacted soil, respectively. On the other hand, concrete pavement is much stiffer and does not rely on the strength of subgrade, and therefore only requires compacted granular base.

Another major distinction between concrete and asphalt is the fact that, unlike asphalt, concrete can be prefabricated or precast at a casting yard and later installed in the field. A precast concrete system can be further broken into the following three subsystems: (1) plain or lightly reinforced concrete, (2) reinforced concrete, and (3) prestressed concrete systems. Plain or lightly reinforced concrete systems require a compacted granular base similar to the current cast-inplace concrete slab typically used in Florida. As both reinforced and prestressed concrete systems are designed to resist flexural bending, the use of a compacted granular base is eliminated. The prestressed concrete system provides greater flexural strength than the reinforced concrete system, even though it has a slightly higher cost. This allows the B\&A pads to have a smaller cross-sectional profile and requires only minor modifications to the site.

Concrete pavers have been used for driveways and sidewalks for many years in Florida. They are very robust systems; however, they have two drawbacks: (1) greater construction time and (2) the need for compacted subgrade. Unlike other products, concrete pavers typically come in small sizes and have to be laid individually to assemble the B\&A pads. The subgrade needs to be leveled and well compacted to ensure no settlement which could potentially lead the concrete paver to crack, or in some cases, to slide down. Weeds can grow in the gaps in concrete pavers generating the need for more frequent maintenance. Concrete pavers are not recommended for movable B\&A pads as their installation, removal, and relocation would not be economical. Nevertheless, concrete pavers are suitable when the gap between the sidewalk and street curb is less than 1' (30.5 cm), as illustrated in Figure 4-1 (a).

In summary, the structural performance rating for concrete/asphalt materials ranges widely depending on the structural system. For the conventional concrete pad, the structural performance is given a rating of 4 out of 5 because of its dependence on compacted subbase. Both asphalt pad and concrete paver are given a slightly lower rating of 3 out of 5 because of their reliance on both base and subbase courses. The precast concrete option has the best rating since it could self-sustain the foot traffic, and therefore is given a rating of 5 out of 5 for structural performance. 


\subsubsection{Long-Term Durability}

Both concrete and asphalt have good chemical resistance, and there are also many chemical admixtures and surface treatments that could be added to enhance their long-term durability. However, like all materials, if they are not properly constructed and maintained, they will eventually suffer from oxidation, cracking, scaling, and raveling. According to the Federal Highway Administration (2013), the normal design life of both concrete and asphalt pavement is between 20 and 25 years. There have also been many initiatives to extend the design life of pavement to over 40 years. However, it should be noted that the design life is based on the roadway surface with truck traffic while B\&A pads will only experience foot traffic.

Considering that there are no known problems with the existing B\&A pads and sidewalks that are constructed with concrete and asphalt, it is anticipated that both will perform well in terms of long-term durability. Based on this assumption, the long-term durability of concrete and asphalt materials is given a rating of 5 out of 5 .

\subsubsection{Adaptability}

The cast-in-place concrete and asphalt pads are very adaptable since they are formed and cast into place. However, the cast-in-place designs are not movable. In other words, they can only be constructed at one specific location and it is almost impossible to remove cast-in-place pad without cracking it. For this reason, cast-in-place pads do not serve well as movable and reusable B\&A pads. Compared to cast-in-place pads, precast concrete has a greater potential to be movable and reusable; however, it is slightly less adaptable, particularly if it is mass produced.

Even though the precast concrete can be molded into various shapes and sizes, they need to be optimized so that the precast concrete section can fit into a variety of prevailing site conditions. Furthermore, the placement of steel reinforcement in the precast concrete also minimizes the need for compacted subgrade, which could also eliminate the cost for MOT. However, precast concrete section might not be a preferred alternative for movable B\&A pads due to its weight. Compared to precast concrete, concrete pavers are light-weight; however, they are labor intensive. Also, as discussed earlier, vegetation growth would also be a recurring maintenance problem for concrete pavers. In summary, in terms of adaptability, concrete and asphalt pads, precast concrete, and concrete pavers are given a rating of 1,2 , and 3 out of 5 , respectively.

\subsubsection{Life Cycle Cost}

The life cycle cost of B\&A pads depends on a variety of factors, including (1) initial construction cost, (2) size of pads, (3) relocation cost associated with route changes, and (4) maintenance cost. For concrete and asphalt pads, the majority of the cost would be the initial construction cost. According to the survey provided in Chapter 2, concrete B\&A pads cost on average approximately $\$ 7,000$ per bus stop ( $\$ 3,920$ for sidewalk replacement, $\$ 1,250$ for handicap ramp installation, $\$ 1,230$ for labor, and $\$ 600$ for MOT). The size of the pads would also play a significant role since it could affect the sidewalk replacement cost. Considering that there is a very little maintenance record of existing B\&A pads and concrete/asphalt sidewalks, it could be safely assumed that their maintenance cost is negligible. 
The relocation costs associated with route changes is more complicated; as indicated in Chapter 2 , a majority of the responding agencies only change routes as needed. However, $38 \%$ of the surveyed agencies did say that they change routes at least once a year. If the agencies do change routes, then the life cycle cost of concrete and asphalt pads would be extremely high since new B\&A pads have to be constructed at the new bus stops. Furthermore, the existing B\&A pads at the old bus stops will also need to be demolished. In such cases (i.e., when bus stops have to be relocated), precast concrete and concrete pavers would be better as they can be easily removed and installed at the new locations.

For these reasons, the rating for life cycle cost for concrete/asphalt materials range widely depending on the structural system and agency's needs. Based on the potential to relocate B\&A pads, the overall life cycle cost of conventional concrete/asphalt pads is given a rating of 1 out of 5 . The concrete pavers are rated 2 out of 5, and precast concrete sections are given a rating of 4 out of 5. More details on the life cycle cost of different materials are provided in Section 4.7.

\subsubsection{Aesthetics}

Aesthetically, concrete would blend well with the surrounding areas as most sidewalks and street curbs are constructed with concrete. Asphalt would also blend well if the existing sidewalks are constructed with asphalt. The precast concrete and concrete pavers can be color matched and should be aesthetically pleasing. Therefore, in term of aesthetics, concrete and asphalt materials are given a rating of $5 / 5$ ( 5 out of 5 ).

\subsubsection{Safety and Accessibility of Transit Riders with Mobility Devices}

Considering that a majority of existing sidewalks are made with concrete and/or asphalt, safety and accessibility of transit riders with mobility devices should not be of concern. The precast concrete may present some problems particularly at the joints. If the B\&A pads are designed as a large precast segment with the joints running parallel to the direction of travel, (e.g., ECR and TraCast), then this design should not present any problem for mobility devices. However, if smaller precast slabs are used where the joints run transversely (e.g., precast concrete boardwalk), then this may pose a problem should a pad be unevenly installed. Similar situation could also occur for concrete pavers but at a higher frequency. Due to these reasons, for the safety and accessibility of riders with mobility devices, the concrete and asphalt pads, precast concrete pads, and concrete pavers are given a rating of $5 / 5,4 / 5$, and $3 / 5$, respectively.

\subsection{Metal}

The metallic materials consist of mainly steel and aluminum plates and are designed to withstand heavy loads. The commercially available steel and aluminum road plates, in particular, are designed for heavy trucks and cranes, and the PortaPad system is designed for a helicopter.

\subsubsection{Structural Performance}

Metals are one of the best materials with regard to structural performance as they are the strongest and most durable construction materials, and are used in the construction of bridges, 
buildings, foundation, pipes, etc. Both steel and aluminum are stronger than concrete and asphalt by an order of magnitude. They also have significantly higher flexural strength that allows them to be used as beams. Therefore, unlike conventional concrete and asphalt pads, metals do not depend on the subgrade. For these reasons, metals are given a rating of 5 out of 5 for their structural performance.

\subsubsection{Long-Term Durability}

The long-term durability depends on the type of metal used. Aluminum has higher long-term durability in terms of corrosion resistance but is prone to scratches. On the other hand, steel is often plagued with corrosion problems, particularly when it is exposed to the outdoor environment. However, steel is much harder than aluminum and is scratch-resistant.

The corrosion problem of steel can be overcome by several methods such as alloying and coating; and of all the methods, galvanization is the most cost-effective method. According to American Galvanizer Association (2013), depending on the exposure, the thickness of zinc used to galvanize the steel can be altered to extend the service life of steel to 100 years. This process would of course add to the overall cost of the steel. Therefore, based on this discussion, the longterm durability for aluminum and steel are given a rating of $4 / 5$ and $3 / 5$, respectively.

\subsubsection{Adaptability}

Both steel and aluminum can be cut to the required sizes and do not have a problem adapting to the various site conditions identified earlier (see Figure 4-1). Because of their high stiffness, the metallic plates have shallower cross sections compared to concrete or asphalt pads. This results in a minimal need for preparing the site (e.g., soil excavation, the use of compact granular base, etc.). However, one of the biggest problems of metals is their weight. Most commercially available steel/aluminum road plates are at least 1 " in thickness and would be too heavy to move without using a crane. For example, a $1^{\prime \prime}(2.5 \mathrm{~cm})$ thick $5^{\prime} \times 8^{\prime}(1.5 \mathrm{~m} \times 2.4 \mathrm{~m})$ steel plate weighs approximately $1,600 \mathrm{lb}$. Aluminum plates would be lighter as aluminum is approximately 3 times lighter than steel; however, because of its lower stiffness (also approximately 3 times lower than steel), more material is needed, resulting in almost no difference in weight between steel and aluminum plates. Furthermore, aluminum is also approximately 3 times more expensive than steel making it not an economically viable option for the proposed movable pads.

For these reasons, the only option for metallic materials to be used as movable B\&A pads is to use the PortaPad system that is used as a helicopter landing pad. The PortaPad system consists of smaller metallic parts that are assembled together to form a larger landing pad. This system, however, is too expensive to be used as B\&A pads. Nevertheless, similar design concepts can be developed in the future, which will be discussed later in Chapter 5. Overall, the adaptability rating for the system with the current design would be 3 out of 5 .

\subsubsection{Life Cycle Cost}

The life cycle cost of metals depends heavily on the mobility of the B\&A pads. If the B\&A pads are to be permanently installed, then the metallic system can be considered as a viable alternative 
to the conventional concrete/asphalt pads. The material cost of steel and aluminum road plates is not very high considering that less material is needed compared to the conventional concrete/asphalt pads. However, if the B\&A pads have to be relocatable, the weight could potentially become a deciding factor. If the metal B\&A pads are too heavy to be hand carried, it may not be a viable option as the cost for lifting (using crane) would be quite expensive. As a result, the metallic materials are given a rating of 3 out of 5 for life cycle cost.

\subsubsection{Aesthetics}

Both galvanized steel and aluminum pads are in silver color and can closely match the color of existing concrete sidewalk. However, the shiny silver surface reflects sunlight onto the passenger waiting at the bus stops, often resulting in intense glare. Also, to create a non-slip surface, the steel plates have to be fabricated with certain textures, as illustrated in Figure 4-2. After fabrication, the texture and color do not blend well with the existing asphalt sidewalks. In such cases, the galvanized steel plates could be powder coated with pigment matching the color of the sidewalk. However, this process increases the cost and reduces the service life to 25 years since the powder coat has to be retouched. Therefore, in term of aesthetics, metals are given a rating of 3 out of 5 .
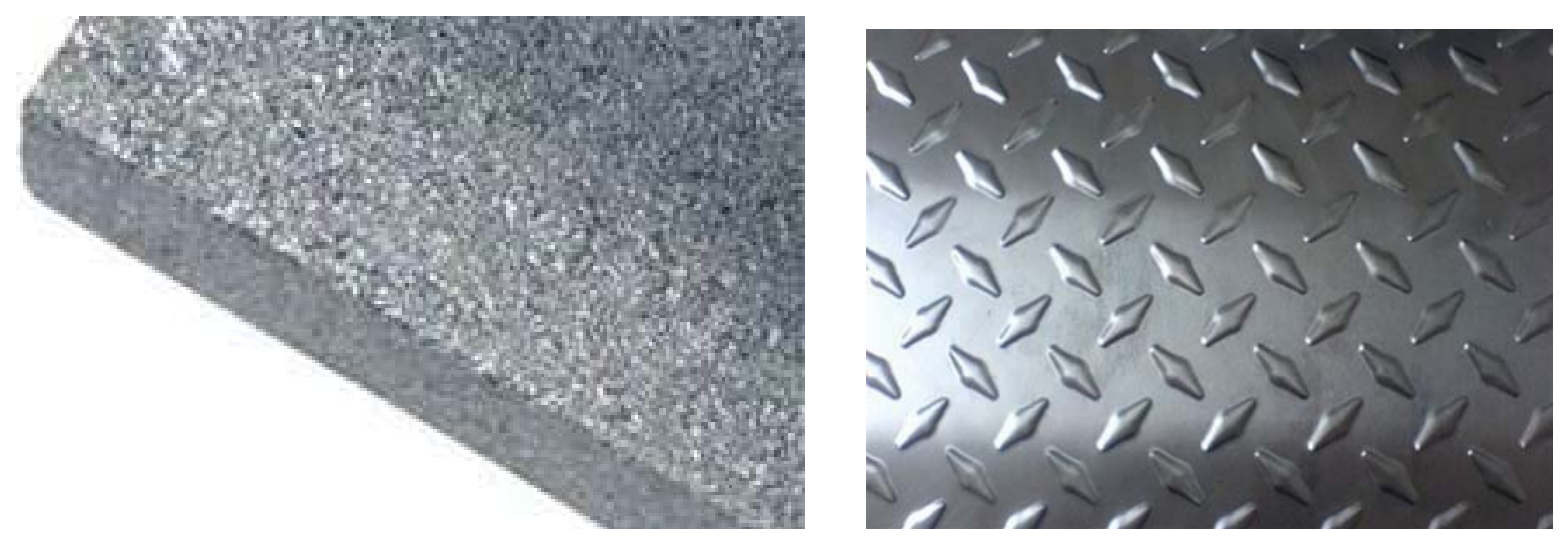

Figure 4-2: Galvanized Steel Road Plate (Sources: SlipNot, 2012b and Archi EXPO, 2012)

\subsubsection{Safety and Accessibility of Transit Riders with Mobility Devices}

Metals have been used on various infrastructure and industrial floors, and therefore, there should not be any concern regarding the safety and accessibility of persons with mobility devices. However, the possible glare as well as the heat absorption property of metals would be a concern to the traveling public. For these reasons, a rating of 3 out of 5 is given to metals in terms of safety and accessibility of passengers with mobility devices.

\subsection{Rubber}

Rubber is one of the best materials for absorbing kinetic energy and is often used on highways as speed controlling devices (e.g., speed bumps, raised crosswalk, etc.). Rubber is also used as load bearings and expansion joints in bridges. Unlike other materials, rubber has very low stiffness and needs to be installed on a relatively flat surface for it to remain flat. Therefore, a compacted 
granular base is needed if the movable B\&A pads are to be manufactured from rubber. Typically, the subgrade will comprise 20" $(51 \mathrm{~cm})$ compacted fill and 4" $(10 \mathrm{~cm})$ granular base. If the sidewalk and the street are widely spaced, heavy machinery will be needed to excavate, fill, and compact the subgrade. Therefore, there would not be any cost savings in terms of MOT if rubber is used to manufacture B\&A pads.

\subsubsection{Structural Performance}

As mentioned earlier, the structural performance of rubber materials is limited by the subbase condition. Because of its dependence on the condition of subbase, the structural performance rating of rubber materials is very low, i.e., 1 out of 5 .

\subsubsection{Long-Term Durability}

Rubber does provide excellent chemical resistance. However, over time, rubber loses its elasticity and becomes brittle, and eventually cracks. Further, its service life depends on many factors. Considering that majority of the warranties offered on rubber speed bumps varies between 5 and 15 years, the movable pads manufactured using rubber will have the lowest service life compared to other alternatives. Therefore, rubber is given a rating of 2 out of 5 for long-term durability.

\subsubsection{Adaptability}

One clear advantage of rubber is its ease of adaptability since it could simply be placed on top of the existing sidewalk with little disruption to traveling public. If the distance between the sidewalk and street is relatively small, instead of trimming off the rubber pads, the rubber pads could simply rest on top of the existing sidewalk, as shown in Figure 4-3. It is also lightweight and does not require heavy machinery to be transported. For these reasons, rubber is given a rating of 5 out of 5 for adaptability.

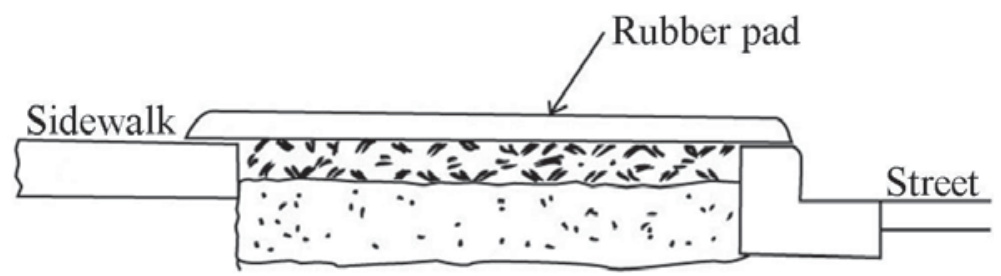

Figure 4-3: Rubber Material

\subsubsection{Life Cycle Cost}

Rubber materials are not cheap: a 3" $(7.6 \mathrm{~cm})$ high, $6^{\prime} \times 1^{\prime}(1.9 \mathrm{~m} \times 0.3 \mathrm{~m})$ speed bump costs approximately $\$ 160$. Hence, material costs alone for a $5^{\prime} \times 8^{\prime}(1.5 \mathrm{~m} \times 2.4 \mathrm{~m})$ movable pad would be over $\$ 1,000$ and this does not include the cost to prepare the subbase. However, if the soil condition at the site is relatively good, then the installation cost of rubber materials could potentially be significantly less compared to the conventional concrete/asphalt pads. Because of the high adaptability of rubber, any rubber system can be easily removed and reused at other 
locations. Nevertheless, considering its poor long-term durability, it is given a low rating of 2 out of 5 for life cycle cost.

\subsubsection{Aesthetics}

Rubber typically comes in black and will blend well with the surrounding environment. Considering that speed bumps are usually made of rubber, it should be well received by the city and county officials. Therefore, rubber is given a rating of 5 out of 5 for aesthetics.

\subsubsection{Safety and Accessibility of Transit Riders with Mobility Devices}

Rubber materials provide good shock absorbance and should provide smooth rides as well as least impact to the persons using mobility devices. It is therefore given a rating of 5 out of 5 .

\subsection{Thermoplastic}

The thermoplastic system consists of a variety of products ranging from small plastic grates to large plastic deck modules. The system relies on an interlocking mechanism that snaps small plastic modules together to form a larger deck system. The advantage of thermoplastic materials is that they become pliable or moldable at high temperature and return to a solid state upon cooling, which allows them to be manufactured in a variety of shapes and sizes. There are many types of thermoplastic materials. The most typical materials used in construction are high density polyethylene (HDPE), polyvinyl chloride (PVC), polypropylene (PP), acrylonitrile butadiene styrene (ABS), and polystyrene (PS). The properties of thermoplastic materials, therefore, vary greatly.

\subsubsection{Structural Performance}

Generally, in terms of structural performance, thermoplastics have good flexural and tensile strength, but have very low stiffness. When compared to steel, the stiffness of thermoplastic is lower by two orders of magnitude. As a result, to have the same stiffness, the structural component of the thermoplastic material would need to be approximately five times thicker than the corresponding steel section. Fortunately, thermoplastic is more than seven times lighter than steel, and therefore, the additional thickness would not significantly impact its weight. Since a majority of thermoplastics are designed to withstand foot and wheelchair traffic, there should not be any problem concerning the material's structural performance. For these reasons, it is given a rating of 5 out of 5 for structural performance.

\subsubsection{Long-Term Durability}

Thermoplastic materials provide excellent resistance to chemical degradation as they rarely react with most chemicals, particularly the chemicals commonly present in the natural environment. One durability concern would be its resistance to UV light. After some exposure to UV light, few thermoplastic materials become brittle and eventually crack. Discoloration is also a common phenomenon found in some thermoplastics after long exposure to UV radiation. Fortunately, 
thermoplastics designed for outdoor application will have resistance to UV radiation. If needed, UV coating could also be applied.

Another potential durability concern with thermoplastic materials is that they have a higher coefficient of thermal expansion (20-160 microstrain per degree Celsius) compared to concrete (8-15 microstrain per degree Celsius). The problem with the high coefficient of thermal expansion is two-fold. First, the joint between the thermoplastic pads and the sidewalk or the street curb must be carefully designed such that there is adequate gap during the cold winter months and the hot summer months. Second, incompatibility exists between the concrete sidewalk and thermoplastic pads when the thermoplastic pads are fastened to the concrete sidewalk. In other words, the thermoplastic pads become restrained by the concrete sidewalk. The cyclic stresses caused by the temperature variation between day and night could tear the thermoplastic pads. Thus, it is recommended that movable pads made from thermoplastics should not be directly mounted on the existing concrete sidewalk.

Nevertheless, plastic lumber has been tested to provide a more durable product and has been approved by the FDOT State Materials Office for bridge fender system. So, it is anticipated that long-term durability is not a concern for plastic lumber. For these reasons, a rating of 3 out of 5 is given to the ArmorDeck, HexiPad, and PortaPath, while a rating of 5 out of 5 is given to plastic lumber.

\subsubsection{Adaptability}

The adaptability of thermoplastic materials depends on the system. The modular systems, such as ArmorDeck, HexiPad, and PortaPath are limited to their fixed dimensions. Placing these systems on top of the concrete sidewalk is not ideal because of their thickness. The thinnest system is the 0.6" $(1.5 \mathrm{~cm})$ thick PortaPath, and it is possible to rest it on top of the sidewalk slab without causing tripping hazard. However, this requires the subgrade to be compacted.

Other materials, such as plastic lumber, are more adaptable since they do not interlock or snap together. Plastic lumber also comes in a variety of shapes and sizes, typically matching ordinary timber, therefore, presenting an advantage over the modular system. Plastic lumber also has good flexural strength and would not require the subgrade to be well compacted. A rating of 4 out of 5 is therefore given to thermoplastic materials for adaptability.

\subsubsection{Life Cycle Cost}

The price of thermoplastic materials varies greatly depending on the type and the system. In general, the average price of a readily available product is approximately $\$ 10$ to $\$ 15$ per square foot. For example, thermoplastic materials for a $5^{\prime} \times 8^{\prime}(1.5 \mathrm{~m} \times 2.4 \mathrm{~m})$ movable pad would cost approximately $\$ 400$ or about 4 times the material cost of cast-in-place concrete. However, the cost saving in terms of labor would be much greater for thermoplastic materials. ArmorDeck, HexiPad, and PortaPath may have lower initial cost; however, since they are designed as temporary roadways and have never been used on highways, their service life is questionable. Overall, the life cycle cost rating of these materials is 2 out of 5, while plastic lumber is given a rating of 5 out of 5 . 


\subsubsection{Aesthetics}

Thermoplastic comes in a variety of colors and provides aesthetically pleasing movable pads. Figure 4-4 (a) and (b) illustrates the use of plastic lumber as the deck for a boat dock and its typical lumber colors, respectively. However, similar to all thermoplastic materials, plastic lumber is not scratch resistant. Scratches, even though not aesthetically pleasing, are not detrimental to its structural performance or long-term durability. A rating of 4 out of 5 is therefore given to thermoplastic materials.

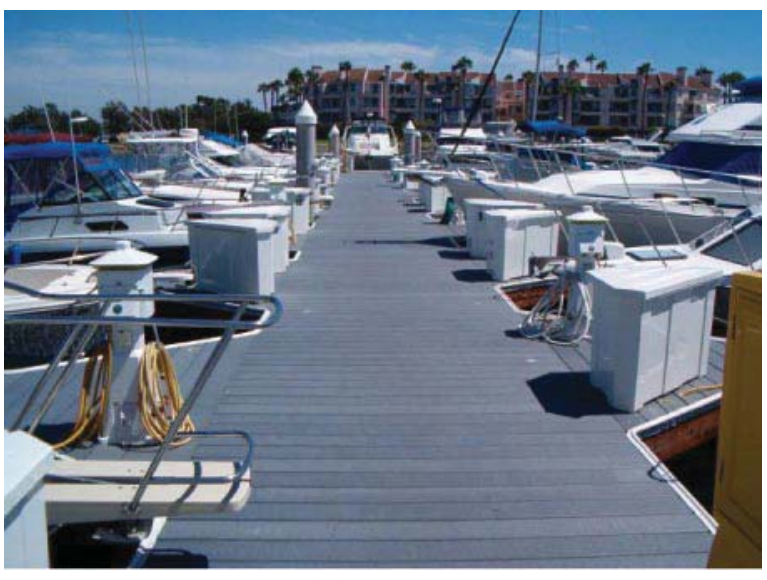

(a) Usage

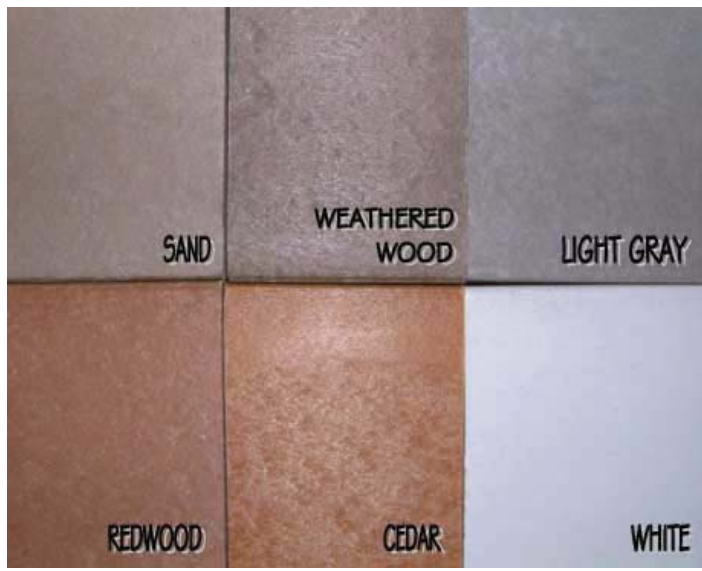

(b) Typical Colors

Figure 4-4: Plastic Lumber (Source: American Plastic Lumber, 2012)

\subsubsection{Safety and Accessibility of Transit Riders with Mobility Devices}

According to ADA requirements for grating, the largest possible gap between the grates should not be larger than $1 / 2^{\prime \prime}(1.3 \mathrm{~cm})$. Transit riders with mobility devices will not have a problem in terms of safety and accessibility as long as this criterion is met. Furthermore, in some cases, the gaps could also be potentially sealed with sand, rubber, or cement to provide smoother surfaces. Thus, safety and accessibility should not be of any concern for thermoplastic materials, which result in a rating of 4 out of 5 .

\subsection{Composite}

Mobi-mat, a commercially available product is evaluated as a composite material, which is fiberglass. Mobi-mat is a temporary walkway and wheelchair access mat often provided on uneven and non-solid surfaces such as sandy soil on a beach.

\subsubsection{Structural Performance}

Mobi-mat is manufactured using fiberglass, which has very good structural performance and durability. Since its lightweight design uses very little material, it has similar problems as rubber materials in that rely on the strength of the subbase. In other words, Mobi-mat needs compacted subgrade and granular base for it to provide adequate support for wheelchair traffic. Because of this limitation, Mobi-mat is given a rating of 1 out of 5 for structural performance. 


\subsubsection{Long-Term Durability}

In terms of durability, fiberglass has good service life; however, since the design is based on temporary access, the system is yet to be tested when permanently exposed to the harsh climate of Florida. Another potential concern is that the mounting system is fastened only at the far ends of the mat. This could be a problem during hurricane season; a minor design adjustment would have to be made should this system be adopted. Due to limited information on long-term durability, Mobi-mat is given a rating of 3 out of 5 .

\subsubsection{Adaptability}

Similar to the rubber system, Mobi-mat is easily adaptable to different site conditions since the mat can simply be rested on top of the sidewalk, which earns it a rating of 5 out of 5 .

\subsubsection{Life Cycle Cost}

Cost is one of the major limitations of Mobi-mat. It has very high initial cost for a product that is designed to provide temporary access. Even though fiberglass is a very durable material, similar to all glass materials, it is very brittle. Therefore, if the mat is struck with a hard object, the mat might break and might need to be replaced. Due to the associated maintenance cost, a rating of 3 out of 5 is given to Mobi-mat for life cycle cost.

\subsubsection{Aesthetics}

Mobi-mat is generally manufactured in blue and white colors. It is anticipated that other colors are available but fading of paint could be a long-term issue, which could impact its aesthetics. Additionally, Mobi-mat is a relatively thin carpet-like material which appears to be temporary. When installing next to concrete sidewalks and curbs, it may look out of place. For these reasons, it is given a rating of 3 out of 5 for aesthetics.

\subsubsection{Safety and Accessibility of Transit Riders with Mobility Devices}

Since Mobi-mat is especially designed for wheelchair access on the beach, there is no reason to believe that this product will be unsafe for transit riders with mobility devices. Hence, it is given a rating of 5 out of 5 .

\subsection{Wood}

The roll-out walkway is constructed using timber planks that are tied together using metal wires, and are often used as walkways in a park.

\subsubsection{Structural Performance}

Wood is a good engineering product with very good structural performance, and has been used in many types of structures. Therefore, in terms of structural performance, wood should not be 
rated lower than any product particularly for B\&A pads. Hence, wood is given a rating of 5 out of 5 for structural performance.

\subsubsection{Long-Term Durability}

Wood is not recommended in Florida as humidity and rainfall would accelerate its deterioration. Furthermore, in certain areas in Florida, subtropical termites could also be a potential problem for wooden planks. Treated lumber could solve some of these problems but considering that B\&A pads would be directly in contact with soil, using wood is not acceptable without having to endure continual maintenance cost. It should also be noted that even in the case of treated wood, manufacturers typically do not provide warranty beyond 15 years. For these reasons, a rating of 2 out of 5 is given to wood for long-term durability.

\subsubsection{Adaptability}

In terms of adaptability, wood is one of the most versatile products that can be easily cut onsite to adapt to the prevailing site conditions. Therefore, it is given a rating of 5 out of 5 .

\subsubsection{Life Cycle Cost}

The life cycle cost of wood depends mostly on the long-term durability and maintenance issues associated with placing wood in direct contact with soil. Nevertheless, wood is one of the cheapest products and therefore, both initial and maintenance costs are significantly lower. For this reason, it is given a rating of 3 out of 5 for life cycle cost.

\subsubsection{Aesthetics}

Wood comes in only one main color; yet, it could be painted to match the color of the surroundings. One big disadvantage with coloring the wood is maintenance. For this reason, it is given a rating of 3 out of 5 for aesthetics.

\subsubsection{Safety and Accessibility of Transit Riders with Mobility Devices}

As in the case of plastic lumber, as long as the gap between planks meets the ADA requirements, there should not be any concerns about the safety and accessibility of persons with mobility devices. It is therefore given a rating of 4 out of 5 .

\subsection{Life Cycle Cost Analysis}

The life cycle cost is estimated by considering five main factors: (1) initial cost, (2) maintenance cost, (3) reconstruction cost, (4) demolition/recondition cost, and (5) cost associated with the frequency of route changes. The formula used to calculate the total life cycle cost is given below (see Equation 1). The total life cycle cost is calculated based on a 50 year service life of the B\&A pad.

$$
\begin{aligned}
\text { Total Cost }= & \text { Initial Cost }+ \text { Maint. Cost } \times 50 \text { years }+ \text { Reconst. Cost } \times(50 / \text { freq per year }) \\
& + \text { Demolition cost } \times(50 / \text { freq per year })
\end{aligned}
$$


The initial cost consists of material and labor costs that are based on historical costs obtained from the 2011 FDOT Annual Statewide Averages (FDOT, 2013). In the case of alternative products with no historical data such as Flexi-Pave, HexiDeck, ArmorDeck, and Mobi-mat, their actual market prices are used. Besides the material and labor costs, other associated costs such as site preparation and MOT are not considered because they offset each other since all material options require similar site preparation and MOT. Note that all cost estimations are based on the construction of a $5^{\prime} \times 8^{\prime}(1.5 \mathrm{~m} \times 2.4 \mathrm{~m}) \mathrm{B} \& \mathrm{~A}$ pad.

The maintenance cost is an annual estimate based on the historical material's long-term performance and manufacturer warranties. As described earlier, traditional materials such as concrete, aluminum, and steel do not require maintenance for B\&A pad since the pads experience only foot traffic. The maintenance cost for concrete paver is based on surface finisher and sealer. The maintenance costs for rubber, thermoplastic, and wooden materials are based on manufacturer warranty for the products. For example, the average warranty of treated wood is 15 years, which means the system might need to be replaced in 15 years. Therefore, the annual maintenance cost is calculated by taking the initial cost divided by the number of years of warranty (i.e., 15 in this example). Plastic lumber has a good track record of performing over 50 years, and therefore, there is no associated maintenance cost.

The reconstruction cost is the cost that is needed for moving the existing B\&A pad to a new site. For conventional concrete/asphalt pad, a new pad has to be reconstructed since the existing pad cannot be salvaged. In the case of concrete paver and wood, it is anticipated that during the removal process of the existing pad, only a fraction of the materials can be salvaged. Concrete paver is a brittle material and would crack if not removed properly. As for wood, some planks might warp over time and the wood at the fastened location could also split during the removal process.

The demolition/recondition cost is the cost associated with demolishing the exiting B\&A pad (as in the case of a conventional pad) and reconditioning the top soil to its original condition. In most cases, reconditioning involves growing grass in place of the existing B\&A pad. The frequency of route changes are analyzed for the following four different rates: once every 5 years, once in a year, twice in a year, and thrice in a year.

Table 4-1 summaries the cost comparison of various materials and their corresponding commercially available products. From the table, it is clear that plastic lumber presents the lowest cost regardless of the frequency at which the bus route changes. The precast concrete system comes in second, next to plastic lumber, with the lowest life cycle cost despite of its high initial cost. The precast concrete option could be cost-effective if the weight of the precast concrete section is low enough that it can be hand carried without the use of equipment. The conventional concrete/asphalt pads have the lowest initial and maintenance costs. However, the B\&A pad becomes the most expensive option if the bus stop has to be relocated at least once a year. If the route changes are less frequent, i.e., once in every 5 years, then the conventional concrete/asphalt pad is quite cost-effective, followed by plastic lumber, precast concrete, concrete paver, and wood. 


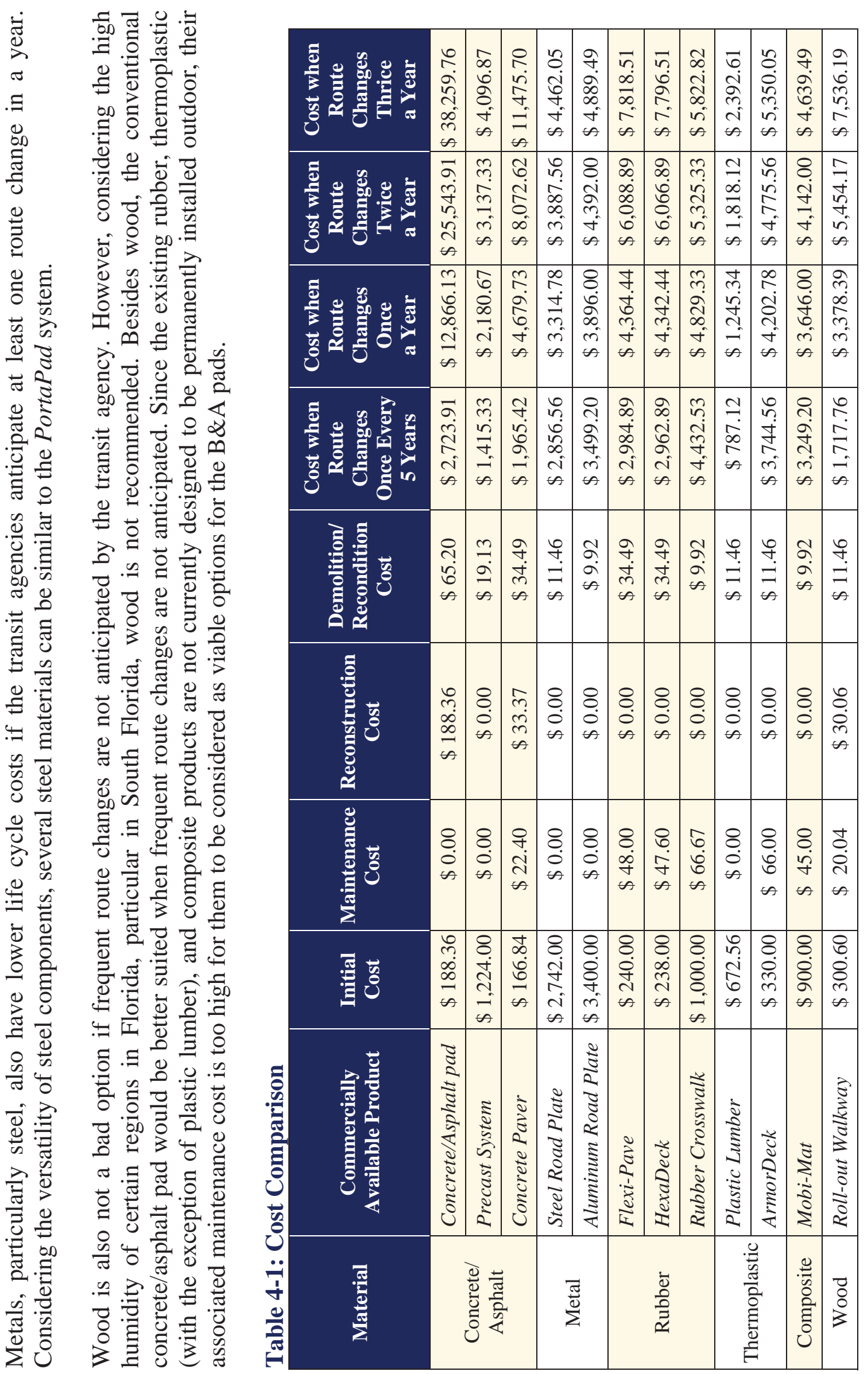




\subsection{Summary}

Six readily available materials were reviewed to determine their potential use and feasibility of replacing the conventional concrete/asphalt B\&A pads. These materials were evaluated for their structural performance, long-term durability, adaptability, life cycle cost, aesthetics, and safety and accessibility of passengers with mobility devices. Table 4-2 summarizes the rating of each criterion for the six materials and their corresponding commercially available products.

Table 4-2: Evaluation of Design Materials for Their Potential Use as Movable B\&A Pads

\begin{tabular}{|c|c|c|c|c|c|c|c|}
\hline \multirow[b]{2}{*}{ Material } & \multirow{2}{*}{$\begin{array}{c}\text { Commercially } \\
\text { Available Product }\end{array}$} & \multicolumn{6}{|c|}{ Rating } \\
\hline & & \begin{tabular}{|c|} 
Structural \\
Performance
\end{tabular} & \begin{tabular}{|c|} 
Long-Term \\
Durability
\end{tabular} & Adaptability & $\begin{array}{c}\text { Life Cycle } \\
\text { Cost }\end{array}$ & Aesthetics & \begin{tabular}{|c} 
Safety and \\
Accessibility
\end{tabular} \\
\hline \multirow{7}{*}{$\begin{array}{l}\text { Concrete/ } \\
\text { Asphalt }\end{array}$} & Asphalt Pads & 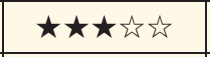 & $\star \star \star \star \star$ & 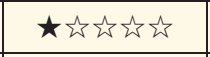 & 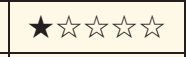 & $\star \star \star \star \star$ & $\star \star \star \star \star$ \\
\hline & Concrete Pads & 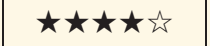 & $\star \star \star \star \star \star$ & 太放动动动 & 太放论动拧 & $\star \star \star \star \star \star$ & 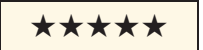 \\
\hline & $E C R$ & \multirow{4}{*}{$\star \star \star \star \star$} & \multirow{4}{*}{$\star \star \star \star \star$} & \multirow{4}{*}{$\star \star え え え$} & \multirow{4}{*}{$\star \star \star \star \star え$} & \multirow{4}{*}{$\star \star \star \star \star$} & \multirow{4}{*}{$\star \star \star \star え$} \\
\hline & TraCast & & & & & & \\
\hline & Precast Panels & & & & & & \\
\hline & Precast Boardwalk & & & & & & \\
\hline & Concrete Pavers & 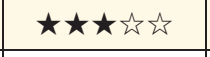 & $\star \star \star \star \star$ & $\star \star \star え え 认$ & 太夫放动方 & $\star \star \star \star \star$ & 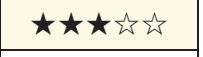 \\
\hline \multirow{3}{*}{ Metal } & Steel Road & $\star \star \star \star \star$ & 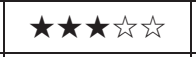 & 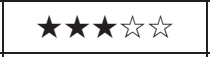 & 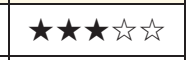 & 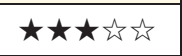 & 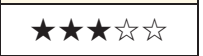 \\
\hline & Aluminum Road & $\star \star \star \star \star$ & $\star \star \star \star \star$ 斿 & 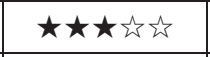 & 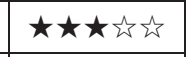 & 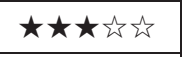 & 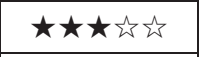 \\
\hline & PortaPad & $\star \star \star \star \star$ & 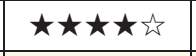 & 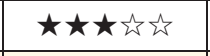 & 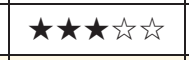 & 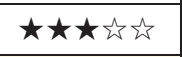 & 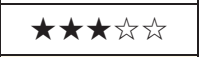 \\
\hline \multirow{4}{*}{ Rubber } & Full-Depth Rubber & \multirow{4}{*}{ 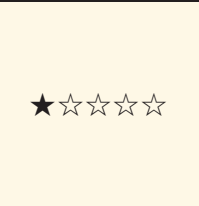 } & \multirow{4}{*}{ 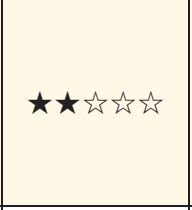 } & \multirow{4}{*}{$\star \star \star \star \star$} & \multirow{4}{*}{ 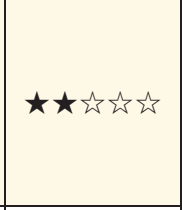 } & \multirow{4}{*}{$\star \star \star \star \star$} & \multirow{4}{*}{$\star \star \star \star \star$} \\
\hline & Flexi-Pave & & & & & & \\
\hline & HexaDeck & & & & & & \\
\hline & Rubber Crosswalk & & & & & & \\
\hline \multirow{5}{*}{$\begin{array}{l}\text { Thermo } \\
\text { plastic }\end{array}$} & PortaPath & \multirow{4}{*}{$\star \star \star \star \star$} & \multirow{4}{*}{ 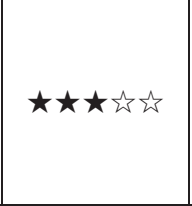 } & \multirow{4}{*}{$\star \star \star \star \star$ 论 } & \multirow{4}{*}{ 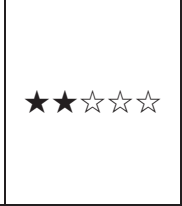 } & \multirow{4}{*}{$\star \star \star \star \star$ 论 } & \multirow{4}{*}{ 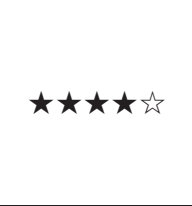 } \\
\hline & ArmorDeck & & & & & & \\
\hline & SupaTrac & & & & & & \\
\hline & Plastic Grates & & & & & & \\
\hline & Plastic Lumber & $\star \star \star \star \star$ & $\star \star \star \star \star$ & $\star \star \star \star \star え$ & $\star \star \star \star \star ~$ & $\star \star \star \star \star え$ & 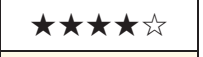 \\
\hline Composite & Mobi-Mat & 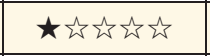 & 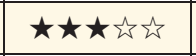 & $\star \star \star \star \star$ & 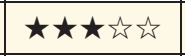 & 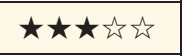 & $\star \star \star \star \star$ \\
\hline Wood & Roll-out Walkways & $\star \star \star \star \star$ & 太太放论场 & $\star \star \star \star \star$ & 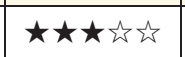 & 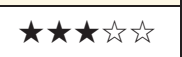 & 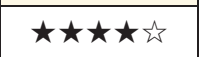 \\
\hline
\end{tabular}

The structural performance criterion is based on the strength, rigidity, and toughness (i.e., the material's ability to plastically deform without fracture) of the material. Metals perform the best in this category; however, since the B\&A pads will typically experience foot traffic, all the materials did well with the exception of rubber and composite. Each of these two materials received a rating of 1 out of 5 because they both rely on the strength of the subbase. Should the subbase not be properly compacted or a settlement occurs to the subbase, both rubber and composite pads will deform in the same manner as the subbase.

The long-term durability is the material's ability to resist scratches and the harsh outdoor environment. Concrete/asphalt, metals, and plastic lumber perform well with a rating of 5/5, 4/5, and $5 / 5$, respectively. Wood did not perform as well considering the humidity and the soil 
condition in Florida which could lead the wood to deteriorate more rapidly. For this reason, wood is not recommended for B\&A pad despite its relatively good life cycle cost.

The adaptability criterion evaluated the material's ability to be modified and adjusted to fit with the various site conditions present at the bus stops. Overall, all materials with the exception of concrete can be easily cut and adjusted onsite.

The life cycle cost looked at the overall costs of the material over a period of 50 years by considering the initial, maintenance, relocation, and demolition costs as well as the cost associated with the frequent relocation of bus stops. Overall, plastic lumber has the lowest life cycle cost if the B\&A pads need to be removed, relocated, and reused frequently. The conventional concrete/asphalt pads have the highest life cycle cost if the frequency of route changes is at least once per year. However, the conventional concrete/asphalt pads do have the lower initial cost.

The aesthetics of the material depends on its color and its ability to blend in with the existing infrastructure such as sidewalks. Overall, all materials can be coated or manufactured to match the color of the existing sidewalk; therefore, aesthetics should not be a main concern in the material selection. However, it should be noted that coating could reduce the material's service life and therefore proper coating should be carefully selected to ensure the longevity of the materials.

The safety and accessibility of transit riders with mobility devices is a very important criterion. Most of the materials, whether it is precast concrete, steel, or plastic lumber, will most likely be assembled onsite similar to a boardwalk deck. This would result in small gaps between the assemblies. These gaps could be a problem for persons with crane or other mobility devices as they could get stuck in the gaps. As long as the assemblies are properly designed, the safety and accessibility of persons with mobility devices should not be of a concern. According to ADA, the maximum permissible gap is $1 / 2^{\prime \prime}(1.3 \mathrm{~cm})$. The gap, if greater than $1 / 2^{\prime \prime}(1.3 \mathrm{~cm})$, could also be filled with rubber pads. Therefore, there should not be a problem in term of safety and accessibility for these materials.

In summary, plastic lumber has the highest potential to replace the conventional design based on design considerations, material properties, and life cycle cost. It has good strength (even though not as high as concrete) and it is also considerably light (even though not as light as Mobi-mat). Plastic lumber is also one of the cheapest and most durable systems. However, its performance under hurricane force wind has to be further evaluated for it to be recommended for extensive adoption. 


\section{CHAPTER 5 \\ DESIGN OF MOVABLE BOARDING AND ALIGHTING PADS}

This chapter focuses on the development of a full system integration and installation using the most suitable materials discussed in Chapter 4. As concluded in the previous chapter, the most cost-effective and readily available material, which can be used to construct the B\&A pads that are movable, reusable, and relocatable, is plastic lumber. Plastic lumber is the only nontraditional material (traditional materials consist of concrete, asphalt, and steel) that has sufficient track record, including both research and field experience by the railroad industry, Department of Defense (DOD), and FHWA. Additionally, FDOT has also approved and used plastic lumber for fender systems. Therefore, plastic lumber should not be of any concerns for the FDOT State Materials Office should it be adopted for constructing the B\&A pads.

In addition to plastic lumber, metallic material could also be used in designing B\&A pads. Even though metal is more expensive than plastic lumber, construction using metal is significantly quicker and could potentially provide cost saving if transit agencies anticipate frequent route changes. This chapter discusses in detail the following four components of the installation process: foundation, slab, supporting beam, and connections for both plastic lumber and metallic pads.

\subsection{Preliminary Design Concept}

To develop the framework for the proposed movable pads, the existing site conditions that could range from narrow to wide distance and hard to soft bases have to be considered. One of the biggest challenges for designing the movable pads is to design an easily adaptable structural component which requires little MOT. To this end, the following two options are proposed: (1) plastic lumber pads, and (2) metallic pads.

The plastic lumber pad is similar to the type used for constructing outdoor decks or boardwalks. The challenge here lies in the ability to make the design reusable and relocatable for the different site conditions. For instance, the beams that were used in an area with a narrow distance between the sidewalk and the street curb can no longer be reused in an area with a wide distance. Additionally, the structural plank forming the slab may need to be trimmed or resized to fit in the new location.

The second option, the metallic pad, provides a more adaptable design since the component could be resized as needed. Figure 5-1 shows the readily available telescopic ramps, commonly used for wheelchairs, which could potentially be used for movable pads. The problem with the telescopic ramps is that they are designed for carrying only one wheelchair at a time. For these ramps to be used as movable pads, they require significant modifications to accommodate passengers boarding the bus. 

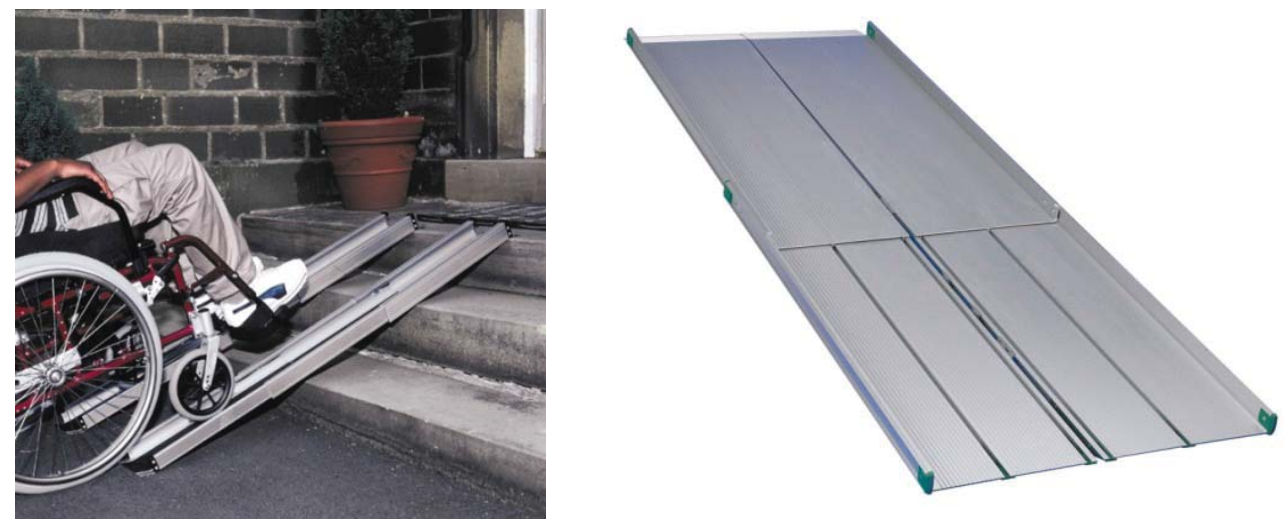

Figure 5-1: Telescopic Ramps

(Sources: Scot Mobility (UK) Ltd., 2012 and Guldmann, 2012)

Maintenance of traffic (MOT), one of the major cost items, could be eliminated when the granular base does not have to be compacted using heavy machinery. However, several potential products such as the PortaPath, ArmorDeck, and SupaTrac require relatively flat subgrade. Also, the granular base has to be compacted to ensure minimum settlement over the pad's service life. Instead of adopting traditional slab-on-grade design, one method for eliminating the granular base compaction is to adopt beam design concept where a system of beams bridge the gap between the sidewalk and the street curb. The proposed design alternatives, therefore, have four main components: 1) foundation, 2) supporting beam, 3) slab, and 4) connections. Figure 5-2 illustrates a preliminary design concept of the proposed movable B\&A pads. All the four components have to be designed to withstand the climate prevalent in Florida, which could be quite extreme, especially near the coast. The salt water, in particular, can create a highly corrosive environment for metallic materials such as steel.

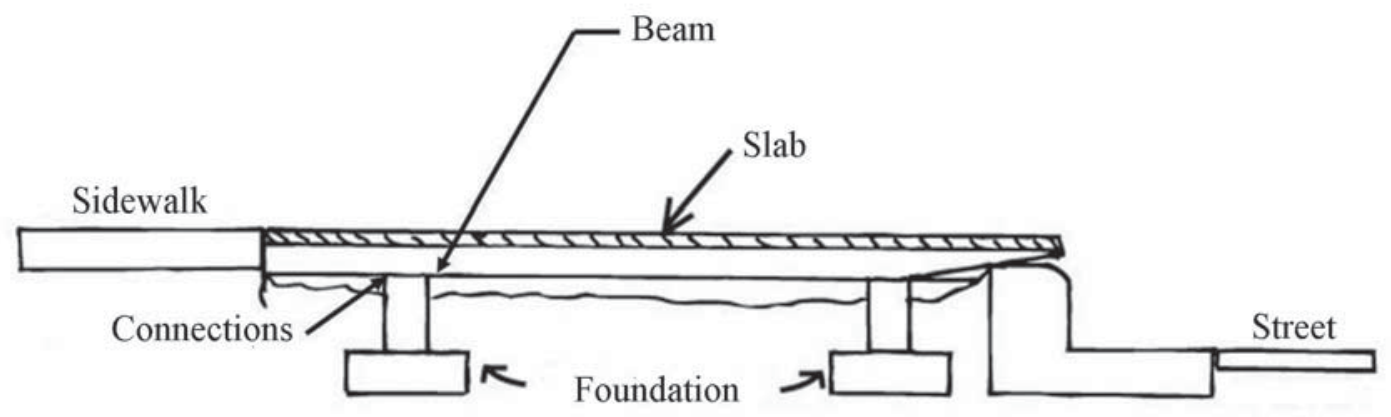

Figure 5-2: Preliminary Design Concept of the Proposed Movable B\&A Pads

\subsection{Foundation}

The foundation of the movable pad is one of the most important design considerations. The foundation is directly exposed to soil which could potentially contain many acidic and corrosive materials. As such, the foundation is designed using concrete materials; concrete has high compressive strength to price ratio and provides very good chemical resistance. Compared to concrete, polymeric materials or thermoplastics provide greater durability. However, they are 
more expensive and have lower compressive strength. Their lower strength also results either in a larger foundation profile or an increase in the size needed to withstand the foot and wheelchair traffic. Hence, more soil would need to be excavated, increasing the construction cost. For these reasons, concrete is chosen as an appropriate material for the foundation.

There are several types of footings that can be used for the proposed movable pads. Their selection depends on the applied load, allowable soil bearing capacity, and frost line. Fortunately, the applied load on the movable pad is minimal and the frost line is not a main concern in Florida. Therefore, any shallow foundation that is readily available in the market can be adopted.

Figure 5-3 shows a precast pier block that was developed for providing a floating foundation for outdoor deck. The advantage of using this readily available product is its cost and availability. The precast pier block can be purchased from any home improvement store for as little as $\$ 7.50$ a block. For a $5^{\prime} \times 8^{\prime}(1.5 \mathrm{~m} \times 2.4 \mathrm{~m})$ movable pad, only four precast pier blocks are needed to support two beams at each ends, and the total cost for the foundation is only $\$ 30$. Another advantage of this product is its light weight; each block weighs only $45 \mathrm{lb}$, and can be handled by one person.
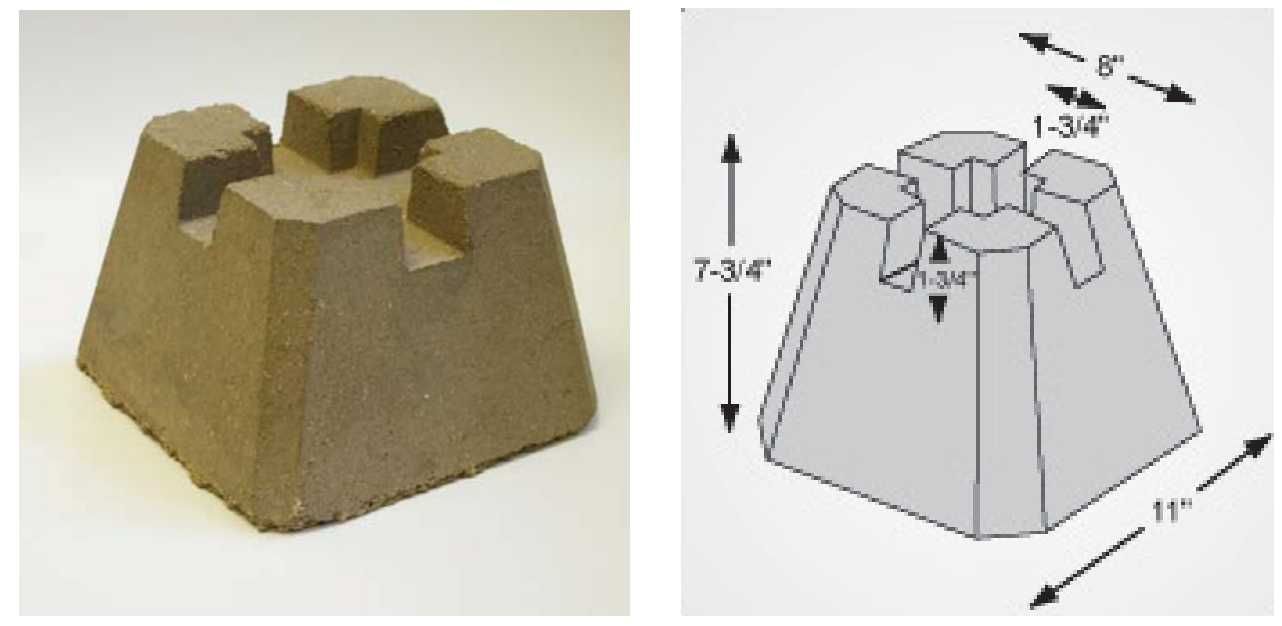

Figure 5-3: Precast Pier Block (Source: DekBrands, 2012)

To adopt this foundation for movable pads, the precast pier block has to be buried under the ground such that there is a clear distance of $5^{\prime \prime}(12.8 \mathrm{~cm})$ from the top of the sidewalk concrete slab to the top of the precast pier block, as shown in Figure 5-4. A preliminary design of the foundation suggests that the excavated hole be $16^{\prime \prime}(40.6 \mathrm{~cm})$ in diameter and $10^{\prime \prime}(25.4 \mathrm{~cm})$ in depth. Depending on the site conditions, a 2" $(5.1 \mathrm{~cm})$ thick granular base consisting of No. 57 stone could be placed beneath the precast pier block to minimize the effect of soil settlement and to ensure that the foundation is leveled. It should be noted that due to the small profile of the foundation, the granular base does not have to be compacted using heavy machinery. The precast pier block is then placed on top of the granular base and covered with top soil that was excavated from the hole. As shown in Figure 5-5, a portion of the soil along the trajectory of the beam also has to be excavated since the site needs a level surface. 


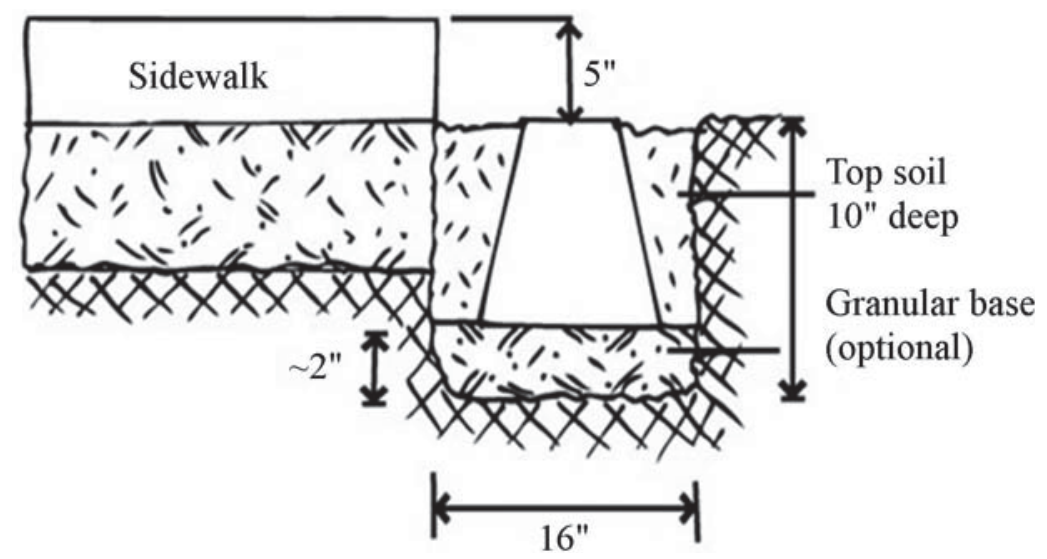

Figure 5-4: Precast Pier Block Installation

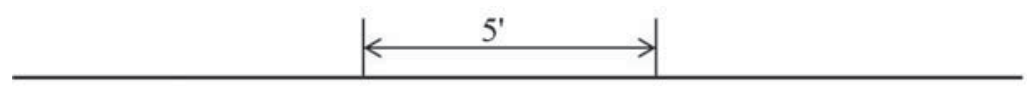

Sidewalk

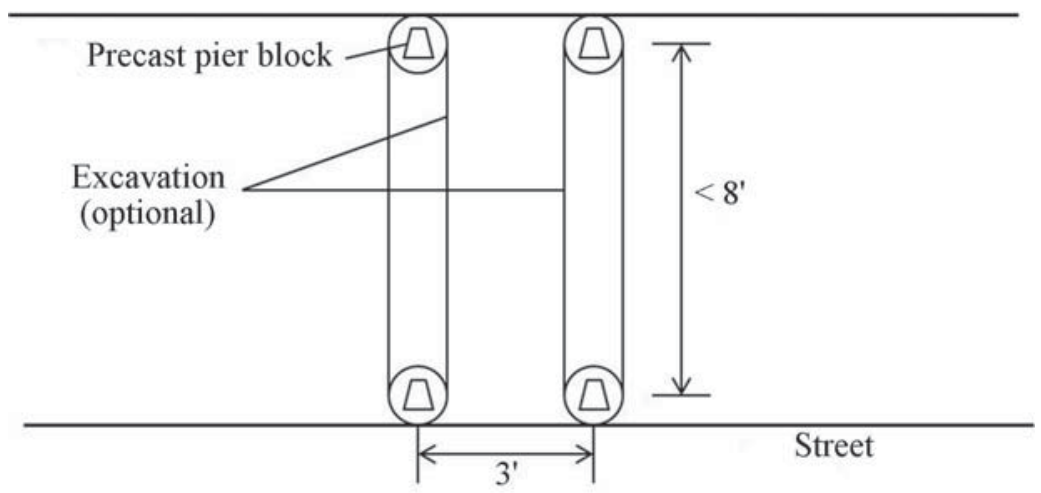

(a) Plan

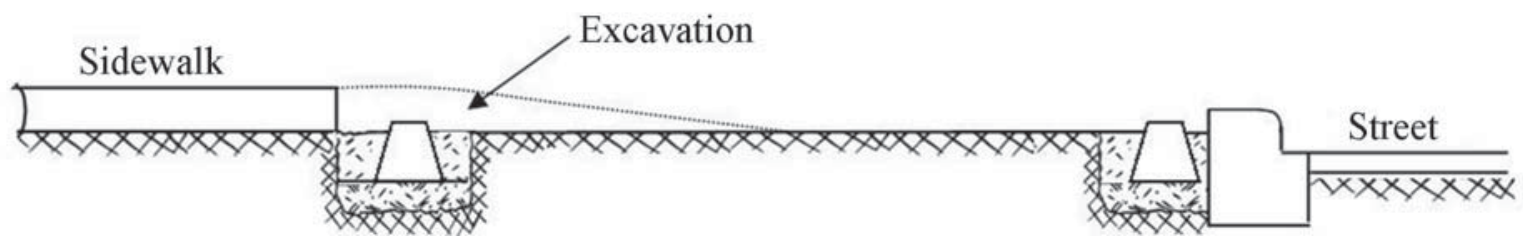

(b) Elevation

Figure 5-5: Soil Excavation Profile

\subsection{Plastic Lumber Pad}

The plastic lumber Pad consists of three components: supporting beams, slabs, and connectors. To make the design more adaptable to different site conditions, the beam is designed to be of variable length. Further, the interlocking beams and telescopic beams are proposed, and are shown in Figures 5-6 and 5-7, respectively. The interlocking beam is built by bolting multiple beams with the same cross section together. The telescopic beam uses beams with different cross 
sections; the beam with a smaller cross section slides into the beam with a larger cross section. The advantage of the telescopic beam is that it is more adaptable to different site conditions whereas the interlocking beam will be limited to the preconfigured dimensions. However, the advantage of the interlocking beam lies in the span length. If the distance between the sidewalk and the street curb is significant, then the only option is to use the interlocking beam. Another advantage of the interlocking beam is that even at a shorter span length, the interlocking beam generally has lower profile, and therefore, less soil needs to be excavated. Note that both the beams are connected using structural bolts.

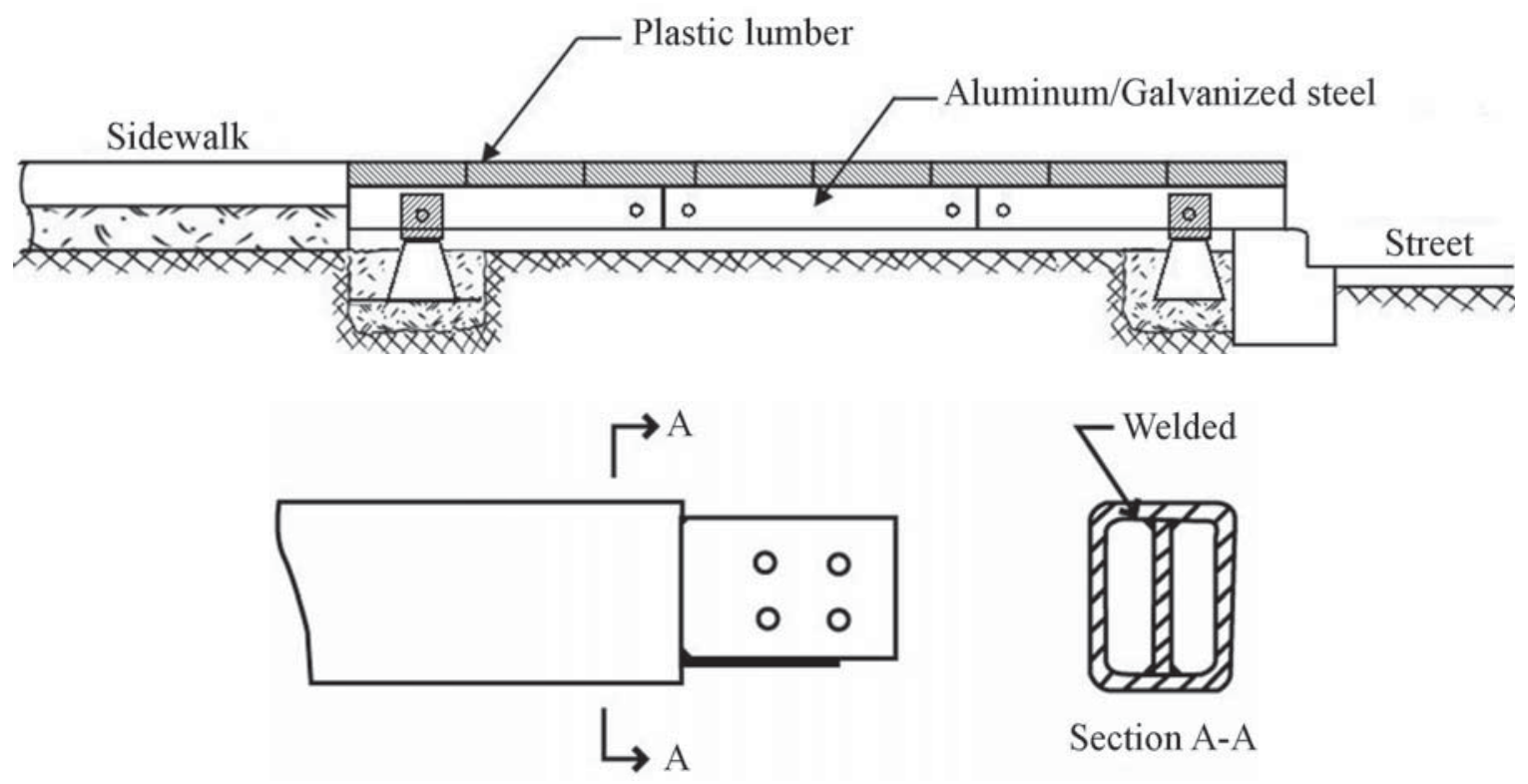

Figure 5-6: Plastic Lumber Pad Using Interlocking Beams Concept
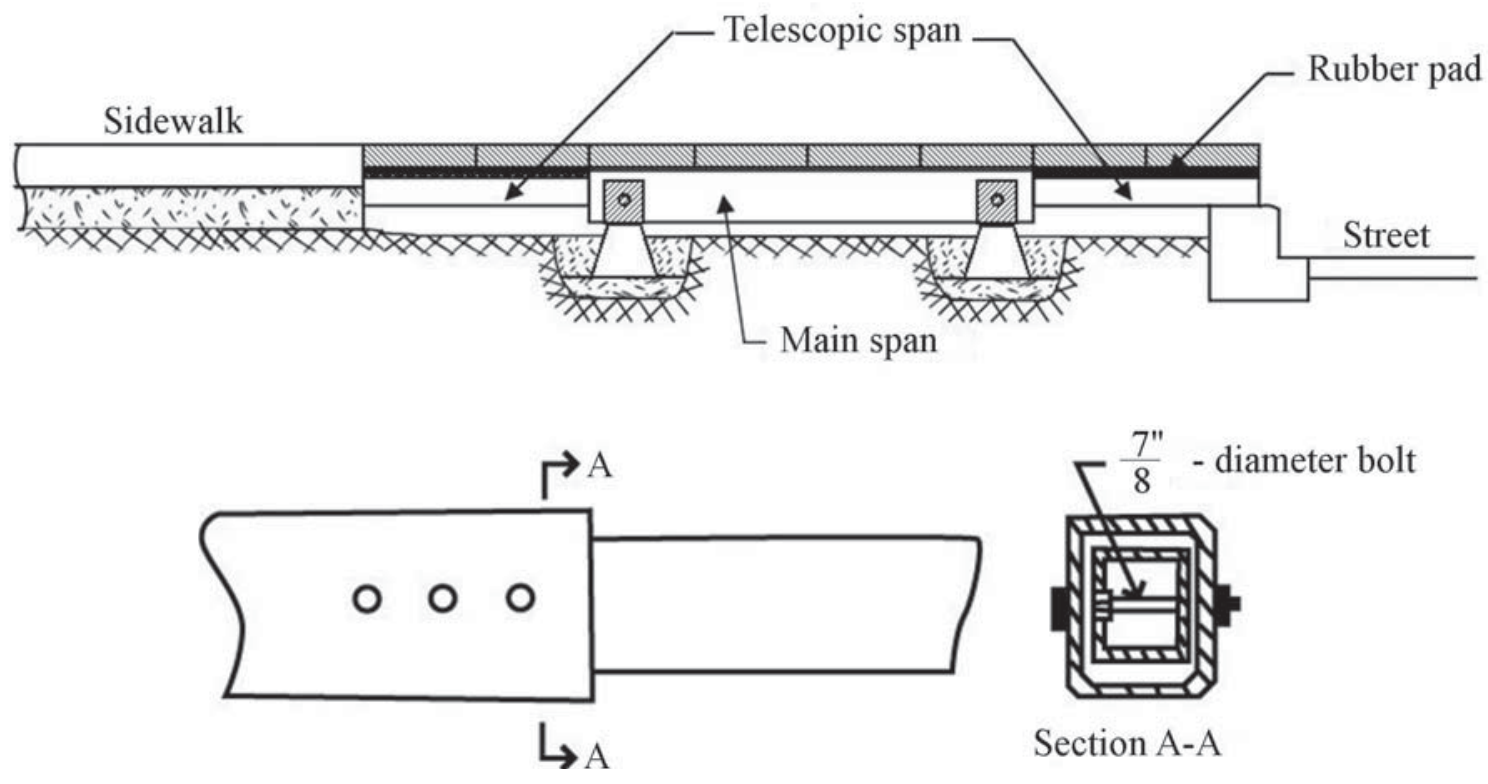

Figure 5-7: Plastic Lumber Pad Using Telescopic Beams Concept 


\subsubsection{Supporting Beam}

The supporting beam needs to have high flexural strength to weight ratio for it to be relatively shallow and to minimize soil excavation. Either steel or aluminum can be used as supporting beams. However, one problem with steel is corrosion, and it has to be either painted or galvanized to protect it from corrosion. Hot-dip galvanized steel extends the service life to 50 years and the process is relatively cheap compared to painting. On the other hand, aluminum does not corrode, yet could be more expensive as more material is needed to compensate for its lower stiffness. Since aluminum is approximately 2 to 3 times costlier than steel and is also more susceptible to theft, galvanized steel is recommended for building the supporting beams for the movable pads.

\subsubsection{Slab}

The slab is directly exposed to the harsh environment and has to withstand the foot and wheelchair traffic. Therefore, the slab has to be designed such that it is durable and slip-resistant. Several materials including reinforced concrete, nonslip steel deck, timber deck, and plastic lumber deck could be considered. Of these materials, plastic lumber is the most economical option when life cycle cost of the deck is considered. Plastic lumber is relatively cheap at $\$ 8.00$ per linear foot for a $2^{\prime} \times 8^{\prime}(0.6 \mathrm{~m} \times 2.4 \mathrm{~m})$ plank. It is very durable and most manufacturers offer 50 years limited warranty. Plastic lumber also comes in multiple colors and textures, which allows it to blend into the surrounding environment resulting in aesthetically pleasing B\&A pads.

Due to the abovementioned reasons, plastic lumber is used to build the slab, and is bolted to the beam using four bolts. The beam has slotted holes predrilled at constant intervals of approximately $3 "$ " $(7.6 \mathrm{~cm})$ to create the flexibility to slide the slab back and forth and to slightly rotate the slab. The rotation of the slab is a very important design concept because not all sidewalk edges are parallel to the street edges.

Additionally, the slab can also be installed with small gaps (not more than $1^{\prime \prime}$ ) to ensure that the slab fits in the available spaces. For example, consider a scenario where $2^{\prime} \times 8^{\prime}(0.6 \mathrm{~m} \times 2.4 \mathrm{~m})$ slabs have to be built using the $1.5^{\prime \prime} \times 7.5^{\prime \prime}(3.8 \mathrm{~cm} \times 19.1 \mathrm{~cm})$ plastic lumber tiles. If the slabs need to span over a distance of $8^{\prime}(2.4 \mathrm{~m})$, only 12 pieces of plastic lumber will fit and there will be a gap of approximately 6" $(15.2 \mathrm{~cm})$. However, if the 12 pieces are spaced approximately $1 / 2^{\prime \prime}$ $(1.3 \mathrm{~cm})$ apart to comply with ADA requirement of 1/2" $(1.3 \mathrm{~cm})$ maximum gratings (U.S. Access Board, 2006c), the 12 pieces will fit perfectly within this space. If a larger gap is needed particularly when the slab has to be rotated, the gap could simply be filled with rubber materials, which can eliminate gratings from the surface. Figure 5-8 illustrates the plastic lumber slab mounted on top of the beam.

\subsubsection{Connections}

A connection has to be designed to attach the supporting beam to the foundation. Additionally, the slab also has to be bolted down to the supporting beams. Galvanized steel brackets and bolts are used for this application because the supporting beam is recommended to be built with galvanized steel. Further, there is no additional benefit if the connections are more durable than the main supporting structure. 


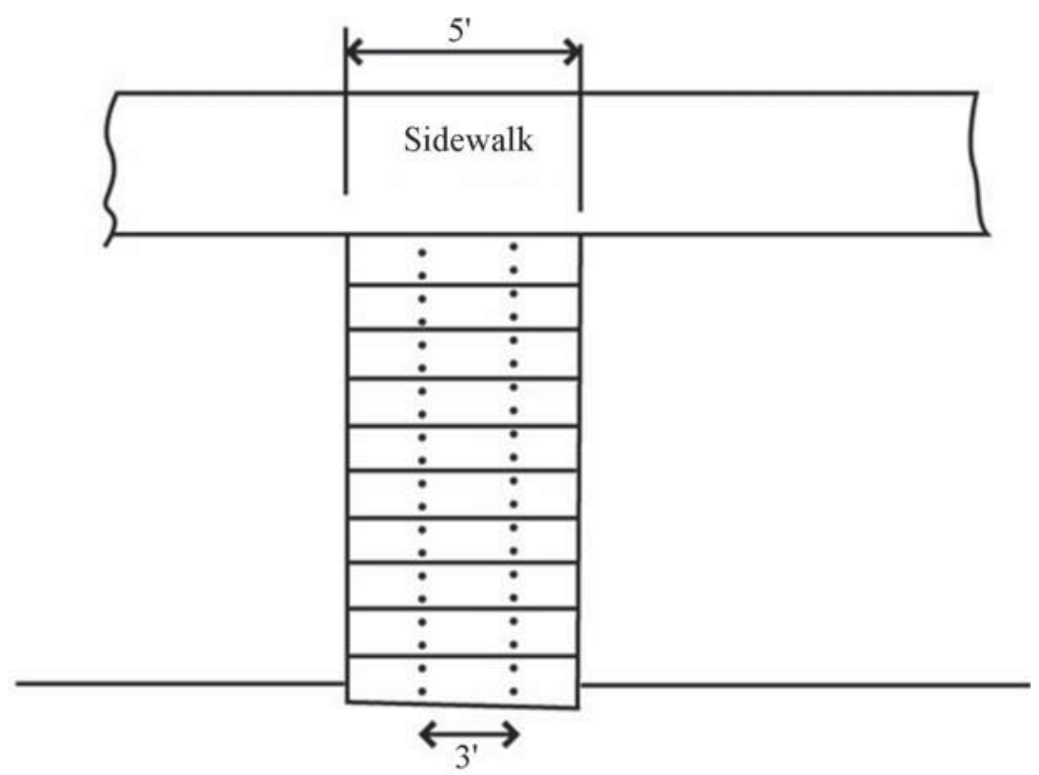

Sidewalk

(a) Slabs Built from Plastic Lumber with No Gaps

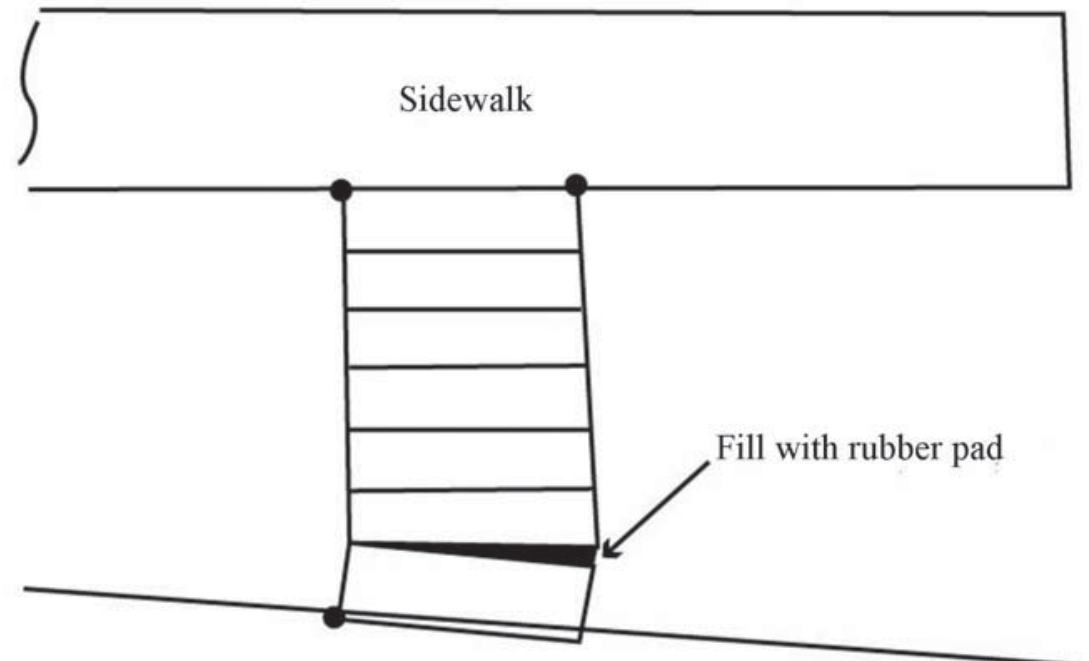

(b) Slabs Built from Plastic Lumber with Gaps Filled with Rubber Pad

Figure 5-8: Slab Panels

To minimize the effect of moment on the precast pier block, a custom steel bracket has to be fastened to the top of the precast pier block, as illustrated in Figure 5-9. The custom steel bracket is composed of a $5 / 16^{\prime \prime} \times 3^{\prime \prime} \times 3^{\prime \prime}(0.8 \mathrm{~cm} \times 7.6 \mathrm{~cm} \times 7.6 \mathrm{~cm})$ base plate and two $3 / 16^{\prime \prime} \times 3^{\prime \prime} \times 3$ $1 / 4^{\prime \prime}(0.5 \mathrm{~cm} \times 7.6 \mathrm{~cm} \times 8.3 \mathrm{~cm})$ side plates welded together to form an oversized channel to support the steel beam. The steel beam is mounted on the oversized channel using a Group A bolt that is $5 / 8^{\prime \prime}(1.6 \mathrm{~cm})$ in diameter. The oversized channel is also anchored at the top of the precast pier block using a concrete anchoring bolt that is also 5/8" $(1.6 \mathrm{~cm})$ in diameter. 
Group A

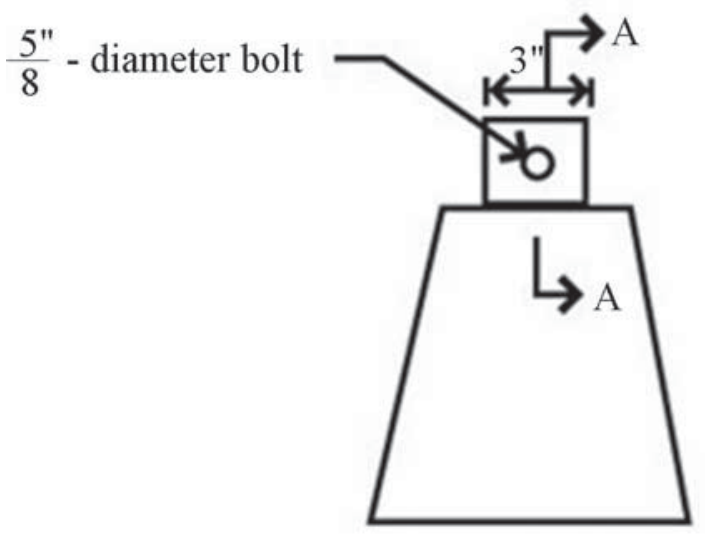

Group A

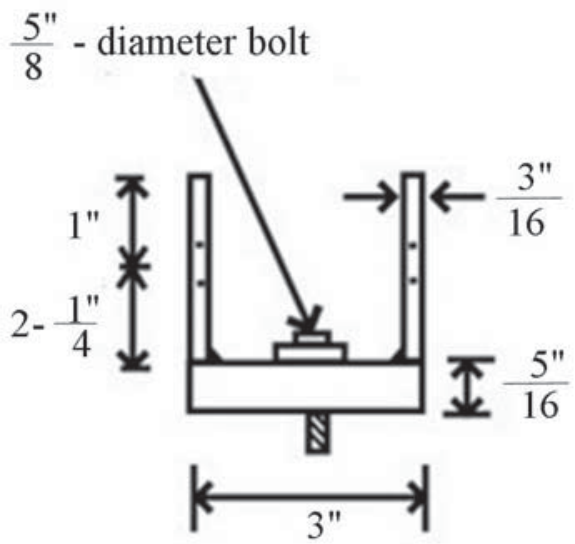

Figure 5-9: Customized Steel Bracket

\subsection{Metallic Pad}

Even though the plastic lumber pad presents a cost-effective solution for movable pads, it is labor-intensive and time-consuming, particularly in laying the slab and measuring the appropriate gaps. Alternatively, a metallic pad could be used to minimize the need to lay down various components. This option, as shown in Figure 5-10, is similar to the telescopic ramp, illustrated in Figure 5-1, but with higher load resistance. The metallic pad consists of two components, where a smaller component (Section B-B in Figure 5-10) slides into the larger component (Section A-A in Figure 5-10). Because of its size, these components have to be made of lightweight materials, such as aluminum or high strength steel, which have a high strength to weight ratio.

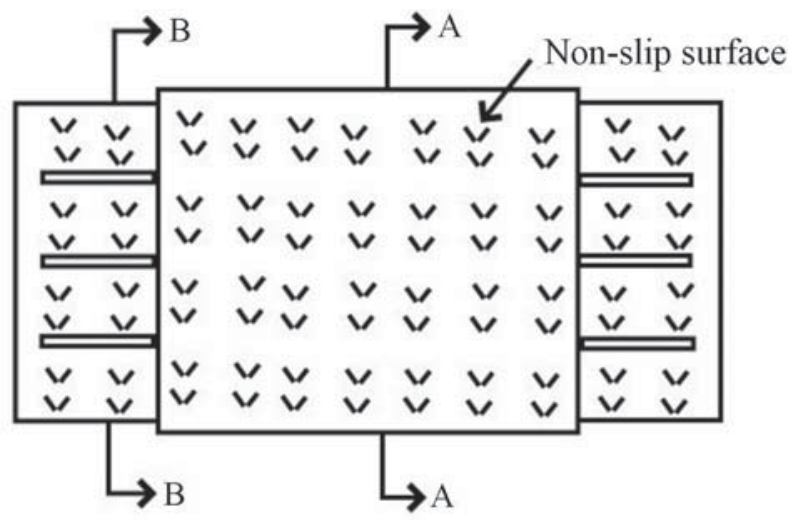

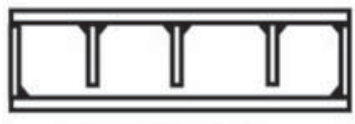

Section A-A

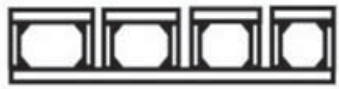

Section B-B

Figure 5-10: Metallic Pad 
The advantage of this design concept is that after the contractor lays the foundation as described in Section 5.2, the contractor has to just mount the larger component and then slide the smaller component to the sidewalk and the street, and lock them in place. Removing this system would also be easy as the contractor only has to unlock the smaller component and disconnect the main component from the footing. The ease and time of installation can potentially allow transit agencies to self-install and self-remove the metallic pad without contracting a third party, which makes it a preferred design alternative for movable B\&A pads, particularly during road work or special event.

\subsection{Summary}

Two design alternatives, plastic lumber pad and metallic pad, are proposed for further investigation to minimize MOT and the need for heavy machinery to excavate, fill, and/or compact the soil. The plastic lumber pad provides the most cost effective solution and has the potential to replace conventional concrete/asphalt B\&A pads. The metallic pad is a more expensive option but does provide significant cost saving in term of time and labor, and hence, is recommended for transit agencies with frequent bus route changes. The ease of installation of the metallic pad also allows transit agencies to install and remove the pads using internal supportive staff.

Both alternatives rely on the concept of bridge construction and consist of four major components, i.e., foundation, slab, beam, and connections. The foundation for both alternatives consists of four or more precast pier blocks that are buried underground to provide the support for the superstructure. The foundation is a readily available precast concrete pier block that can be purchased from any home improvement store. The connections are made of metallic (galvanized steel or stainless steel) U-brackets and attach the foundations to either the plastic lumber beam or the metallic pad.

The difference between the two alternatives (i.e., plastic lumber pad and metallic pad) lies in the slab and beam components. There are two design concepts for the beams in the plastic lumber design option, namely the interlocking beams and telescopic beams. The telescopic beam concept is proposed to provide faster installation time. The plastic lumber slab consists of several plastic lumber planks placed side-by-side on top of the plastic lumber beams. In lieu of the beam and slab, the metallic pad relies on using a single superstructure component consisting of two telescopic parts that slide into each other. The advantage of the metallic pad lies in its construction speed, while the plastic lumber pad design is cheaper and can span farther. As these

are new alternatives that can potentially replace the conventional and the readily available systems, further study is needed to understand their applications and associated costs. 


\section{CHAPTER 6 CONCLUSIONS AND RECOMMENDATIONS}

The main goal of this project was to explore the feasibility of using movable bus stop boarding and alighting pads, and was achieved by performing the following objectives:

1. Conduct a national survey of transit agencies about the use of movable boarding and alighting (B\&A) pads.

2. Research and evaluate the existing materials for potential use in constructing B\&A pads.

3. Develop and evaluate design alternatives for movable B\&A pads.

4. Recommend specific materials and design alternatives for potential testing and implementation.

\subsection{National Survey of Transit Agencies}

An online national survey of bus transit agencies was conducted. The survey aimed to find out how transit agencies are meeting the ADA bus stop accessibility requirements and to get feedback and related information on the potential use of movable B\&A pads at bus stops. A total of 84 transit agencies responded to the survey. From the survey analysis, it was found that onefifth of responding agencies have over $90 \%$ of their bus stops fully ADA-compliant. The main criteria for prioritizing bus stops for ADA improvements were high ridership stops, accessibility, rider complaints and requests, availability of right-of-way, high concentration of disability passengers, and safety. It was also found that cost of excavation, installation and maintenance, traffic control, landscaping, and property acquisition were the major line items for constructing bus stop B\&A pads.

According to the responding agencies, the main reasons for changing bus stop locations included safety concerns, municipality requests, complaints by home owners, lack of accessibility, changes in passenger ridership, roadway improvements, vandalism, and funding issues/budget cuts. The responding agencies also indicated that the potential benefits for using movable pads included lower installation and maintenance cost, ease of installation and use, time saving, flexibility, portability, and passenger accessibility. Some potential concerns for installing movable pads were identified as lower durability, strength and stability; greater risk of theft; space limitations; safety; and aesthetic issues. In general, a majority of responding transit agencies showed interest in potential alternatives for ADA-compliant movable B\&A pads.

\subsection{Potential Design Materials}

A review of the existing materials for potential use in constructing movable B\&A pads at bus stops was conducted. For ADA-compliant bus stops, the standard is to use conventional wheelchair lifts and buses equipped with a $2^{\prime} \times 3^{\prime}(0.61 \mathrm{~m} \times 0.9 \mathrm{~m})$ ramp that deploys from the bus to the standard height curb. Moreover, B\&A pads are necessary when deploying these ramps. In addition, a $5^{\prime}(1.5 \mathrm{~m})$ construction width (with a $3^{\prime}(0.9 \mathrm{~m})$ clear passage width) is preferred for sidewalks to accommodate patrons with physical disabilities. The ADA-compliant B\&A pads currently use either concrete or asphalt pads. Even though they are commonly used, their implementation is costly and time consuming. 
The review identified several alternatives that could potentially replace the existing conventional cast-in-place concrete slabs. Six materials, (1) concrete/asphalt, (2) metal, (3) rubber, (4) thermoplastic, (5) composite, and (6) wood, were found to be feasible alternatives, and were reviewed in detail. These six materials, along with their commercially available products, were evaluated based on their structural performance, long-term durability, adaptability, life cycle cost, aesthetics, and safety and accessibility of transit riders with mobility devices. Table 4-1 gives the ratings of each of the products based in the six evaluation criteria.

The structural performance criterion is based on the strength, rigidity, and toughness (i.e., the material's ability to plastically deform without fracture) of the material. The long-term durability is the material's ability to resist scratches and the harsh outdoor environment. The adaptability criterion evaluated the material's ability to be modified and adjusted to fit with the various site conditions present at the bus stops. The life cycle cost looked at the overall costs of the material over a period of 50 years by considering the initial, maintenance, relocation, and demolition costs as well as the cost associated with the frequent relocation of bus stops. The aesthetics of the material depends on its color and its ability to blend in with the existing infrastructure such as sidewalks. The safety and accessibility of transit riders with mobility devices is rated based on the design issues/limitations associated with ADA compliancy.

Out of the six materials, plastic lumber and metals were found to have the highest potential to replace the conventional design. Plastic lumber is rated highest based on design considerations, material properties, and life cycle cost. It has good strength (even though not as high as concrete) and it is also considerably light (even though not as light as composite material). Plastic lumber is also one of the cheapest and most durable systems. However, its performance under hurricane force wind has to be further evaluated for it to be recommended for extensive adoption.

\subsection{Design Alternatives}

Two design alternatives, plastic lumber pad and metallic pad, were proposed for further investigation. These new design alternatives are anticipated to minimize MOT and the need for heavy machinery to excavate, fill, and/or compact the soil. The plastic lumber pad provides the most cost effective solution and has the potential to replace conventional concrete/asphalt B\&A pads. The metallic pad is a more expensive option but does provide significant cost saving in term of time and labor, and hence, is recommended for transit agencies with frequent bus route changes. The ease of installation of the metallic pad also allows transit agencies to install and remove the pads using internal supportive staff.

Both alternatives rely on the concept of bridge construction and consist of four major components, i.e., foundation, slab, beam, and connections. The foundation for both alternatives consists of four or more precast pier blocks that are buried underground to provide the support for the superstructure. The foundation is a readily available precast concrete pier block that can be purchased from any home improvement store. The connections are made of metallic (galvanized steel or stainless steel) U-brackets and attach the foundations to either the plastic lumber beam or the metallic pad. 
The difference between the two alternatives (i.e., plastic lumber pad and metallic pad) lies in the slab and beam components. There are two design concepts for the beams in the plastic lumber design option, namely the interlocking beams and telescopic beams. The telescopic beam concept is proposed to provide faster installation time. The plastic lumber slab consists of several plastic lumber planks placed side-by-side on top of the plastic lumber beams. In lieu of the beam and slab, the metallic pad relies on using a single superstructure component consisting of two telescopic parts that slide into each other. The advantage of the metallic pad lies in its construction speed, while the plastic lumber pad design is cheaper and can span farther. As these are new alternatives that can potentially replace the conventional and the readily available systems, further study is needed to understand their applications and associated costs. 


\section{REFERENCES}

American Galvanizers Association, “Time to First Maintenance Chart for Hot-Dip Galvanized Coatings",

http://www.galvanizeit.org/images/uploads/publicationPDFs/Galvanized_Steel_Time_to_First Maintenance.pdf?tracked=yes. Accessed on March 10, 2013.

American Plastic Lumber, “American Plastic Lumber's Docks \& Boardwalks", http://www.american-plasticlumber.com/docks.html. Accessed on June 20, 2012.

Archi EXPO, “Anti-slip Steel Flooring”, http://www.archiexpo.com/prod/actis-furio/anti-slipsteel-floorings-62693-586800.html. Accessed on June 25, 2012.

Belgard Hardscapes, "Belgard Concrete Pavers", http://belgard.biz/pavers-concrete.htm. Accessed on June 20, 2012.

Century Group, "Pedestrian Crossings", http://www.centurygrp.com/Products/Railroad-GradeCrossings/Pedestrian-Crossings. Accessed on June 20, 2012.

ConcreteNetwork.com, "Thickness of Concrete Pavers”, http://www.concretenetwork.com/concrete/pavers/thickness_of_concrete_pavers.htm. Accessed on June 21, 2012.

DekBrands, “Dek-Block Pier Specifications”, http://www.deckplans.com/dek-blockspecifications. Accessed on July 10, 2012.

Delaware Department of Natural Resources and Environmental Control (DNREC), 'Mobi Mats' at Cape Henlopen State Park provide easier beach access for the physically challenged", DNREC Public Affairs Office.

http://www.dnrec.delaware.gov/News/Pages/\%E2\%80\%98MobiMats\%E2\%80\%99atCapeHenlo penStateParkprovideeasieraccesstothebeachforpeoplewhoarephysicallychallenged.aspx.

DESCHAMPS, “Mobi-Mat RecPath”, http://www.mobi-mat-chair-beach-accessdms.com/prod_recpath.php. Accessed on June 20, 2012.

Easter Seals Project ACTION (ESPA), "Toolkit for the Assessment of Bus Stop Accessibility and Safety," Washington, D.C., 2006. http://www.oregon.gov/ODOT/PT/docs/ada/ada-bus-stoptoolkit-aug2011.pdf. Accessed on June 20, 2012.

Eastsea Rubber, "Rubber Pedestran Crossing / Walking Crossing", http://www.zjeastsea.com/en/pedestrian-crossing.html. Accessed on May 25, 2012.

Event Deck, “ArmorDeck”, http://www.eventdeck.com/ArmorDeck.shtml, 2012b. Accessed on June 20, 2012. 
Event Deck, "HexaDeck", http://www.eventdeck.com/HexaDeck.shtml, 2012a. Accessed on June 20, 2012.

Federal highway Administration, "Pavements" http://www.fhwa.dot.gov/pavement/, 2012. Accessed on March 10, 2013.

Florida Department of Transportation, "Specifications and Estimates", http://www.dot.state.fl.us/specificationsoffice/Estimates/HistoricalCostInformation/HistoricalCo st.shtm. Accessed on March 10, 2013.

Guldmann, "Telescopic EasyFold Ramps", http://www.guldmann.net/Default.aspx?ID=4529\&GroupID=GROUP5\&ProductID=PROD488. Accessed on June 25, 2012.

Heliports Equipment, "Portable Helipads", http://www.heliportsequipment.com/portablehelipads/. Accessed on June 22, 2012.

KBI, "Product Info: Flexi-Pave", http://www.kbius.com/product-info/summary.html. Accessed June 16, 2012.

Landscape Pavers, "Flexi-Pave", http://www.landscapepavers.com/gallery.html. Accessed on June 22, 2012.

Mister Boardwalk, "Material...", http://www.misterboardwalk.com/material.ivnu. Accessed on July 10, 2012.

Murray's Recycled Plastic, "Products in: Fishing Stands, Marina, \& Walkways", http://www.recycledplastic.ie/index.php?cID=17. Accessed on July 10, 2012.

OMNI Grade Crossing Systems, "Products: Embedded Concrete-Rubber (ECR) Crossing", 2012a, http://www.omnirail.com/products_concrete_ecr.asp. Accessed on April 25, 2012.

OMNI Grade Crossing Systems, "Products: Full Depth Heavy Duty Crossing", 2012c, http://www.omnirail.com/products_rubber_heavy.asp. Accessed on April 25, 2012.

OMNI Grade Crossing Systems, "Products: TreCast Crossing", 2012b, http://www.omnirail.com/products_concrete_tracast.asp. Accessed April 25, 2012.

PermaTrak, "Technical Information", http://www.permatrak.com/technical-information/. Accessed on June 25, 2012.

PlasTEAK, "Plastic Grates For Docks, Decks \& Walkways", http://www.plasteak.com/plasteak-recycled-plastic-products/plastic-flooring-grates. Accessed on June 25, 2012. 
Scot Mobility (UK) Ltd., "Telescopic Ramp", http://www.scotmobility.co.uk/telescopic-ramp100-p.asp. Accessed on June 25, 2012.

SlipNot, "Non-Slip Steel Road Plates and Trench Solutions", http://www.slipnot.com/products/road-plate/steel/, 2012a. Accessed on June 20, 2012.

SlipNot, "Galvanized Steel Road Plate", http://www.slipnot.com/products/road-plate/galvanized/, 2012b. Accessed on June 22, 2012.

TRAC, "TRAC Products for Hire: ACCESS 2 - SUPATRAC", http://www.tracltd.co.uk/products.php, 2012c. Accessed on June 15, 2012.

TRAC, 2012, “TRAC Products for Hire: ACCESS 1", http://www.tracltd.co.uk/products.php, 2012b. Accessed on June 15, 2012.

TRAC, "PORTAPATH - Lightweight Plastic Flooring and Turf Protection", http://www.tracltd.co.uk/products.php, 2012a. Accessed on June 15, 2012.

TriMet, "Bus Stops Guidelines", July 2010. http://trimet.org/pdfs/publications/bus-stopguidelines.pdf. Accessed on June 15, 2012.

UAC Group, "Mobi-Mat", http://www.uacgroup.co.uk/products/mobi-mat.php. Accessed on June 20, 2012.

U.S. Access Board, "A Guide to ADAAG Provisions", 2006b. http://www.accessboard.gov/adaag/about/guide.htm. Accessed on April 25, 2012.

U.S. Access Board, "ADA Accessibility Guidelines for Buildings and Facilities”, 2006c. http://www.access-board.gov/adaag/html/adaag.htm\#4.5. Accessed on March 10, 2013.

U.S. Access Board, "ADA Standards for Transportation Facilities", 2006a. http://www.accessboard.gov/ada-aba/ada-standards-dot.cfm. Accessed on April 25, 2012. 
APPENDIX A:

SURVEY QUESTIONS 
Florida Department of Transportation

\section{Survey of Transit Agencies on Movable Bus Stop Boarding and Alighting Pads}

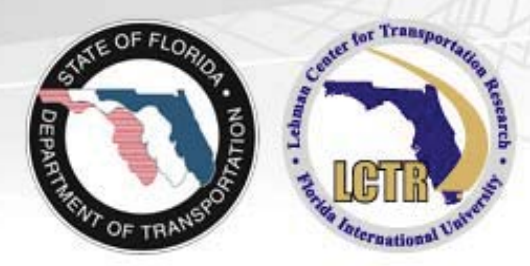

Thank you for accepting our invitation to complete this survey!

The American with Disabilities Act (ADA) requires that a 5'x 8' firm, stable, non-slip surface be provided for B\&A pads at bus stops to accommodate riders with disabilities. While the ADA requirements are clearly well-intentioned, compliance with such requirements inevitably presents a major burden to many cash-strapped transit agencies. To meet the ADA requirements, transit agencies typically install concrete slabs at bus stops. Depending on the existing site conditions, these pads can be quite costly to install and maintain.

To help maximize limited capital revenues, the Florida Department of Transportation (FDOT) is interested in evaluating the feasibility of using movable B\&A pads that can be quickly installed and/or removed and reused elsewhere. The use of movable pads with portable materials and designs could potentially save in labor, material, and construction costs. Because their installation and removal are expected to be quicker, they could reduce the costs associated with Maintenance of Traffic (MOT) and minimize impacts to abutting businesses.

The purpose of this survey is to find out how transit agencies are meeting the ADA bus stop accessibility requirements and to get your input on the potential use of movable bus stop B\&A pads.

This survey includes a total of 18 questions. We estimate that it will take around 15 minutes to complete. Your kind assistance in providing your input through this survey is greatly appreciated. If you have any questions, please do not hesitate to contact us. Thank you.

Fabian Cevallos, Ph.D.

Transit Program Director

Lehman Center for Transportation Research

Florida International University

10555 West Flagler Street, EC 3680

Miami, FL 33174

Phone: 305-348-3144

Fax: 305-348-2802

E-mail: fabian.cevallos@fiu.edu

\section{Diane Quigley}

Transit Planning Administrator

Florida Department of Transportation

605 Suwannee Street, MS 26

Tallahassee, FL 32399-0450 


\section{Please provide the following general information:}

First Name:

Last Name:

Title:

Transit Agency:

Phone:

Email:

Please use only the Prev and Next buttons below to move between the survey pages. If you use your browser's Back button by mistake, you may need to press the Refresh button to return to your current page. 
Q1. Please describe your agency's service area.

Large urbanized area (population over 200,000)

O Small urbanized area (population 50,000-200,000)

O Rural or non-urbanized area (population under 50,000)

Other (please specify)

Q2. How many bus stops does your agency have currently?

Q3. Roughly what percentage of these bus stops is considered fully ADA-compliant?

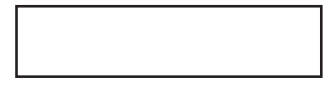

Q4. What are the criteria and methods used to select and prioritize bus stops for ADA improvements?

Q5. What is the total budget allocated to bus stop ADA improvements last and this year?

Last year:

This year:

Q6. What is the approximate average total cost associated with the installation of a bus stop boarding and alighting pad at your agency? 
Q7. Please list and provide the average cost of three major line items (e.g., Maintenance of Traffic) associated with the construction of bus stop boarding and alighting pads at your agency.

Q8. Have there been any legal challenges and/or complaints to non-ADA-compliant bus stops?

O Yes

O No

If Yes, please explain the nature of the challenges/complaints and what were the outcomes.

Q9. How often do you change bus routes?

Once a year

Twice a year

O Three times a year

$\bigcirc$ Other (please specify)

Q10. What are the reason(s) for changing the bus routes? 
Q11. Other than for route changes, what are the other reason(s) for changing bus stop locations?

Q12. When your bus stops are relocated, what bus stop facilities are moved and reused?

B Boarding and Alighting Pad

Bus Stop Pole

Bus Stop Sign

Shelter

Bench

Trash Receptacle

$\square$ Other (please specify)

Q13. Are you aware of any other agencies that have used movable bus stop boarding and alighting pads?

O Yes

O No

If Yes, please provide any information you may have.

Q14. What do you see are the major benefits for using movable bus stop boarding and alighting pads? 
Q15. What do you foresee are the limitations, if any, with using movable bus stop boarding and alighting pads?

Q16. Please provide any other opinions you may have on using movable bus stop boarding and alighting pads.

Q17. If you are interested in the results of this survey and the outcomes of this research, please answer "Yes" or "No" below and we will send you updates.

O Yes

O No

Q18. Please use the space below to provide any other comments you may have.

Note that this is the last question in the survey. Once you press the Submit button, the survey will be closed. If you want to review your responses, you can do so by pressing the Prev button now.

\section{THANK YOU!}

On behalf of the Florida Department of Transportation, we thank you for completing this survey! 
APPENDIX B:

SURVEY RESPONSES 


\section{Q4. What are the criteria and methods used to select and prioritize bus stops for ADA improvements?}

\section{Table B-1: Criteria for Selecting and Prioritizing Bus Stops for ADA Improvements}

- Bus Stop Inventory data is used to prioritize stops for future improvements. Some of the criteria used for prioritizations are: presence of ADA landing pads, crosswalks, curb ramps, and accessible pathway. Ridership at stops, proximity to special needs customers, safety issues and amenity problems are also considered.

- Bettendorf Transit uses the flag system for passengers utilizing the bus system. We do have information signs posted throughout the city to provide phone numbers for passengers to call for information. There are 16 bus shelters located throughout the city that are all ADA accessible.

- All stops are currently being evaluated. New stops are totally accessible, any stops moved or upgraded, in new construction areas are brought up to ADA standards.

- 1. Customer Complaints; 2. Roadway Improvements; 3. Availability of Right-of-Way; 4. High Ridership.

- Bus Stops are modified to meet ADA requirements when the roadway owner does roadway improvements. When installing a new stop, if permits are approved by the land owner, concrete pads are installed to connect the curb with the sidewalk.

- After reviewing the ADA guidelines earlier this year, COTA's conclusion is that construction must commence at a site for the ADA law to be in effect for new or modified stops after 1992. So for instance if we are placing a new passenger shelter that would require a concrete pad, we would make the stop ADA-compliant. In other cases in history if a passenger shelter was placed with a concrete pad where there is a non compliant route, COTA is moving forward with an inventory of those locations and developing plans to make this sites ADA-compliant. This often requires curb cuts and pedestrian walkways that for accessibility to the passenger shelter. So our inventory of bus stops that are non-ADA-compliant along with reviewing the ramp deployment on our bus fleet and pick up and drop offs for our paratransit service, we will prioritize the improvements. We will also consider the number of people boarding and lighting a stop and the proximity to special generators such as retirement homes, hospitals, etc.

- Although many of our bus stop are accessible to some degree, most are not fully accessible with a 5' X 8' waiting pad. We prioritize bus stops for improvement by: ridership (more ridership, higher priority); location near facility (like a senior center, medical complex); cost (less costly improvements are more likely to get priority); customer request; complexity of stop (for example, can it just be moved a little, or is it more complex).

- Number of boardings; Right-of-way availability; Transfer point; Sidewalk availability or ADA requirements; Cost; Requests.

- Usage.

- We currently are completing an evaluation of every bus stop in our system. We use a combination of ADA guidelines and guidelines submitted to us from CalTIP (our transit insurance consortium). When we complete the evaluation we can enter our data into a spreadsheet that will prioritize stops by determining accessibility options (or lack thereof) at each stop.

- 1) A request from a disabled individual; 2) ridership numbers for that stop; 3) ease of implementation; 4) Title VI compliance.

- Frequency of use and number of riders per stop.

- After a local issue regarding bus stop designations was brought forward to FTA 7 years ago, pretty much all new bus stops must be placed on existing sidewalks at a minimum where possible, and concrete pads must be put in place 3 in most circumstances as well before putting in new stops.

- Cost, current infrastructure, ridership.

- We are in the process of completing a project that will make approximately 98\% of our bus stops barrier free. I am not sure if they are all "ADA-compliant" in that pedestrian access may not be ADA-compliant (lack of curb cuts). 
- Ownership of the Area. If it is city owned we can get a permit to make changes if the site meets the permit requirements. If it is state owned we have to go through a similar process with the state. If is privately owned, we have to get permission from the property owner. There has to be enough right of way for us to make the improvements. There also has to be funding available. The other consideration is the condition of the stop. For example if the stop can become muddy such as a passenger is standing or sitting (wheel chair) in mud and it is an area where we can make changes we will. The primary methods of prioritization are the number of boardings at a location, bus operator feedback, service worker feedback (clean bus stops) and customer and or political complaints.

- They are complaint driven. When Metro receives a complaint of a non ADA stop that can't be used by a wheelchair patron, we investigate the stop and forward a recommendation to the appropriate city that has jurisdiction over the parkway. A study is underway to determine what stops are not ADA-compliant and a process will be developed to prioritize them.

- If there are customer inquiries we look at the stop and determine if something needs to be changed.

- Planned improvements to adjacent roadways (i.e. curb/sidewalk replacement; reconstruction); specific accessibility requests.

- 1. Prioritized by highest number of ADA boardings on fixed route - Based on monthly ADA boarding report; 2. Highest usage of a stop by all riders - Through on bus boarding counts; 3. Number of passenger complaints about a stop - Customer contacts to the transit system via phone, emails, and newsletter.

- Usage; available funding; current/projected road improvement projects.

- Highest priority to bus stops where the wheelchair lift cannot deploy, bus stops with high elderly/disabled passengers followed by bus stops near medical facilities.

- High Ridership and mostly used, also if disabled passenger request.

- Passenger boardings and alightings, type of generators, passenger requests, property owner's willingness to work with us.

- Curb type, size of the landing, access requirements.

- We are currently beginning the process of establishing designated bus stops. Currently at this time we operate a flag stop system.

- SFRTA operates a regional shuttle bus system with a service area of 5,128 square miles serving 17 TRI-RAIL commuter rail stations. SFRTA operates within the boundaries of the existing local fixed route bus provider Miami-Dade Transit, Broward County Transit and Palm Tran service areas. SFRTA utilizes each of the three local designated fixed route transit agency existing bus stop locations where present along shuttle routes. I I SFRTA works closely with FDOT, Miami-Dade Transit, Broward County Transit, Palm Tran, each of the three county MPO's and the South Florida Commuter Services regarding capital projects through multi-agency coordinated committees such as the Planning Technical Advisory Committee / Operations Technical Committee / ADA Advisory Committee. I SFRTA is actively involved yearly in each of the three local bus fixed route public transit agency and their required Transportation Disadvantaged Service Plan (TDSP) outlying ADA bus stop improvements.

- Passenger use, location, and local zoning requirement.

- Pedestrian/passenger activity, routes served, surrounding property.

- Sun Metro makes sure that all its bus stops, regardless of location, are designed to meet all ADA requirements. This includes the construction of sidewalks for accessibility, construction of landing/shelter pads to dimensions which allow the placement of amenities with sufficient space to permit unimpeded pedestrian flow.

- 1. Upgrade as part of city or county project in same location; 2. Upgrade based on new shelter installation (based on ridership); 3. ADA-community request (especially where ADA ort medical facilities located); 4. Cost of upgrade where no other criteria above overrides.

- Bus Corridors are selected based on ridership volumes. The most heavily used corridors are prioritized as the most important to improve from an ADA perspective.

- Ridership; LIFT; ramp deployment.

- As projects are undertaken along specific roads or routes, our stops are upgraded. 
- Demand and ability to get permission.

- All shelters were installed under State and Local Building Permits; Demand Stops or flag stops are what they are, people hail the bus.

- Safety, available r.o.w, stop usage, and rider requests.

- New installs are designed to meet the standards. At this time ET is installing APC equipment on the buses. Once the data is validated, a priority list by usage will be developed. Then funding will dictate the effort on updating stops to meet ADA requirements.

- Bus stops are placed approximately every two blocks along the fixed routes. In instances where the driver deems boarding/alighting of mobility aids to be safer out of the mainstream of traffic, the driver may elect to pull into a driveway to facilitate the process. As a department of the city, our staff elected to ride with the local police department staff to ensure bus stop locations would minimize disruption to traffic flow and not restrict the view of motorist when approaching a nearby intersection. It is our policy and practice to serve everyone choosing to use the fixed route service.

- Availability of space, amount of passenger traffic, suitability of location.

- Working with the City of Bowling Green Department of Public Works, Kentucky Highway Cabinet, The Bowling Green City Commission The Bowling Green Warren County Planning and Zoning Commission, and The Bowling Green Warren County Metropolitan Planning Organization to upgrade these locations as funds become available, or other upgrades are planned at these locations.

- Ridership levels, areas known to have a higher concentration of passengers with disabilities.

- Our agency does not own or maintain bus stops. That is the responsibility of our member jurisdictions. When new bus stops are requested, they are constructed on our behalf by the member jurisdictions and are ADA-compliant.

- We will begin changing all flag stops now to designated stops in 2013. All stops will have public input from the disabled community and must be able to meet ADA standards.

- We did a global pad project.

- No formal process exists. The 18 stops listed above represent the locations with actual bus shelters. In total, the system has approximately 200 bus stops that are just signs on posts with no shelter/bench.

- Specialized People to improve the bus stops in order to fix the damages to comply with the service.

- Installed bus stops for the first time October 1, 2011. Previously used flag-stop system, stopping at any intersection, with no designated or marked transit stops. Installed stops with mobility in mind, but were not able to make all stops accessible from the outset. Efforts will be made to upgrade stops as resources permit and ridership demands.

- Frequency of use, demographics, comments of users.

- Volume of use, urgency of need, available funding for improvements.

- We select by the ADA use of a specific stop that does not meet ADA standards.

- Accessibility and relationship to client destinations.

- We use a flag stop system, so riders are allowed to board anywhere along the route that they choose to alert the driver. The number indicated in Q2 represents the current \# of bus shelter locations, and all are ADAcompliant.

- Passenger loadings.

- Amount of usage, amount of requests from public, any new construction or improvements and requests from Bus Stop Committee.

- Location and ridership.

- Cost, ridership, part of streetscape project.

- Area in which the stop is in and how much right of way we have.

- While the route based service run by the City of Spartanburg does utilize specific bus stops, our transit agency is $100 \%$ demand response. All of our transit vehicles are ADA-compliant.

- A procedure based on level-of service is being developed. 
- 1) Whether or not the lack of accessibility adversely affects a passenger's ability to use the fixed route service; 2) number of passengers using the stop; 3) location of stop in relation to nearest sidewalks or driveway/area that would offer some accessibility; 4) need of accessibility as identified by passengers; 50 need of accessibility as identified by bus drivers.

- Current criteria are based on a bus stop survey completed in 2009 by a Sorority House's community service exercise. The information was not collected consistently, but we have not had the resources to update the survey information since then. Prioritized bus stop improvements have been directed based on a complaint basis, although our Capital Improvement Plan does prioritize stop improvements based on their location in areas with high levels of low income, minority and zero vehicle household populations. Transfort's 2013 work plan identifies updating our bus stop inventory and updating our Capital Improvement Plan based on the newly collected data.

- Amount of usage or need.

- Stops with high number of daily passenger boardings or alightings and stops with high number of boardings/alightings by passengers with disabilities.

- Passenger usage.

- Traffic Conditions; accessible path to the stop; available right of way; intersection conditions.

- With our fixed routes and Paratransit, we are able to handle all requests from all ADA Certified passengers within the Corporate Limits of the City of Bristol Virginia.

- Sidewalks; Curb cuts; ADA pad.

- Site evaluation and municipal planning consultation.

- Trolley stops are labeled, and ramps have measures in place to access for people with disabilities.

- 1. Any new developments or roadway construction with bus stops must be made ADA-compliant; 2. Adjacent sidewalks where there is sufficient r-o-w behind sidewalks; 3. Swale between back face of curb and front face of sidewalk; 4. All others.

- Level of ADA deficiency and wheelchair count logs. 
Q7. Please list and provide the average cost of three major line items (e.g., Maintenance of Traffic) associated with the construction of bus stop boarding and alighting pads at your agency.

\section{Table B-2: Average Cost for Construction of Bus Stop Boarding and Alighting Pads}

- MOT - \$500; Curb and Gutter - \$12 per LF; 6" Concrete - \$54 per SY

- Private Property Acquisition (\$4000); NCDOT regulations (\$1000); Utility Issues (\$3000)

- Surveying; pedestrian connection; concrete

- Concrete, installation, hardware

- Cost for personnel to administer the process (locating, contracting, monitoring process); grading; pouring and finishing of concrete

- Traffic control \$500; demo and excavation $\$ 1500$; concrete pad $\$ 3,000$

- Design and survey - \$4,800; Labor - \$3,400; Equipment - \$1,000

- Landscaping (mowing, trimming) around the pad area. We do not currently have many other costs associated with our pads at this time.

- Engineering - 1500; Construction - 3500-5500

- The overwhelming majority of the expense is concrete work

- Brasco Shelter \$2,975; Shelter Installation \$850.00; Shelter Pad \$2,271.50

- Metro only makes ADA improvements on property it owns. We are currently in the process of surveying all of our 15,528 bus stops to determine what needs to be done for those that aren't American Disability Act compliant and will forward that information to the appropriate municipality

- \$20 per cubic yard for pad excavation; \$16 per ton for crushed stone base; \$4 per square yard for topsoil restoration; $\$ 3.90$ per square yard for concrete pad installed

- 1. Construction - concrete bus pad; 2. Staff salary - Research analyst

- Unavailable at this time.

- \$2,500 construction; \$250 permit/inspection; $\$ 250$ staff time to manage project, update records, etc.

- Installation $=\$ 2,000.00 ;$ Demo $=\$ 1,000.00 ;$ Permits $=$ Depends

- Demolition/excavation of site - \$750; Concrete - \$2,250; Traffic control - \$300

- Maintenance of Traffic Each \$500.00; Concrete material and installation (6") thick, 1-500 SF Square Foot \$13.75; Concrete material and installation (6") thick, 501-1000 SF Square Foot \$8.25; Concrete material and installation (6") thick, 1001-9000 SF Square Foot \$8.00; Subgrade Preparation for Concrete Pour Square Yards \$2.00; Curb Cuts, Drawing I Each \$800.00; Concrete removal Square Foot \$4.50; Curb removal Foot $\$ 11.00$

- Shelter: 3200; site work 23,00

- Permit and inspection fees; Concrete work

- 1. 4" Sidewalk Replacement \$5,055; 2. 4" Reinforced Sidewalk Replacement \$3,704; 3. Wheelchair Ramp/Curb Cut $\$ 3,886$

- Design drawings \$3,000 (not always needed); Construction $\$ 2,000$

- 1) Sidewalk extensions from street intersection to bus stop (approx. 50 ft.) - \$3,000; 2) Handicap Ramps per ADA specifications - \$1,500 each; 3) Boarding Area with curding - $\$ 500$

- Design is done in-house; Projects and grouped/packaged and bid out to on-call civil contractors; It is awarded as a low bid contract - lump sum.

- Materials, Labor, MPT

- Cement \$800; Shelter\$3,600; Installation $\$ 400$

- We include ADA upgrades into the cost of adding passenger waiting shelters. The actual cost of the landing pad is relatively small compared to the cost of the shelter.

- Structure $=\$ 50,000 ;$ Security Cameras $=\$ 25,000 ;$ Foundation $=\$ 10,000$

- We just completed a bus stop sign project; the next step is constructing shelters. We have about $\$ 600,000$ remaining to build these shelters.

- Shelter, Design, Construction

- As a transit we have not installed bus stop pads. The cost for a shelter pad with texture pad, sidewalk, and access is $\$ 5,000$ per shelter.

- Our only major cost is the price of the concrete pad about $\$ 5200$ and the shelter about $\$ 5800$. We have had no 
traffic issues with our boarding and alighting areas.

- Not sure I understand this question. But 3 major line items for installation of stop landing pads and shelters:

Engineering: \$2,000 per stop; Permitting: $\$ 600$ per stop; Construction: $\$ 5,600$ per landing pad

- Pouring concrete; building of the shelter; maintaining the shelter and pad area

- $\$ 5,000.00$ APROX

- Pad-2,500; landing front back door of bus 1,100

- Planning, Construction, traffic

- Concrete and Labor

- Distance from accessible sidewalk, whether or not curb cuts are needed, degree of ground slope or amount of dirt that would need to be removed in order to create level surface

- Property acquisition (if necessary) - \$20,000; Construction - \$5,000; Traffic Control - \$1000

- Bus shelter: 8,000; Pad work: 1,000; Ramps: 1,000

- Concrete: \$250; Labor: \$150; Materials: $\$ 100$

- Purchase of Right of Way; Construction; Design

- Labor to excavate site - \$600; Material - \$300; Labor to install - \$500

- Concrete and installation labor

- Combined funds

- Provided under contract with Palm Beach County or by developer

- $M O T=\sim \$ 700-900 ;$ Concrete $=\$ 250 ;$ Excavation of soil $=\$ 8$ per cubic yard 


\section{Q8. Have there been any legal challenges and/or complaints to non-ADA-compliant bus stops?}

\section{Table B-3: Legal Challenges and Complaints on Non-ADA-Compliant Bus Stops}

- Broward County was sued for non-compliant bus stops and a settle was reached in 2006. The county agreed to improved approximately 1600 bus stops over a 5 year period. The goals of the lawsuit were met as of 2/29/2011.

- At one location where a new passenger shelter and concrete pad were installed, accessibility was not available from the nearest roadway and we have one passenger that was constrained to a wheelchair that used the location to shop. So we made the necessary improvements for the bus stop to be accessible by constructing a pedestrian walkway and curb cut.

- It was not a formal complaint, but a threat of a complaint by a Disabilities Rights group. In response, we surveyed all of our bus stops and we are currently developing an action plan on how to move forward to improve accessibility at stops.

- We have removed stops that had been installed years ago that did not have sidewalk access or level area for boarding or disembarking.

- Requests for more pads and request for ADA-compliant wheelchair bays in shelters. We put them on a list and implement as resources are available.

- In late 2004/early 2005 a chair of a local ADA advocacy group complained that the majority of our bus stops were not ADA accessible and that as such our system should be closed down unless all bus stops were $100 \%$ accessible. Ultimately, getting pads in a majority of location where there is no sidewalk access provided to be satisfactory.

- Just complaints so far. Not accessible or safe.

- The greatest complaints have come from stops located at shopping centers. The FTA indicated at a civil rights workshop that we are not liable because we do not have control of the property. One property owner because of the complaints they are receiving is working on creating a pad on their location. For other places on our routes we have instructed operators to allow the passengers to board and alight a safe location near the stop. None of the issues have reached the point of litigation thus far.

- Metro receives many requests over the years for making the stops we use ADA-compliant. We in turn forward these requests to the appropriate municipality for parkway and landing improvements.

- Most complaints are resolved thru education of what constitutes an accessible bus stop, what the transit agency is responsible for $v$ s. the local jurisdiction and collaborating on short and long term solutions.

- Some complaints are no sidewalks available. The challenges are still ongoing.

- Periodically we are challenged. All stops installed since the ADA was passed are compliant. Stops that predate ADA are being addressed as the budget allows. Under the ADA legislation, we have the right to address the old stops without being found in violation of ADA.

- Uneven or no sidewalk; No curb cut; Poor lighting.

- Challenges and complaints include inquiries regarding curb height, bus pull-in clearance, curb cut-outs (lack thereof), fixed object interference, rough surface, cracked sidewalks, ice/snow removal, road grade challenges, etc. Each challenge or complaint would be documented, addressed, and/or shared or passed on to the appropriate city/town's department which manages the bus stop or area near the stop in an attempt to find resolution.

- Some complaints by the visually impaired. At Everett Station, talking bus information was installed.

- If it is a complaint we investigate and document the issue and resolution. While we cannot always accommodate a customer's request for a variety of reasons if they are disabled or fragile (a senior citizen) we direct them to our paratransit service. We also track complaints/requests for stop improvements and when funding becomes available we then see if that particular bus stop can be improved.

- A suit was filed against the city for non-ADA-compliant facilities, including bus stops. The suit was settled with accessibility improvements to various facilities mandated.

- Right-of-way issues and encroachment permits

- Many stop improvements require locating outside of the City's Right-of-Way and or are on slopes that require additional space to build retaining walls, etc. If we pay for a stop using federal funding, we have to go through their process to acquire the property necessary, which requires mediation, additional appraisals, an acquisition negotiator and Davis Bacon wages for the contractor that does the work. This all add additional costs to the project. 


\section{Q10. What are the reason(s) for changing the bus routes?}

\section{Table B-4: Reasons for Changing Bus Routes}

- Reasons are various - ridership changes, expansion into areas that lack transit service, new developments, service adjustments by other transit agencies serving the region.

- Passenger demand

- Request by municipality / Construction / Ridership

- Truncation of Routes and budget cuts

- Adding service by extending alignments or implementing new routes; modifying current service for productivity improvements, etc.

- New Development that needs to be served / Infrastructure improvements like new park and rides / Improve efficiency of bus route by adjusting service area of route

- Improvements

- Route studies

- Financial constraints, low productivity or reliability

- New development or closure of a street segment for construction of a bridge or underpass

- To improve service to our customers. / To provide service to unserved areas. / To improve connectivity.

- Creating more accessibility to the public but adding areas that were previously unserved, refining routing to try and improve on time performance.

- Travel demand/ demographics

- New generators, street changes, ridership

- Demand, major employment centers

- Scheduling issues, i.e., bus does not have enough running time. / Adding or removing stops / New or alternative routing solutions / Customer request and feedback / Operator and service committee suggestion.

- To improve our bus scheduling and planning so that the routes are most efficiently utilized by the public during the hours of service it operates.

- Demand for service and public requests.

- 1. Budgets /2. Shift in ridership /3. Other infrastructure changes /4. Political reasons

- Demand; ridership; growth expansion/contraction; funding

- New development, deteriorating infrastructure, funding

- Money

- Rider requests / Long term detours/construction / Municipal requests / Efficiency / Ridership

- Reduce/increase service to meet budget, passenger requests, major generators.

- To improve service. Only a few routes are changed at any given time.

- Notre Dame service begins in August and ends in May/early June along with our trippers for some of the public schools.

- Changes are made based on SFRTA annual Shuttle Bus comprehensive operational analysis. / / System Survey Findings / System Ridership Findings / Service Quality Findings / Service Performance Findings / Peer Review Findings - Average Weekday Boardings / Subsidy Per Passenger Boarding / Revenue Per Passenger Boarding / Public Involvement / Fluctuation in Population and Employment Density / Connectivity With "new" Service Starts / /

- Passenger request, ridership, or survey data

- We have the opportunity to change routing 4xyear, but usually only make changes once a year other than minor adaptations. Routes are changed based on customer request, budget constraints, municipal requests

- Sun Metro makes modifications to its bus routes in order to improve its system efficiency and effectiveness. Our goal is to provide the citizens of El Paso with access to the system, thus as the city continues to grow we need to adjust accordingly. We also receive comments throughout the year assisting us in understanding where modification needs to be made.

- There are three service change dates per year. These do not always include route changes. I Our area had experienced growth and we have needed to expand coverage and serve new residential and retail/service locations.

- Adjustment to routes due to changing ridership demands and budget considerations

- Service efficiency. 
- New major trip generator - or construction.

- Long term road closings or new development

- New routes and funding

- Natural disaster, commercial development, rider requests.

- Mainly ridership demands but also for reasons of: cost efficiency, local business demands, city or town demands, new residential neighborhoods, access-to-jobs/schools/medical/shopping demands, local connections, transfer hub opportunities, changing traffic demands, etc.

- Passenger demand and efficiency.

- Minor changes to schedule.

- Usually changes are minor in nature to correspond with changes in large demand generators such as the relocation of Walmart or Target, etc.

- Increased efficiency, and service level, change in demographics, changes in points of origin or destinations, road improvements, additions, or closings.

- To provide new service to requested destinations, to address timing issues

- Schedule modifications, route modifications, new routes, route cuts.

- After a consultant study was done 21 years ago it was determined what was needed and after community buy in, and it has never changed since.

- Passenger demand, new commercial/residential developments

- Improve service efficiency and performance of a particular route / The need to improve and/or change a schedule to better serve the area that we operate through / Land-use changes: new roads, residential or commercial developments. / Service extensions or reduction for an existing service route due to the agency's budget constraints

- Efficiency

- Changes in funding accounts for the majority. Demand shifts also play a role as well as new developments.

- Expanding service / road closures / demographic changes / business changes

- Customer Demand

- Timing of route, condition of street, neighbor complaints, new land uses/trip generators, etc.

- Added service, low ridership

- Time savings, road closures, traffic issues

- Better access the public with minimal funding. We try to reach a larger target audience.

- Change in demographics as well as origins and destinations.

- Unproductive sections are eliminated to allow for new potential service.

- Land use changes or requests

- Different times of the year require different service levels such as school year beginning or ending, tourist season and other demands.

- City growth

- Seasonal service requirements, better operational flow / accessibility, unserved areas

- 1. Route efficiency and safety. /2. Patron comments and requests.

- Increasing efficiency and effectiveness of the fixed route service, expanding or increasing service/service area.

- New routes, transferring to productivity model rather than a coverage model we have used in the past.

- Study of ridership needs

- Changing travel patterns (new residential developments, new/closed retail, etc.). / Improve efficiency (reduce crowding, increase productivity, improve on-time performance).

- Population growth

- Operational concerns, schedule adjustments.

- Increase ridership and revenue. Expansion to new businesses.

- Rider demand / Improve ridership / Logistics

- Changing demographics, budget constraints, ridership changes

- Service requests, new development or major attractors, budget constraints.

- Productivity of route or segment of route in question. 


\section{Q11. Other than for route changes, what are the other reason(s) for changing bus stop locations?}

\section{Table B-5: Reasons for Changing Bus Stop Locations}

- $\quad$ Protest from home owners or businesses

- 1. Complaints by riders; 2. Complaints by adjacent property owners; 3. ADA Improvements; 4. Road reconstruction projects

- Property owner requests, customer requests

- A few years ago, we began a Bus Stop Service Improvement Project where we adopted a new bus stop spacing criteria and are implementing the project throughout our system. At the end of the project in 2016, we will have removed, consolidated, or relocated stops which will reduce the number of stops by more than $20 \%$.

- Streetscape projects; new developments

- Requests; safety issues; new development

- New business, neighbor revitalization

- Installations that were performed that did not consider ADA accessibility

- New development requiring changes to driveways; complaints from adjacent business owners; adjust spacing to 1/4 mile between stops; add a new stop when constructing a new bus pullout or shelter pad

- Community demand/requests; To attract new/choice riders; To serve new development.

- Complaints from local businesses/property owners, roadway redesign projects (local, state, federal). We've eliminated the first issue greatly due to pre locating negotiations with property owners.

- Customer complaints

- Community complaints, road changes

- Safety, lack of use

- Safety issues, i.e. if the bus stop causes part of a bus to be in an intersection. / Asked to move it by the owner of the right away. A better location is identified.

- ADA compliance issues, long term construction activities, signal and crosswalk changes, requests from municipalities and patrons.

- Public requests.

- 1. Consumer complaints; 2. Business complaints; 3. Advocacy interest; 4. Traffic control changes; 5. Construction - temporary

- Changes to nearby activity centers; traffic; customer/driver demand; safety.

- Better accessibility as part of new development/road improvements, change in physical characteristics, change in turning movements, traffic revisions

- Rider requests; Long term detours/construction; Municipal requests

- Passenger requests, property owner requests, traffic/sight issues, safety.

- Complaints and to improve service. We often move stops to support a business owner.

- Requests from the Public; Safety or Security Concerns

- Resident complaints, passenger requests, road construction

- Adjacent property, economic changes (i.e. closed or newly opened passenger generators)

- Sun Metro will change its bus stop locations in situations where it has been deemed that the distance between the stops is either too close or too far apart. We would like to potentially see that our bus stops agree with the smart growth ideas of pedestrian shed (1/4 mile) and transit shed (1/2 miles) separation distances. We will also change bus stops if it has been deemed that the current location is seen as a safety hazard.

- We changed our stop spacing policy so we relocated and removed some stops; We have relocated on some occasions for safety factors such as proximity to intersection where bus turns left; We have relocated on some occasions due to development occurring at previous location (construction impacts); We have added new stops for new residential developments and commercial centers.

- 1)Constituent complaints; 2)Changing field conditions (i.e.- property redevelopment issues); 3) Service improvements

- Business/land use impacts and changes; Safety; Efficiency (when stops are deleted/removed)

- Requests by the adjacent property owners who don't like the stop locations.

- Complaints from nearby property owners.

- Rider requests. 
- Complaints, unsafe passage or road clearance, safety purposes, road hazards, boarding/alighting problems, ridership numbers, city or town recommendations, efficiency purposes, etc.

- Safety and the ability to make a stop ADA-compliant. IE new construction on a street. During this process I would request ADA-compliant pad be installed? Then move the stop to new location.

- Multiple requests for a specific location.

- Business and residential developments, changes in passenger traffic

- Improvements on parallel corridors, sidewalks installed on adjoining street, better, safer ADA access, partnering with developer for better access to locations (bus pull off, shelter, ADA access etc.)

- We may need to address issues with safety in boarding and alighting.

- New construction.

- Passenger boarding and alightings locations have changed and customer requests and public approval.

- Land use changes to roads and/or developments that may occur at or near a bus stop. / A new resident or an existing resident opposes a bus stop in front of their house. Sometimes it is associated with changes in the riders that board or alight at the stop or who may create other issues for that resident or neighborhood. There are numbers of reasons why a bus stop may get changed and usually happens on a case by case basis.

- Road design changes, vandalism complaints, or safety concerns.

- People may not want the stops in their yards or in front of their businesses

- Property owner request, major trip generator changes

- Construction, complaints from property owners

- Operational challenges at existing locations

- Safety concerns, Non-use

- Construction issues.

- Safety, passenger requests

- Budget cuts and other changes in demands for service.

- Street improvement or new business or residential access change

- Complaints, operational hazards, improved public access

- Construction

- Roadway and/or facility alterations.

- Safety of location (e.g. proximity to intersection or crosswalk, amount of traffic and how it responds to a stopped bus); amount of use by passengers; ease of use by passengers;

- As development occurs in a corridor, the most appropriate location for bus stops may change too.

- Passenger request; Attracting ridership

- Safety (based on suggestion from rider, driver, or City traffic department); In response to a request from property owner or bus rider to have the stop closer (or further away, in some cases).

- Development

- Complaints, lack of use, lack of accessibility

- Improve boarding/alighting; Better location; Current stop causes traffic impediment

- Safety considerations due to changing traffic patterns

- Safety, relocation to a more safe or ADA-compliant location, low ridership

- Accessibility of location, construction

- Improving spacing standards or removing stops with low activity. Also, complaints about trash at stops seem to be increasing even when the stop activity is low. 


\section{Q14. What do you see are the major benefits for using movable bus stop boarding and alighting pads?}

\section{Table B-6: Benefits for Using Movable Bus Stop Boarding and Alighting Pads}

- Ease of installation and lower cost.

- Long term cost reduction

- Convenience / availability, eliminating wait time

- I'm assuming the cost is lower, which could be a benefit. Also, perhaps maintenance is less costly, although I really don't know how long they last. Finally, it could permit you to address a situation quickly.

- Reduction in construction cost

- Cost

- I have not seen an example of a movable bus pad as yet but I would assume that installation would be far less complicated and time consuming as well as less expensive.

- Cost savings and quick response

- Please provide an example of what is contemplated for the use of movable bus stop boarding and alighting pads. If this is something that would be permissible in Collier County, the benefits would be a reduction in labor and construction costs.

- Connectivity to other infrastructure would be a concern.

- Cost effective

- The permitting process can take months. If a permanent pad is not required this can speed up the placement process. The pad is also most expensive part of the stop placement process.

- Greater use of the stops that are not American Disability Compliant.

- They are portable and can be used in different places.

- Bus stop locations can be furnished with an accessible surface in a more expedient manner with a movable unit (as compared to scheduling installation of a concrete boarding surface). This movable unit would also be reusable if the bus stop location were abandoned in the future, or otherwise relocated. Such movable units could also be incorporated into construction work zones where transit continues to operate.

- Ability to respond to the following changes in service demands or trip generators: 1. Special events; 2. Seasonal changes; 3. Construction; 4. Temporary routes

- Cost and expediency.

- Temporary construction areas would be a good use. Or as an interim until 'complete' improvements are made

- I see them only to be use if permanent changes are made but mainly used during temporary construction.

- Passenger accessibility/improvement

- Reduced construction costs, faster implementation.

- We are interested in learning more about these types of movable pads especially since we are anticipating that some of the original bus stops will need to be adjusted. Due to our agency just being in the beginning stages of planning designated bus stops this would help us control our costs.

- ADA complimentary paratransit riders may have greater utilization of fixed route services, providing greater mobility to the transportation disadvantaged population; Pooled Procurement Flexibility; Certified Design Standards; Rapid Implementation

- Other than major one-time events - like a super bowl - I don't see a practical benefit to temporary boarding and alighting pads. They might be useful as an interim device until a permanent landing pad can be installed.

- Reduced labor and the immediate enhancement of a site thus instantly having a fully functional bus stop made ready.

- Pads have other benefits even when we move away (easier curb pick up for cars). Many of our locations (not all though) have full curb. They may be useful in our unimproved areas (rural areas with no curb/sidewalk and no likely change to this situation)

- Cost saving

- Cost savings vs. pouring a new pad. 
- Savings

- Time savings and cost savings over new construction.

- Reduced response and waiting time for approved bus stop moveltransfer requests, ease of determining safest alighting/boarding locations, increase in bus stop testing or functionality of trial stops.

- Easy installation and portability.

- They are good for utility relocations and road work.

- Potential cost reduction of install and removal. Ability to move stop as area is developed, degrades, or changes

- If the location of a proposed new stop is not ADA-compliant, movable stop treatments that are ADA-compliant would be useful.

- Short term use to really determine the amount of boarding and alightings at a particular. This would be great in setting up a location when funding was not available for a permanent location.

- Cost

- It could work as a temporary measure until a landing pad get put in.

- Flexibility

- The large cost and permanency of bus shelters prohibits them from being used nearly as often as we would prefer. If the shelter and pad could be relocated, the risk on wasted time and funds is significantly reduced.

- Our boarding and lighting pads are permanent they are not movable

- Liability

- Security for participants.

- Address accessibility complaint quickly while awaiting permanent installation

- Flexibility, ability to relocate when needed

- The device has to be integral with the sidewalk infrastructure for snow removal

- Reusability, lower cost and ease of installation. This is speculation on our part as Metro currently only uses permanent pads

- Cost

- Lower cost (pre-fabrication)

- Won't have to pour another pad

- Potential cost savings, ability to replace as items become worn, and availability of pads at every stop rather than just at a few.

- Flexibility and cost containment.

- May be good for use at temporary bus stop.

- Ease of installation and cost.

- Ease of putting bus stops where needed.

- Reduced cost and ability to improve accessibility in a shorter time frame.

- Undeveloped locations where curb and gutter may not exist.

- Flexibility to place at relocated bus stops, without incurring capital costs to reconstruct the pad.

- Cost

- 1) Good for demonstration routes where a long term investment may not be warranted just yet; 2) Less previous surface left behind if stop locations ultimately don't work; 3) improvement is made much faster. 


\section{Q15. What do you foresee are the limitations, if any, with using movable bus stop boarding and alighting pads?}

\section{Table B-7: Limitations with Using Movable Bus Stop Boarding and Alighting Pads}

- Each bus stop geography is unique, and the movable pads might not fit the situation.

- The pedestrian connection may not exist

- Theft

- I would be concerned with theft, durability, strength, surface adhesion

- Durability and ADA-compliance with connections to sidewalk

- Permissibility within local jurisdictions; How would the pads be affixed to ground; Would there be a potential for vandalism; How secure would the pad be given the weather, terrain and environmental conditions typical to Florida; The area surrounding the pad needs to be ADA accessible which adds to the cost of providing the movable pad.

- Securing them both for safety and to minimize vandalism or theft. Bulkiness of the items - transportation issues, potential for Worker's Compensation situations.

- Does the bus stop pads include cuts to access the pads and is there a clear access to the pads?

- Ease of move. Durability.

- Durability

- Durability, deployment and acquisition once the location is no longer needed.

- Depending on their weight and their size, a vehicle will need to be dispatched to the non ADA stop locations prior to the bus arrival for a wheelchair patron to use the stop.

- Having them at the right place at the right time.

- Winter weather conditions may limit or impede the ability to maintain the movable accessible surface. Frost heaving or other instability may occur in contact with snow/ice, removal of snow/ice from the surface may not be possible with traditional methods (i.e. having snow plow truck run blade over surface of concrete boarding pad).

- Logistical concerns - how to move/remove, personnel issues, confusing to passengers, storage, load bearing constraints, ADA compliance and uniformity of structural integrity, replacement costs and life span of the bus stop

- Permitting requirements from local jurisdictions, equipment requirements

- How much do they weigh

- Property availability / Space limitations

- Vandalism.

- The possibility of the pad being easily removed by others. The durability and will there be any deterioration in the product due to multiple movements.

- Limited design selections for each unique curbside application need; Durability of product material; Equipment; Labor necessary for implementation /

- The ability to conform to different geographical situations (such as uneven surfaces) and to surrounding builtout areas (such as areas where sidewalks are adjacent to parkways).

- Condition of pad after first location use is our concern? How durable is it? How movable is it?

- Safety concerns and aesthetics

- Cost and resources required to move and reuse.

- Attaching shelters? Theft?

- Limited number of configurations could limit functionality and securing movable pads to prevent theft.

- Durability and/or potential for increased vandalism. Possibility some pads are not compliant with local, state, or federal anti-crime or terrorism requirements for safety and security of bus stops.

- I would be concerned with the useful life of the pad vs. concrete.

- We requested that the advertising agency remove enough soil to locate the pads at the same level as the 
sidewalk that sets in front of the amenity for ease in maneuvering mobility devices.

- Durability

- Settling, Theft, Damage, alignment and matching with sidewalks, curbs, and other access points (Trip factor over time)

- We don't change our stops that often for these to make sense. We would also have concern with their durability in winter weather conditions.

- Lack of right of way to install them.

- Storage of unit when not in use

- Effects of winter (snow/ice freezing ground) conditions. Special equipment needed to move/transport

- A movable pad will allow: a connection from the curb to a sidewalk/pedestrian pathway; provides a hard surface on public right-of-way for a bus stop to be located; improves the ability for those with mobility aids to have a firm/hard surface to board or alight from a bus; it doesn't sound like it would solve the issue of not having a sidewalk to begin with or an area that lacks a 6" high curb for a low floor bus.

- Cost

- Security having not seen the design of one. Is it stable?

- Theft

- Impact of heavy snow load, shoveling, plowing, and salting on the movable pad material

- Prep (earth work), durability, snow removal, theft

- Right-of-way issues in our city.

- Snow removal - connecting access- sidewalks

- Durability and vandalism. This is speculation on our part as Metro currently only uses permanent pads

- We are in an old city most convention shapes may not apply

- Permanent facilities would be easier to maintain assuming that the stop is not later relocated

- Durability and stability.

- Depending on their construction and ease of use, could be tampered with, moved or otherwise stolen from the location.

- Grade and drainage in some areas may require construction of an actual concrete pad.

- Can they be stolen? How substantial are they? How durable?

- How well it works. Does it stand up to use and weather conditions over time? Is it vandal-proof?

- Durability

- The costs associated with its relocation; How to relocate the pad

- Safety and durability?

- Longevity, ADA compliance installation issues

- Sidewalk space limitations.

- 1) Slope; 2) varying distances between curb and sidewalk in utility strip. 


\section{Q16. Please provide any other opinions you may have on using movable bus stop boarding and alighting pads.}

\section{Table B-8: Opinions on Using Movable Bus Stop Boarding and Alighting Pads}

- If COTA installs a simple sign and post, our interpretation of the ADA law is that we don't have to install a 60" $x$ 96" pad. We only are required where we are doing construction which can be new or renovating the stop.

- I would consider them as an occasional solution. We find more areas where the surrounding conditions are not suitable for the bus pad period, i.e., encroaching on private property, buildings next to the proposed stop, uneven terrain, no sidewalks, crosswalks, adequate lighting. There are a number of times where the pad is the least of the issues but in spots where a quick and easy solution will work, as long as these can be adequately anchored, why not.

- I'd be curious to see what the product is. Even if it's a lightweight polymer or some other such product, there would still have to be site work \& prep in order to make sure the movable pad was safely secured and leveled/pitched properly.

- Vandalism and can the ADA individual access the pad, and when the pad is functional will the bus ramp (lift) have the correct boarding ramp angle percentage?

- The concept seems like a good idea.

- It would be costly to have drivers running the routes in trucks so that the movable bus stop boarding and alighting pads could be used by patrons before they arrive or depart.

- Liability issues (trip hazards) may be heightened due to greater ability for a movable boarding surface to shift out of alignment with adjacent curb and sidewalk surfaces.

- Interesting idea, would like to learn more, especially about peer system usage of this concept

- Would there be an option for a larger version that could support a passenger shelter?

- None at this time other than I feel this would be very advantageous to be able to move the pads to help with costs.

- Temporary or permanent application possibility. Temporary such as "new" service route alignments, roadway construction or other factors. Permanent such as where route segments may be "Flag \& Stop" service areas such as corporate parks \& the ability to re-locate the Permanent (precast) bus stop pads based on utilization needs.

- I don't understand what the intended benefit is to temporary movable landing pads. If the stop garners enough activity to upgrade the amenities, it really needs a permanent solution.

- Our agency actually has 85 bus stops with amenities (55 benches) (30 shelters) compared to the 400 stops total.

- I would like for you to follow up with everyone completing survey at 1, 5, and 10 year anniversaries of install.

- Is very useful.

- The accessibility issue has not been critical enough to warrant this product in our community.

- What equipment is required to move pads?

- Don't understand the cost-benefits of movable pads unless the route network is subject to frequent significant service changes/reductions/additions.

- Go for it.

- Great idea! How do we get this going!

- How about a heated pad to melt the snow? 


\section{Q18. Please use the space below to provide any other comments you may have.}

\section{Table B-9: Additional Comments}

- I guess not having seen the actual product my main concern would be theft or vandalism or a lack of durability impacting the quality of the surface.

- Please provide samples of the movable bus pads or systems where they are in use in the United States.

- Is there a website to learn more about this product?

- Please consider the design criteria of the precast bus stop pad configured with the ability to affix / attach: bus stop sign posts / trash can / bench / bike rack / passenger shelter, etc.

- I would be interested to see how movable pads are used. It seems our local concrete companies would prefer to use forms and pour new.

- ADA pad improvements require cost and staff time investments to Transit agency. Choice to improve should be carefully evaluated against possibility for future abandonment or deletion of a bus stop or route. For TriMet, it is a long term investment that should be in place in 5 years. TriMet rarely abandons stops where investments have been made. TriMet has used prefabricated concrete pads along a bus stop corridor. Summary: no net cost reduction.

- I'm interested in learning more about the concept of movable pads.

- We have 30 stops with shelters. Otherwise, riders can get on or off anywhere along the fixed routes where it is safe for the bus to stop. They just wave at the driver as the bus approaches.

- We are not an RTA that fits the normal profile, our fixed routes have set stops but we do a great deal of FLAGGED stops / Our on Demand Service is greater, however again that is door to door home and office. All of our Shelters are ADA, however our stops change daily.

- Bus stop amenities are difficult to place in Fort Smith, Arkansas because most of the desired locations are on routes that are actually state highways. State rights-of-way do not allow advertising, so to support the program through advertising agencies placement must be done on private property requiring permission, which can be very difficult to obtain. Additionally the state maintains a beautification law which prohibits any advertising without permitting. Permitting is governed at the local level but in no case is the agency allowed to locate any advertisement (amenity) within 100 feet of any other advertisement.

- This looks like an innovative approach. If it's real practical I would consider a demo.

- Great idea if done right- what kind of subsurface and level of compaction is required? Warranty? Liability? Security (theft proofing)? Color match? Durability? Slip proof surface? ADA texture pad?

- I like the concept but it would have been helpful to have a photo and/or details of what this type of product might look like. I would also assume that a local jurisdiction would have an interest in it as well as including engineering requirements, etc. before they permitted anything like this. Liability would certainly play some role into anything placed on a public right-of-way.

- The areas that were left blank are because we do not have budgets for them or the amount of funds is unknown.

- It will be interesting to see what y'all come up with - if this proves a useful and cost-efficient technology; there may be applications for our transit agencies here in Spartanburg (both the route based and the demand response). Looking forward to seeing the results of your survey as well as examples of how other jurisdictions are implementing similar technologies to meet ADA requirements.

- Potentially, this is a great idea. Would like to know more.

- I am struggling to picture what these would look like.

- Sounds like a swell idea. Good luck with your research. 